\title{
2 Vorgeschichte
}

\subsection{Skisport zwischen den beiden Weltkriegen - Entwicklungslinien und -tendenzen}

\subsubsection{Verbreitung, Professionalisierung und Internationalisierung einer Sportart}

Der alpine Skilauf entwickelte sich nach dem Ersten Weltkrieg zu einer Massensportart. Durch die voranschreitende Professionalisierung, eine Vereinheitlichung des Lehrwesens und den stetigen Ausbau der Infrastruktur in den Alpen erreichte der Skisport in den 1920er- und 1930er-Jahren immer größere Gesellschaftsschichten. „Bis zum Ersten Weltkrieg hatte das Skilaufen fast ausschließlich die wohlhabenden Bevölkerungsschichten in seinen Bann gezogen "1, stellt der deutsche Sporthistoriker Lorenz Peiffer fest. Das lag nicht nur an der fehlenden Ressource Zeit, sprich Freizeit. Die Partizipation am Skisport scheiterte bei vielen Arbeiterfamilien schon am Haushaltsbudget. ${ }^{2}$ Damit war der frühe Skilauf am Beginn des 20. Jahrhunderts den bürgerlichen Schichten vorbehalten. Viele Vereinsgründungen gehen zwar auf die Jahrhundertwende zurück und schufen somit schon vor 1914 eine Basis für die Verbreitung des Sports, dennoch war die Klientel in vielen Klubs sehr exklusiv. Sowohl die Pioniere des Skilaufs als auch die Gründungsmitglieder entstammten dem Bildungsbürgertum, waren Beamte, Lehrer, Ärzte oder Rechtsanwälte. ${ }^{3}$ Die skifahrenden Gäste kamen aus den Städten, sie waren wohlbetuchte TouristInnen. Selbst wenn die junge Sportart Skilauf zu Beginn des 20. Jahrhunderts vereinzelt Interesse in alpinen Kreisen hervorrief, ${ }^{4}$ so war der frühe Skisport vor dem Ersten Weltkrieg noch keine Massensportart. Das sollte sich nach 1918 grundlegend ändern. Dabei trieb gerade der Erste Weltkrieg mit dem militärischen Skilauf die Entwick-

1 Peiffer, Vom Soldatensport zum Volkssport, S. 78.

2 Vgl. Peiffer, Vom Soldatensport zum Volkssport, S. 78.

3 Vgl. Rudolf Müllner, The Importance of Skiing in Austria, in: The International Journal of the History of Sport, 30 (2013) 6, S. 659-673, hier S. 661.

4 Vgl. Eugen Oertel, Sport, Alpinismus und Schilauf, in: Mitteilungen des Deutschen und Österreichischen Alpenvereins, 35 (1909) 1, S. 6 und 35 (1909) 2, S. 17-21. Der aus Bayern stammende Alpinist Eugen Oertel beschrieb den alpinen Skilauf ebenso wie den Alpinismus in einem im Jahr 1909 veröffentlichten Artikel als Sportart und ging dabei auf die Bedeutung des Skisports für das Bergsteigen und als Wettbewerbssport ein. Oertel verstand den Skilauf noch mehr als Skibergsteigen und weniger als Abfahrtsskilauf, erkannte jedoch bereits eine Weiterentwicklung in diese Richtung. 
lung des Skisports in den Folgejahren voran. ${ }^{5}$ „[...] nationalism and imperialism of the nineteenth century, which culminated in the First World War, provided the most important impulse for the establishment of skiing as a collective culture in Austria“, stellt Rudolf Müllner fest. ${ }^{6}$

Der zu Kriegszeiten für militärische Zwecke bestimmte Skilauf öffnete sich nach dem Ende des Ersten Weltkriegs einer breiten Zivilbevölkerung. Ehemalige Kriegsteilnehmer, die in Bergführerkompanien gedient hatten, machten später als Berufsskilehrer Karriere und gaben ihr skiläuferisches Wissen an eine jüngere Generation weiter. ${ }^{7}$ Auf diese Weise profitierte der alpine Skisport der 1920erund 1930er-Jahre in seiner Entwicklung von den militärischen Errungenschaften des Ersten Weltkriegs. Die technische Basis legten die ehemaligen Skiwerkstätten der k. u. k-Armee wie jene in Salzburg. Diese produzierten gegen Ende des Ersten Weltkriegs an die 50000 Paar Ski pro Jahr. Insgesamt sollen während des Ersten Weltkriegs 140000 Paar Ski in der von Oberst Georg Bilgeri geleiteten Skiwerkstätte in Salzburg produziert worden sein. Ein großer Teil dieses Materials gelangte ab 1918 durch Verkäufe an die Zivilbevölkerung. ${ }^{8}$ Bilgeri selbst, der bereits 1897 beauftragt wurde das erste Skibataillon in ÖsterreichUngarn ins Leben zu rufen und im Ersten Weltkrieg als Offizier die Skitruppen führte, lehrte noch bis zu seinem Tod 1934 Interessierten den Skilauf. ${ }^{9}$ Der für die Verbreitung der alpinen Skifahrtechnik (Arlbergtechnik) weltweit berühmt gewordene Hannes Schneider hatte bereits vor dem Ersten Weltkrieg in St. Anton am Arlberg eine Skischule betrieben. Während des Krieges lehrte er Heeressoldaten das Skifahren und nach 1918 sollten der Arlberg mit der Arlberg-Skischule unter Schneider zum Zentrum des Skilehrwesens und des

5 Vgl. Sabine Dettling, Die historische Entwicklung von Skisport und Skitourismus von 1860 bis heute. Schwerpunkt Arlberg-West, in: Tobias G. Natter (Hg.), Schnee. Rohstoff der Kunst, Bregenz 2009, S. 54-65, hier S. 57.

6 Müllner, The Importance of Skiing, S. 661.

7 Heinrich Frank, Die Entwicklung von Alpinistik und Wintersport in Österreich, in: Ernst Bruckmüller/Hannes Strohmeyer (Hg.), Turnen und Sport in der Geschichte Österreichs, Wien 1998, S. 105-132, hier S. 125; Gilbert Norden, Breitensport und Spitzensport vom 19. Jahrhundert bis zur Gegenwart, in: Ernst Bruckmüller/Hannes Strohmeyer (Hg.), Turnen und Sport in der Geschichte Österreichs, Wien 1998, S. 56-85, hier S. 66.

8 Vgl. Müller, The Importance of Skiing, S. 662 und Anneliese Gidl, Von elitären Versuchen zum Massensport, in: Wintersportmuseum Mürzzuschlag (Hg.), $3^{\text {rd }}$ FIS Ski History Conference, Mürzzuschlag/Graz 2004, S. 121-129, hier S. 128.

9 Vgl. John B. Allen, The Military Foundations of Civilian Skiing in Europe, in: Wintersportmuseum Mürzzuschlag (Hg.), $3^{\text {rd }}$ FIS Ski History Conference, Mürzzuschlag/Graz 2004, S. 113 129, hier S. 114. 
Wintertourismus werden. ${ }^{10}$ In den 1930er-Jahren unterrichteten Schneider und seine Skilehrerkollegen an die 1000 Personen pro Winter. ${ }^{11}$

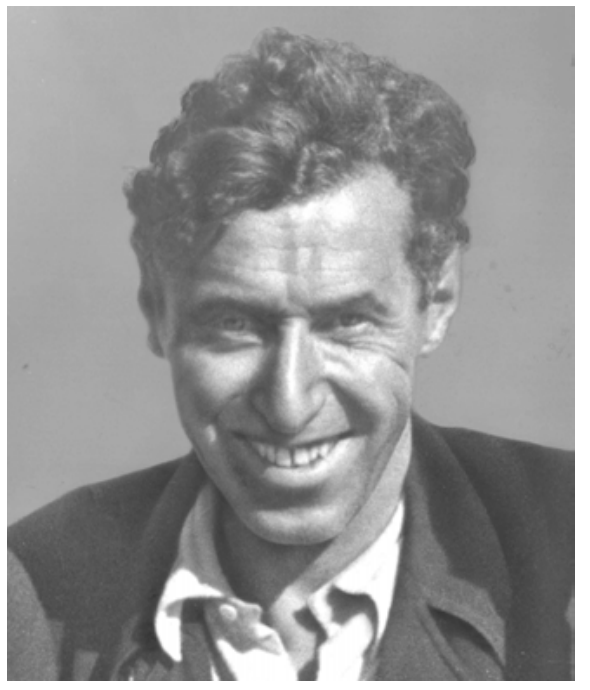

Abb. 1: Hannes Schneider revolutionierte mit seiner Arlbergtechnik den alpinen Skilauf und sorgte für eine weltweite Verbreitung der Sportart, Tiroler Skiverband.

Auch wenn die Gästeschicht in touristischen Skiorten wie St. Anton am Arlberg oder Zell am See auch nach dem Ersten Weltkrieg vorwiegend einer höheren Schicht entstammte, so mischten sich unter die skifahrende Bevölkerung nun vermehrt Aktive aus nicht privilegierten sozialen Schichten. Die soziale Herkunft war ab Mitte der 1920er-Jahre nur mehr bedingt ausschlaggebend für die Ausübung der Sportart. Die Verfügbarkeit von Skiern war leichter geworden, Skigebiete waren mittels Eisenbahn oder Postbussen erreichbar und das touristische Angebot in Bergdörfern hatte sich bis in die 1930er-Jahre stetig ausgeweitet. ${ }^{12}$ Eine einsetzende Sozialgesetzgebung ermöglichte das Entstehen einer Freizeitkultur. Die veränderten Arbeitswelten mit der zunehmenden Trennung von Arbeitszeit und Freizeit steigerten den Wert der individuellen wie kollekti-

10 Hannes Schneider hielt während des Ersten Weltkriegs für die Truppen der 4. Bergführerkompanie unter anderem Skikurse auf dem Monte Bondone südwestlich von Trient ab. Im Winter 1919/20 nahm er in St. Anton am Arlberg den Betrieb seiner Skischule wieder auf. Vgl. Hannes Schneider, Auf Schi in Japan, Innsbruck/Wien/München 1935, S. 18 und 22; Gidl, Von elitären Versuchen, S. 128.

11 Vgl. Robert Groß, Die Beschleunigung der Berge. Eine Umweltgeschichte des Wintertourismus in Vorarlberg/Österreich (1920-2010), Wien/Köln/Weimar 2019, S. 88.

12 Vgl.Groß, Die Beschleunigung, S. 90. 
ven körperlichen Ertüchtigung. ${ }^{13}$ Skisport wie der Sport allgemein wurde nach dem Ende des Ersten Weltkriegs zu einem Bestandteil der Alltags- und Populärkultur, sowohl für Menschen am Land als auch in der Stadt. Der alpine Skilauf wurde in der Zwischenkriegszeit zur Lebens- und Erfahrungswelt großer Teile der Bevölkerung in Mitteleuropa. ${ }^{14}$ Die im und nach dem Ersten Weltkrieg-Geborenen wuchsen mit dem Skilauf auf. Diese Generation erlernte das Skifahren in den ersten Skischulen, die ab den 1920er-Jahren im Alpenraum gegründet wurden, zumeist schon im Kindheits- und Jugendalter. Als Kinder und Jugendliche erlebten viele ihre ersten Wettbewerbe und sahen ihren Vorbildern bei Skirennund Skisprungveranstaltungen zu. In den Schulen der Ersten Republik wurden 1921 die ersten verpflichtenden Schulskikurse eingeführt. Das Erziehungsministerium unter der Leitung von Karl Gaulhofer machte es sich zur Aufgabe, Skikurse für SchülerInnen in Österreich bundesweit zu initiieren. ${ }^{15}$ Damit fand die junge Generation der Zwischenkriegszeit ihren Weg zum Skisport. Die Mitgliederzahl des ÖSV stieg 1923 erstmals über 10 000, vor dem Ersten Weltkrieg waren es $6000 .{ }^{16}$ Im Herbst 1925 waren laut Jahres- und Rechenschaftsbericht 163 Vereine und knapp 11000 Mitglieder im ÖSV organisiert. ${ }^{17}$

Zum einen erfuhr die Sportart durch die Internationalisierung im Wettbewerbswesen eine Professionalisierung, zum anderen gab es auf nationaler Ebene Bestrebungen, die Regeln und das Lehrwesen zu vereinheitlichen. Der Ausbau des Skilehrwesens und die Vereinheitlichung der Ausbildung trugen aber nicht nur dazu bei, dass immer mehr Menschen das Skifahren erlernen und ausüben konnten, sondern beförderten den Spitzen- und Leistungssport. Hinzu kamen technische Errungenschaften wie die Erfindung und Patentierung der Stahlkante für Ski durch Rudolf Lettner im Jahr $1926 .^{18}$ Skier mit Stahlkanten wurden erstmals von Mitgliedern des Innsbrucker Skiklubs bei den Akademischen Weltwinterspielen 1930 in Davos verwendet. Sie trugen mit zum Erfolg

13 Vgl. Gilbert Norden, Sport in Österreich. Vom 19. Jahrhundert bis zur Gegenwart, in: Matthias Marschik/Georg Spitaler (Hg.), Helden und Idole. Sportstars in Österreich, Innsbruck/ Wien/Bozen 2006, S. 25-39, hier S. 32.

14 Vgl. Andrew Denning, Alpine Modern: Central European Skiing and the Vernacularization of Cultural Modernism 1900-1939, in: Central European History, 46 (2013) 4, S. 850-890, hier S. 853; Matthias Marschik, Transformationen der Bewegungskultur, in: Matthias Marschik/Rudolf Müllner/Otto Penz/Georg Spitaler (Hg.), Sport Studies, Wien 2009, S. 23-34, hier S. 33-34.

15 Vgl. Müllner, The Importance of Skiing, S. 663-664.

16 Vgl. Gidl, Von elitären Versuchen, S. 129.

17 Vgl. dazu Tiroler Anzeiger, 2.10.1925, S. 11.

18 Zur Entwicklungsgeschichte der Skikanten bis hin zur Stahlkante von Rudolf Lettner siehe Herta Stadler, Die Skikante, unveröff. Hausarbeit, Innsbruck 1936. 
der Innsbrucker SkiläuferInnen in den alpinen Bewerben bei. ${ }^{19}$ Im Wettbewerbswesen entwickelte sich die Österreichische Skimeisterschaft um die alpine Disziplin weiter. Die erste nationale Meisterschaft nach dem Ersten Weltkrieg wurde 1921 in St. Johann im Pongau ausgetragen, damals noch im Lang- und Sprunglauf sowie eine Kombination der beiden. Später kam der Abfahrtslauf als dritte Disziplin dazu und die Zweierkombination wurde zu einer Dreierkombination ausgeweitet.

\subsubsection{Mediatisierung und Kommerzialisierung des Skisports}

Eine weitere Bedeutungssteigerung brachte die Mediatisierung des Sports, insbesondere des Spitzensports mit sich, die schon gegen Ende des 19. Jahrhunderts wirksam wurde, sich aber ab den 1920er-Jahren immer weiter ausdehnte und ausdifferenzierte. In der ersten Hälfte des 20. Jahrhunderts „mutierte der Sport mithilfe der Printmedien und ab den 1920er Jahren vor allem mit dem Einsatz des Radios zu einem Massenphänomen. "20 Diese Mediatisierung erfasste in der Ersten Republik auch den Skisport, der von der Sportpresse als heimischer Sport begriffen und über den in entsprechender Weise berichtet wurde. Das Wiener Sport-Tagblatt, das im November 1919 aus dem Sportblatt am Mittag hervorging und ab diesem Zeitpunkt täglich erschien, ${ }^{21}$ verschrieb sich von Beginn an dem Skisport und wies erstmals in der Ausgabe vom 11. Jänner 1919 unter dem Titel „Schneesport. Junge Kultur“ auf die sportliche und zugleich touristische Bedeutung des Skilaufs für Österreich hin.

Hätten die Skireviere Deutschösterreichs den wintersportlichen Fremdenverkehr, den sie verdienen, so wären die ungeheuren Zahlungspflichten, die auf unserer schwergeprüften Heimat lasten, minder mühselig zu erfüllen! ${ }^{22}$

19 Vgl. Franck, Die Entwicklung von Alpinistik, S. 127 und Hans Müller, Die Lettner-Kante, in: Wintersportmuseum Mürzzuschlag (Hg.), $3^{\text {rd }}$ FIS Ski History Conference, Mürzzuschlag/Graz 2004, S. 171-176, hier S. 174-176.

20 Vgl. Matthias Marschik/Rudolf Müllner, Kulturen des Mediensports in Österreich. Zur Einführung, in: Matthias Marschik/Rudolf Müllner (Hg.), „Sind's froh, dass Sie zu Hause geblieben sind.“ Mediatisierung des Sports in Österreich, Göttingen 2010, S. 9-22, hier S. 18.

21 Minas Dimitriou, Historische Entwicklungstendenzen des Mediensports, in: Matthias Marschik/Rudolf Müllner (Hg.), „Sind's froh, dass Sie zu Hause geblieben sind.“ Mediatisierung des Sports in Österreich, Göttingen 2010, S. 25-37, hier S. 30.

22 Sport-Tagblatt, 11.1.1919, S. 3. Mit den „ungeheuren Zahlungspflichten“ sind die Reparationszahlungen gemeint, die die Republik Deutsch-Österreich nach der Niederlage im Ersten Weltkrieg und dem Friedensschluss von St. Germain leisten musste. 
$\mathrm{Ab}$ diesem Zeitpunkt verfolgte das Sport-Tagblatt in seiner Berichterstattung nicht nur regelmäßig das skisportliche Geschehen in Form von Wettbewerbsberichten, sondern informierte seine LeserInnen darüber hinaus über sportorganisatorische Neuerungen wie die erste Vertreterversammlung des ÖSV nach dem Ersten Weltkrieg. ${ }^{23}$ Der Hörfunk erweiterte die Kommunikationsmöglichkeiten mit Beginn der 1920er-Jahre. Die ersten Olympischen Winterspiele, die im Radio übertragen wurden, waren jene von St. Moritz im Jahr 1928. Radio Bern berichtete damals live von der Eröffnung. ${ }^{24}$ Auch die österreichische Radioverkehrs AG (RAVAG) erkannte den Nutzen der Sportberichterstattung. Die Live-Reportage wurde ab Herbst 1928 zu einem fixen Bestandteil der nationalen Radioübertragung. Auf diese Weise fand auch der der Skisport seine massenhafte Verbreitung über die Ländergrenzen hinweg. Durch den Austausch mit anderen europäischen und amerikanischen Rundfunkanstalten gelangten die „Hörbilder" von den FIS-Rennen im Februar 1933 in Innsbruck zu einer internationalen ZuhörerInnenschaft. ${ }^{25}$

Die Werbung in der Presse für Skiprodukte, Skireisen und Ski-Unterkünfte verdeutlicht die steigende Popularisierung des Skisports im Sinne einer Massensportart. Skisujets tauchten in allen Formen und Variationen auf. Selbst Unterwäsche-Hersteller bewarben ihre Produkte in einschlägigen Printmedien in Verbindung mit wintersportlichen Aktivitäten. ${ }^{26}$

\subsubsection{Aufbau und Ausbau der Infrastruktur}

Aus skitouristischer Sicht kam ab den 1920er-Jahre die infrastrukturelle ErschlieBung der Alpen hinzu, die den Skilauf für breitere Gesellschaftsschichten öffnete und Investitionen möglich machte. ${ }^{27}$ Das österreichische Bundesministerium für Verkehr vergab erstmals 1921 staatliche Subventionen an den ÖSV, um Hütten und Schanzen zu errichten und Skiabfahrten zu markieren..$^{28}$ Um den Bau

23 Vgl. Sport-Tagblatt, 5.3.1919, S. 4

24 Vgl. Dimitriou, Historische Entwicklungstendenzen, S. 32.

25 Vgl. Theodor Venus, Sport im Rundfunk. Die Entwicklung der aktuellen Sportberichterstattung im österreichischen Hörfunk 1924-1938, in: Matthias Marschik/Rudolf Müllner (Hg.), „Sind's froh, dass Sie zu Hause geblieben sind.“ Mediatisierung des Sports in Österreich, Göttingen 2010, S. 67-76, hier S. 72.

26 Unter dem Slogan „Für die Mutter, wie für die Tochter!“ bewarb das deutsche Modehaus Warner seine elastische Spezialunterwäsche, die nicht nur für den täglichen Gebrauch, sondern auch für den Sport geeignet sein sollte. Vgl. Sport im Bild, 2 (18.1.1938) 4, S. 42.

27 Vgl. u. a. John Hughes, Austria and the Alps: Introduction, in: Austrian Studies, 18 (2010), S. 1-13, hier S. 5.

28 Vgl. Gidl, Von elitären Versuchen, S. 129. 
von Bergbahnen in den Alpen entbrannte ab Mitte der 1920er-Jahre ein regelrechter Wettbewerb. Die erste Seilschwebebahn in Österreich erschloss ab Juni 1926 die Rax, gefolgt von jener auf die Zugspitze in Deutschland. ${ }^{29}$ Schon zwei Jahre zuvor beförderte die erste Seilschwebebahn in Deutschland ihre Gäste auf einen Gipfel, den Fichtelberg im Erzgebirge. ${ }^{30}$ In Zell am See, das schon vor dem Ersten Weltkrieg als Wintersportplatz seine internationalen Gäste begrüßte, führte ab Jahresende 1927 eine Bergbahn auf die Schmittenhöhe. ${ }^{31}$ Auf der Nordabfahrt konnten fortan 1200 Höhenmeter mit Ski bewältigt werden, ohne vorher mühsam aufzusteigen. Laut dem Bericht von Ernst Hanausek über „SeilbahnAbfahrten in Österreich“ waren bis zu sechs Fahrten am Tag mit der Seilbahn möglich, vorausgesetzt man hatte sich vorher den richtigen Fahrplan zurechtgelegt und war sportlich genug. ${ }^{32}$ Noch vor der Schmittenhöhebahn war im Frühjahr bzw. Sommer 1927 auf den Pfänder in Vorarlberg und den Feuerkogel in Oberösterreich eine Seilschwebebahn in Betrieb genommen worden. Allerdings waren die Bahnen in Bregenz und Ebensee dem Ausflugstourismus im Sommer geschuldet, während jene in Zell am See durchaus den Wintersportbetrieb fördern sollte. Im selben Jahr gründete sich in Zell am See die erste Skischule und keine zehn Jahre später sprang der Salzburger Skispringer Josef Bradl beim Eröffnungsspringen auf der neuen Köhlergrabenschanze einen Schanzenrekord. ${ }^{33}$ Zehn Jahre nach Zell am See, im Jahr 1937, bekam St. Anton am Arlberg mit der Galzigbahn eine Seilschwebebahn für den Winterbetrieb. ${ }^{34}$ Die Förderkapazität lag damals bei beachtlichen 210 Personen pro Stunde. ${ }^{35}$ Zur gleichen Zeit als die Galzigbahn von St. Anton aus den Arlberg erschließen sollte, nahm auf der Vorarlberger Seite in Lech der erste Umlaufschlepplift den Betrieb auf. Dieser wurde

29 Vgl. Erich Bazalka, Skigeschichte Niederösterreichs, Waidhofen a.d. Ybbs 1977, S. 56-57; Frank, Die Entwicklung von Alpinistik, S. 115; Hermann Gruber/Josef Metzger, Es begann in Wien. Eine Spurensuche im Schnee. 100 Jahre Wiener Skiverband, Wien 2013, S. 77.

30 Interessanterweise wurde die erste Seilschwebebahn in Deutschland nicht in den Alpen erbaut. Dieser Umstand hängt mit den im Erzgebirge einflussreichen Alpin- und Skivereinen und dementsprechenden regionalen Initiativen zusammen. Vgl. Peiffer, Vom Soldatensport, S. 86.

31 Vgl. Ski-Klub Zell am See. Festschrift zum 75-Jahr-Jubiläum, Zell am See 1981, S. 30.

32 Vgl. Ernst Hanausek, Seilbahn-Abfahrten in Österreich, in: Skileben in Österreich, Wien 1938, S. 51.

33 Vgl. Ski-Klub Zell am See, S. 30.

34 Die Galzigbahn wurde am 19. Dezember 1937 eröffnet. Vgl. Christof Thöny, Arlberg: The Creation of a Resort and the Transfer of Knowledge, in: Philipp Strobl/Aneta Podkalicka (Hg.), Leisure Cultures and the Making of Modern Ski Resorts, Cham 2019, S. 117-142, hier S. 127.

35 Vgl. https://www.skiarlberg.at/de/regionen/geschichte/die-galzigbahn (6.10.2019); Tiroler Anzeiger, 18.12.1937, S. 3 
1937 nach dem Patent von Ernst Constam am Zürsersee erbaut. Die gemeinsame Errichtung des Schlepplifts durch Josef (Sepp) Bildstein und Emil Doppelmayr bedeutete den Startschuss für den „Weißen Ring“, den bis heute so genannten Rundkurs am Arlberg. ${ }^{36}$ Der Versuch, die Alpen zum Zwecke des Skisports zu erschließen, lässt sich ab Anfang der 1920er-Jahre immer stärker in den Vereinsstatuten der Skiklubs ablesen. ${ }^{37}$ Neben der skitechnischen Ausbildung der Mitglieder und der Veranstaltung von Skirennen rückte die Errichtung von Skihütten in den Fokus der Vereine. ${ }^{38}$ Damit befand sich der alpine Skisport auf der Überholspur gegenüber der Fortbewegung auf Skiern im flachen Gelände. ${ }^{39}$

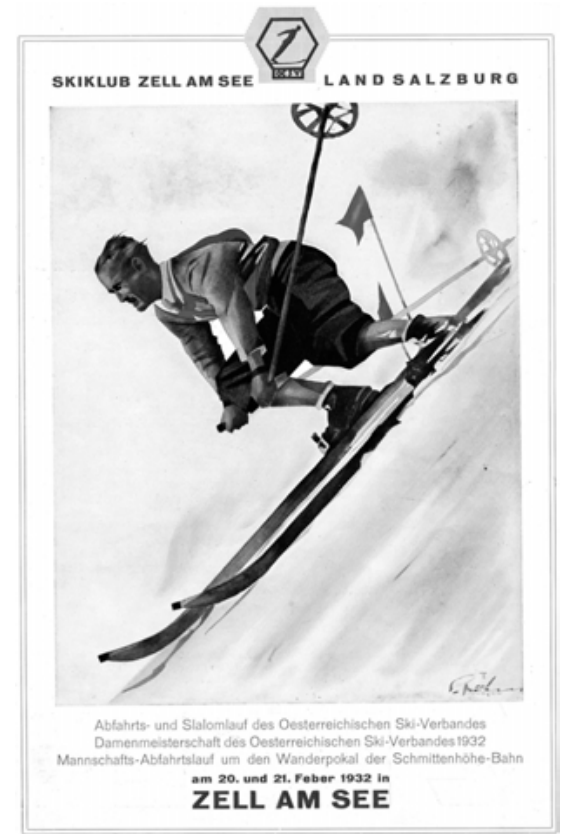

Abb. 2: Der alpine Skisport nimmt Fahrt auf. Zell am See als frühes Zentrum des Rennsports und Austragungsort von österreichischen Meisterschaften, Bezirksarchiv Zell am See.

„Das alpine Skifahren war einzigartig in der Art, wie es moderne Massenkultur und Wertschätzung gegenüber der Natur verband“, ${ }^{40}$ schreibt Andrew Denning

36 Vgl. Groß, Die Beschleunigung, S. 95; Dettling, Die historische Entwicklung, S. 61. 37 Vgl. u. a. Satzungen des Österreichischen Skiverbandes, §1 Zweck des ÖSV, in: Österreichischer Skiverband, Satzungen des Ö.S. V., beschlossen in der Vertreter-Versammlung in Salzburg am 8. Oktober 1922, Wien 1923, S. 5.

38 Vgl. u. a. Satzungen Wintersportsektion des Kitzbüheler Sportklubs (K.S.C.), Tiroler Landesarchiv (TLA), Abt. I, XVIII 93b, ex 1926, Zl. 3066; Statuten des Skiklub Arlberg, TLA, Abt. I, XVI 78c, ex 1924, Zl. 1321.

39 Vgl. Peiffer, Vom Soldatensport, S. 86.

40 Denning, Alpine Modern, S. 853. 
über die Entwicklung des alpinen Skilaufs von 1900 bis 1939. Und dennoch: Nicht überall verliefen die ambitionierten Pläne, die Berge mittels technischer Aufstiegshilfen zugänglich zu machen, friktionsfrei. Touristische Infrastrukturprojekte, die nicht selten von lokalen Skivereinen unterstützt und vorangetrieben wurden, stießen in manchen Gebirgstälern auf Widerstand von Naturschützern. Vor allem der Alpenverein trat gegen die Technisierung auf und mahnte vor der Gefahr des „Massen-Skilaufs“. ${ }^{41}$ Andernorts gerieten Seilbahnprojekte aufgrund fehlender finanzieller Mittel in Zeiten der Wirtschaftskrise ins Stocken. Trotz einer breiten Initiative des Wintersportvereins Bad Gastein, des Skiklubs Bad Gastein und der Gastwirtsgenossenschaft gegen Jahresende 1935 konnte das Seilbahnprojekt auf den Stubnerkogel vor Ausbruch des Zweiten Weltkriegs nicht realisiert werden. Ins Treffen geführt wurden dabei die klimatischen Vorteile, die der Stubnerkogel gegenüber der Schmittenhöhe hätte. ${ }^{42} \mathrm{Da}$ mit nahmen die Befürworter des Gasteiner Projektes direkten Bezug zur bereits existierenden Schmittenhöhebahn, die als Konkurrenz gesehen wurde. In einem Schreiben an den Leiter des Salzburger Landesverkehrsamtes Hans Hofmann-Montanus legte der Obmann des Wintersportvereins Dr. Fritz Windischbauer die Vorteile der Erschließung des Skigebietes und die Wirtschaftlichkeit dessen dar. Der Obmann des Skiklubs, Hans Windischbauer, unterstützte das Vorhaben, indem er auf die skisportliche Bedeutung verwies. Laut seinen Angaben soll der Skiklub in Bad Gastein zu dieser Zeit über 180 Mitglieder gezählt haben. Anscheinend hat sich aber auch eine Gegnerschaft formiert. ${ }^{43}$ Das Projekt verschwand in der Schublade. Es dauerte bis Jänner 1951 bis tatsächlich eine Seilbahn auf den Stubnerkogel eröffnet wurde. Auch bei der Galzigbahn auf den Arlberg verzögerte sich der Baubeginn auf das Jahr 1937. Der Skisport als Massenbewegung gewann aber trotz regionaler Rückschläge bei Infrastrukturprojekten Mitte der 1930er-Jahren so sehr an Bedeutung, dass die Österreichischen Bundesbahnen ab Mitte Dezember eigene „Wintersportgarnituren“ einsetzten, die als „Sportzüge“ in die Skigebiete rollten. ${ }^{44}$

41 Vgl. Bedenkliches vom Massen-Skilauf, in: Mitteilungen des Deutschen und Österreichischen Alpenvereins, 64 (1938) 2, S. 25-26.

42 Zum Seilbahnprojekt in Bad Gastein vgl. Salzburger Landesarchiv (SLA), Rehrl-Brief 1936/ 0057.

43 Vgl. Brief von Hans Windischbauer an Hofmann-Montanus, Leiter des Landesverkehrsamtes, 19.12.1935 und Brief von Dr. Fritz Windischbauer, Obmann des Wintersportvereins Badgastein, an Hofmann-Montanus, Leiter des Landesverkehrsamtes, 22.12.1935, SLA, Rehrl-Brief $1936 / 0057$.

44 Vgl. Erwin Benesch, Wegweiser für den Winterverkehr in Österreich, in: Skileben in Österreich, Jahrbuch des Österreichischen Skiverbandes, Wien 1936, S. 167. 


\subsubsection{Internationale Vergleichbarkeit}

Im Hotel Majestic in Chamonix gründete sich am 2. Februar 1924 der Internationale Skiverband (FIS). Auf diesem achten Internationalen Skikongress in den französischen Alpen wurden nicht nur die Olympischen Winterspiele diskutiert, sondern gleichzeitig die Internationale Wintersportwoche durchgeführt. ${ }^{45}$ Der Skihistoriker John Allen beschreibt dieses Ereignis als „Wendepunkt hinsichtlich der wachsenden Anerkennung für den internationalen Skisport““ ${ }^{46} 258$ AthletInnen aus 16 Nationen nahmen an der ersten internationalen Wintersportveranstaltung nach dem Ersten Weltkrieg teil. ${ }^{47}$ An den nordischen Skibewerben beteiligten sich elf Nationen, Deutschland war aufgrund der Nachkriegsbestimmungen nicht teilnahmeberechtigt. ${ }^{48}$ Der Erfolg führte dazu, dass das Internationale Olympische Komitee (IOC) bei seinem jährlichen Kongress, der 1925 in Prag stattfand, die Internationale Wintersportwoche im Nachhinein als Olympische Winterspiele deklarierte und die Olympischen Winterspiele in einem VierJahres-Rhythmus beschloss. ${ }^{49}$ Vier Jahre nach den ersten Olympischen Winterspielen in Chamonix veranstaltete Hannes Schneider gemeinsam mit Arnold Lunn im März 1928 das erste Arlberg-Kandahar-Rennen, benannt nach den beiden Vereinen SC Arlberg und dem Kandahar-Ski-Club. ${ }^{50}$ Bei dem internationalen alpinen Skirennen starteten SkiläuferInnen aus Österreich, England, der

45 Vgl. Elfriede Werthan, Weiße Pisten, Gold \& Geld. Die Geschichte des alpinen Skisports, Reichling 1976, S. 30; Heinz Polednik, Weltwunder Skisport, Wels 1969, S. 102 und 104.

46 John B. Allen, 1924 - Die Geburt des modernen Skisports, in: SportZeiten, Sport in Geschichte, Kultur und Gesellschaft 2 (2002) 1, S. 7-16, hier S. 13.

47 Vgl. Andrew Denning, Going Downhill? The Industrialisation of Skiing from the 1930s to the 1970s, in: Philipp Strobl/Aneta Podkalicka (Hg.), Leisure Cultures and the Making of Modern Ski Resorts, Cham 2019, S. 25-42, hier S. 28.

48 Vgl. Walter König/Gustl Berauer, Handbuch des Schilaufs, Innsbruck 1943, S. 17. Bei den ersten Olympischen Winterspielen nach dem Ersten Weltkrieg wurden zunächst nur nordische Skibewerbe ausgetragen, alpine Skirennen kamen erstmals 1936 in Garmisch-Partenkirchen zur Austragung.

49 Andrew Denning nennt in seinem Artikel das Jahr 1926 für den IOC-Kongress, an dem die Olympischen Winterspiele beschlossen wurden. Tatsächlich fand dieser 1925 in Prag statt. Vgl. Denning, Going Downhill, S. 28; Chamonix 1924. Winter Games given Stamp of Approval, https://www.olympic.org/news/winter-games-given-stamp-of-approval (29.8.2019).

50 Das erste Arlberg-Kandahar-Rennen war nach einer Idee des englischen Skiläufers Arnold Lunn durch eine Vereinbarung mit Hannes Schneider erstmals 1928 zustande gekommen und sollte die SkiläuferInnen des Kandahar-Skiklubs in Mürren mit jenen des Skiclubs Great Britain und des Skiclubs Arlberg zusammenbringen. Ab 1930 wurde das Rennen abwechselnd in Mürren und St. Anton ausgetragen, wobei St. Anton die geraden und Mürren die ungeraden Jahre zufallen sollten. Vgl. 45 Jahre Ski-Club Arlberg. 1901-1946, St. Anton Winter 1945/46, S. 4-5. 
Schweiz und den USA.51 Das erste Arlberg-Kandahar-Rennen diente als Modell für die alpinen Disziplinen, nachdem die FIS zuvor ausschließlich die nordischen Bewerbe gefördert hatte. Das blieb nicht ohne Folgen. Zwei Jahre später nahm die FIS den Abfahrtslauf sowie den Slalom in die internationalen Wettkampfbestimmungen mit auf und 1931 wurden in Mürren die ersten alpinen Skiweltmeisterschaften ausgetragen, die noch bis 1937 als FIS-Wettkämpfe geführt und bis 1939 jährlich veranstaltet wurden..$^{52} 1933$ wurde die erste nationale Abfahrtsmeisterschaft in den USA nach den offiziellen FIS-Regeln ausgetragen. ${ }^{53}$ Damit war Anfang der 1930er-Jahre eine internationale Vergleichbarkeit im alpinen Skirennsport hergestellt worden.

\subsection{Vom „Volkssport“ zum Nationalsport - zur Bedeutung des Skisports in der Ersten Republik und im Austrofaschismus}

Der Skisport war neben dem Fußball die Sportart in der Ersten Republik, der auf Spitzenniveau am meisten Bedeutung zukam. Auf Österreich bezogen liegen die Gründe zum Gutteil in der soeben geschilderten Professionalisierung der Sportart und damit in der Herausbildung eines Spezialistentums, das den Sport sowohl auf einem hohen Leistungsniveau ausüben als auch in der Breite vermitteln konnte. International gesehen war die Professionalisierung auch der Tatsache geschuldet, dass der Skilauf ab 1924 mit der FIS in einem internationalen Verband organisiert war und die ab 1930 stattfindenden Abfahrts- und Slalomrennen unter standardisierten Regeln stattfanden. ${ }^{54}$ Die internationalen Wettbewerbe ermöglichten einen direkten sportlichen Vergleich mit anderen Nationen. Erst dieser Vergleich schuf die Voraussetzung für das Entstehen einer nationalen Identität über den Skisport. Dieter Reicher beschreibt diese Entwicklung als „Prozess der Umwandlung von ,Ethnosport“ in Nationensport““.55 Ebenso wie die Massensportart Fußball konnte auch der Skilauf ab Ende der 1920erJahre als professioneller Sport begriffen werden. Der österreichische Skisport war ebenso international ausgerichtet, hatte aber im Unterschied zum Fußball weniger einen urbanen, großstädtischen Charakter, sondern war durchaus

51 Vgl. Polednik, Weltwunder, S. 101.

52 Die Weltmeisterschaften im alpinen Skisport wurden zunächst als FIS-Wettkämpfe tituliert und erst 1937 offiziell als Skiweltmeisterschaften bezeichnet. Vgl. Werthan, Weiße Pisten, S. 33-34; Falkner, Deutscher Skilauf, S. 23; Seefranz, Der Weiße Rausch, S. 65.

53 Vgl. Allen, From Skisport, S. 125.

54 Vgl. Werthan, Weiße Pisten, S. 33-34.

55 Dieter Reicher, Nationensport und Mediennation. Zur Transformation von Nation und Nationalismus im Zeitalter elektronischer Massenmedien, Göttingen 2013, S. 75. 
kleinstädtisch und provinziell geprägt und wies, darüber darf die internationale Ausrichtung nicht hinwegtäuschen, starke nationalistische Züge auf. Matthias Marschik schreibt davon, dass der Fußball in der Ersten Republik „als Paradebeispiel eines urbanen, internationalen und ab 1924 professionellen Sportes gelten kann “. ${ }^{56}$ Diese Attribute würde ich ebenso dem Skisport in Österreich zu jener Zeit zuschreiben. Auch der Skilauf vermochte wie der proletarische Fußball ${ }^{57}$ urbane Schichten wie die Arbeiterschaft zu durchdringen. Der Unterschied lag aber darin, dass der von der Arbeiterschaft getragene Skisport mit dem bürgerlichen Skisport nie in Konkurrenz trat. ${ }^{58}$

Auch wenn eine Identifikation mit der Ersten Republik auf breiter Basis in der österreichischen Zwischenkriegsgesellschaft nicht hergestellt werden konnte, so kann der Skisport in Österreich ab Mitte der 1920er-Jahre und spätestens ab 1930 durchaus als eine Art Nationalsport bezeichnet werden, indem die Leistungen individueller SportlerInnen oder eines Teams national gedeutet und interpretiert wurden..$^{59}$ Dazu trugen nicht nur die skisportlichen Erfolge auf internationaler Ebene bei, die sicherlich wesentlich waren, um den Skilauf im kollektiven Bewusstsein als nationale Sportart zu verankern. Vielmehr war es die räumliche Durchgängigkeit der Sportart. Während sich der professionell betriebene Fußball in der Zwischenkriegszeit auf Wien beschränkte und das Nationalteam eine Wiener Fußballmannschaft war und keine gesamtösterreichische, ${ }^{60}$ schaffte es der Skisport bundesländerübergreifend bis in abgelegene Gebirgstäler hinein Strukturen aufzubauen, die eine Vergleichbarkeit und einen bundesweiten einheitlichen Sportbetrieb möglich machten. Die AthletInnen kamen anders als im österreichischen Spitzenfußball zumeist aus der Provinz und stammten aus ländlich geprägten Regionen. Damit bot der Skisport in der Zwischenkriegszeit auf Gesamtösterreich bezogen eine breite Identifikationsfläche an. Der Skilauf war zwar aus touristischer Sicht ein urbanes, großstädtisches Phänomen, weil er eine zahlungskräftige Gästeschicht benötigte, die ausüben-

56 Vgl. Marschik, Sportdiktatur, S. 31.

57 Proletarischer Fußball meint hier den von der Arbeiterschaft initiierten und getragenen Fußballsport in der Ersten Republik, der in starker Abgrenzung zum bürgerlichen Fußball stand und sich ab Mitte der 1920er-Jahre in einem eigenen Verband organisierte. Zum Arbeiterfußball in der Ersten Republik und zur Verbandstrennung im Fußball siehe Marschik, „Wir spielen nicht“.

58 Vgl. hier das Kapitel zum proletarischen Skilauf.

59 Vgl. dazu Reicher, Nationensport, S. 88.

60 Zur Abgrenzung des Wiener Fußballs vom Provinzfußball in den Bundesländern vgl. u.a. Matthias Marschik, Metropolen statt Provinzen. Mitropa-Idee vs. Verösterreicherung des Fußballs in der Zwischenkriegszeit, in: Siegfried Göllner/Albert Lichtblau/Christian Muckenhumer/ Andreas Praher/Robert Schwarzbauer (Hg.), Zwischen Provinz und Metropole. Fußball in Österreich. Beiträge zur 1. Salzburger Fußballtagung, Göttingen 2016, S. 88-96, hier S. 91. 
den (Spitzen-)SportlerInnen kamen aber vorwiegend aus kleineren Landgemeinden bis mittelgroßen Städten. Nicht Wien, sondern die gebirgsnahen Landeshauptstädte wie Salzburg oder Innsbruck waren Zentren des frühen Wintersports und hatten mit ihren Skiklubs einen großen Einfluss auf die Entwicklung und Verbreitung des vereinsmäßig ausgeübten Skisports. In Salzburg war der 1910 gegründete und im Dezember 1918 wiedergegründete Skiclub Salzburg (SCS) im Laufe der 1920er-Jahren mit seinen wintersportlichen Aktivitäten im Großraum Salzburg nicht mehr wegzudenken. ${ }^{61}$ Frühe Skisprungveranstaltungen, wie jene beim Eröffnungsspringen auf der Zistel im Februar 1923, lockten hunderte bis tausende ZuschauerInnen an. ${ }^{62}$ Jungen SkisportlerInnen wie Hans Hauser oder Käthe Lettner ermöglichte der SCS den Sprung in das internationale Skisportgeschäft. In Innsbruck war es der Skiklub Innsbruck (SKI), ${ }^{63}$ der abgesehen vom Sportnachwuchs den nationalen und internationalen Skisport beförderte und Akzente setzte. Vier Jahre nach Salzburg konnte der SKI gemeinsam mit dem Tiroler Skiverband am 23. Jänner 1927 die Skisprungschanze auf dem Bergisel eröffnen. ${ }^{64}$ Das Eröffnungsturnier vor 5000 ZuschauerInnen wurde als Meisterschaft von Tirol im Skilauf ausgetragen und fand in der klassischen Kombination Langlauf und Sprunglauf statt. ${ }^{65}$ Beim ersten Alrberg-Kandahar-Rennen im März 1928 machten die SkiläuferInnen aus Innsbruck erstmals von sich zu hören, 1930 bei den Akademischen Weltwinterspielen in Davos erfolgte dann der Durchbruch der jungen Skigeneration des SKI. ${ }^{66}$ Sowohl die jungen Innsbrucker wie auch Salzburger SkiläuferInnen gehörten durchwegs einer bürgerlichen, zum Teil akademischen Schicht an, verkörperten aber gleichzeitig eine Generation, der es erstmals möglich geworden war über den Sport den Provinzstatus abzulegen.

Abgesehen vom Spitzensport beförderten die Stadtvereine den Breitensport. Ein Blick in die Jahresberichte des Salzburger Landesskiverbandes der 1930er-

61 Vgl. dazu Andreas Praher, Sport und Körperkultur. „Ohne Widerstand bis zum Endsieg“, in: Sabine Veits-Falk/Ernst Hanisch (Hg.), Herrschaft und Kultur. Instrumentalisierung, Anpassung, Resistenz. Die Stadt Salzburg im Nationalsozialismus (Band 4), Salzburg 2013, S. 268317, hier S. 271.

62 Vgl. Praher, Sport und Körperkultur, S. 271; Skiclub Salzburg (Hg.), 75 Jahre Skiclub Salzburg 1910-1985, Salzburg 1985, S. 21-22; Skiclub Salzburg (Hg.), 100 Jahre Skiclub Salzburg 1910-2010, Salzburg 2010, S. 21.

63 Der Skiklub Innsbruck wurde am 20. November 1906 von der k. k. Statthalterei behördlich genehmigt und nahm nach dem Ersten Weltkrieg ab Dezember 1918 wieder seinen Betrieb auf. Vgl. Graf/Gidl, Skisport, S. 18 und 33.

64 Vgl. Tiroler Skiverband (Hg.), 100 Jahre Tiroler Skiverband 1913-2013, Hall in Tirol 2013, S. 18.

65 Vgl. Gidl/Graf, Skisport, S. 37.

66 Vgl. Gidl/Graf, Skisport, S. 45-46. 
Jahre verdeutlicht die Bedeutung des städtischen Skiclubs anhand der Mitgliederzahlen. So hatte der Skiclub Salzburg in den Vereinsjahren 1931/32 und 1932/33 im Vergleich zu den Skivereinen in den ländlichen Gebirgsregionen mit Abstand den höchsten Mitgliederstand. Das sollte sich auch im Vereinsjahr 1933/34 nicht ändern. Während der Skiclub Salzburg seine Mitgliederzahl weiter ausbauen konnte, stagnierte die Zahl bei den anderen beiden Vereinen im Pongau und Pinzgau oder ging sogar zurück. ${ }^{67}$ Das kann auf die schlechte Wirtschaftslage und Strukturschwäche der ländlich geprägten Regionen zurückgeführt werden, die von der „Tausend-Mark-Sperre“ mehr betroffen waren als die Landeshauptstädte. ${ }^{68}$

Tab. 1: Mitgliederstand ausgewählter Vereine im Salzburger Landesskiverband.

\begin{tabular}{lc}
\hline Vereinsjahr 1931/32 & Mitgliederzahl \\
\hline Verein & 455 \\
\hline Skiclub Salzburg & 284 \\
\hline Skiklub Zell am See & 135 \\
\hline Skiclub Badgastein & \\
\hline Vereinsjahr 1932/33 & Mitgliederzahl \\
\hline Verein & 548 \\
\hline Skiclub Salzburg & 227 \\
\hline Skiklub Zell am See & 136 \\
\hline Skiclub Badgastein & \\
\hline Vereinsjahr 1933/34 & Mitgliederzahl \\
\hline Verein & 200 \\
\hline Skiclub Salzburg & 112 \\
\hline Skiklub Zell am See & \\
\hline Skiclub Badgastein & \\
\hline
\end{tabular}

Quelle: SLA, HB C 02253 1932/33, Salzburger Landes-Skiverband Jahresbericht 1932/33 und HB C 02253 1933/34 Salzburger Landes-Skiverband Jahresbericht 1933/34, eigene Zusammenstellung.

67 Vgl. SLA, HB C 02253 1932/33, Salzburger Landes-Skiverband Jahresbericht 1932/33; HB C 02253 1933/34, Salzburger Landes-Skiverband Jahresbericht 1933/34.

68 Die so genannte Tausend-Mark-Sperre war eine Wirtschaftssanktion gegen Österreich, die das Deutsche Reich im Mai 1933 anordnete und die im Juli 1933 in Kraft trat. Demnach hatte jede/r reichsdeutsche TouristIn beim Grenzübertritt 1000 Mark zu zahlen. Diese Sanktion traf vor allem die Tourismusorte in Westösterreich, führte aber gleichzeitig zu einem Ausweichen auf andere Gästeschichten, vor allem aus Frankreich, Großbritannien und den Benelux-Staaten. Vgl. u.a. Groß, Die Beschleunigung, S. 82-83; Brugger, Vom Pioniergeist, S. 118. 
Ausgehend von den damaligen Einwohnerzahlen und der Struktur der beiden Städte Innsbruck und Salzburg, kann in beiden Fällen aber nicht von einem großstädtisch geprägten Umfeld gesprochen werden. ${ }^{69}$ Den Skisport in den 1930er-Jahren daher als rein urbanes Phänomen zu bezeichnen, wäre ebenso unzureichend, als ihm den ländlichen Stempel aufdrücken zu wollen. Ebenso war die Stadt Dornbirn, in der sich schon sehr früh eine skisportliche Infrastruktur entwickelte, kleinstädtisch und kleinbürgerlich geprägt. So gesehen, darf der Skisport der 1930er-Jahre nicht als großstädtisches Phänomen gesehen werden. Vor allem, wenn man bedenkt, dass der Skiklub Zell am See bei einer Einwohnerzahl im Jahr 1934 von 2867 an die 200 Mitglieder aufwies. $^{70}$

Für ganz Österreich gesprochen, kristallisierten sich selbst in Gebirgsregionen, die vor dem Ersten Weltkrieg und danach sportlich gesehen als Brachland galten, gewisse Strukturen heraus, die ab den 1920er-Jahren von öffentlicher und staatlicher Seite gefördert wurden und ein nationales Interesse hervorriefen. Die vom Bundesministerium für Verkehr erstmals 1921 getätigten Subventionen im organisierten Skilauf wurden bereits erwähnt. ${ }^{71}$ Aber auch auf Ebene der Bundesländer flossen ab 1920 öffentliche Gelder in den Ausbau der Skisportinfrastruktur. Landeshauptmänner in den Gebirgs-Bundesländern gaben sich als Förderer der „weißen Zunft“. Sie stifteten Ehrenpreise und bewilligten Infrastrukturprojekte. ${ }^{72}$ Das beflügelte und regte Visionen an. So gab es Ideen, die Stadt Salzburg Mitte der 1930er-Jahre ebenso wie Kitzbühel oder St. Anton zu einem Wintersportort auszubauen. Die Idee kam vom Präsidenten des Allgemeinen Österreichischen Skiverbandes Alexander Hartwich. Er meinte das internationale Publikum der Festspielstadt Salzburg für den Wintersport begeistern zu können. ${ }^{73}$ Gleichzeitig benötigte das staatlich organisierte Skilehrwesen ab 1928 Skischulen und diese mussten von Landesseite genehmigt werden. Da-

69 Die Stadt Salzburg wies im Jahr 1934 einen Bevölkerungsstand von 40456 EinwohnerInnen auf. Vgl. Stadt Salzburg, Salzburg in Zahlen, Bevölkerungsstatistik, Bevölkerungszahlen 1811 bis 1945. www.stadt-salzburg.at/internet/bildung_kultur/salzburg_in_zahlen/bevoelkerungsstatist_321402/bevoelkerungszahlen_235122/bevoelkerungszahlen_1811_bis_1945_270918.htm (6.10.2019). Die Stadt Innsbruck im selben Jahr 78797 EinwohnerInnen. Vgl. https://www.innsbruck.gv.at/page.cfm?vpath=verwaltung/statistiken-zahlen/bevoelkerung (6.10.2019).

70 Zur Wohnbevölkerung von Zell am See 1934 vgl. Laurenz Krisch, Die Wahlerfolge der Nationalsozialisten in der Spätphase der Ersten Republik im Pongau und Pinzgau. Eine empirische Analyse zur Struktur der NSDAP-Wählerschaft, Sonderdruck aus: Mitteilungen der Gesellschaft für Salzburger Landeskunde, Salzburg 2000, S. 215-267, hier S. 255.

71 Vgl. Gidl, Von elitären Versuchen, S. 129.

72 Verschiedene Quellenfunde, unter anderem im Salzburger Landesarchiv bestätigen das politische Interesse seitens der Landespolitik am jungen Skisport.

73 Vgl. Brief von Alexander Hartwich an die Landesregierung Salzburg, z. H. Hofmann Montanus, 16.4.1936, SLA, Rehrl-Brief 1936/2980. 
mit kam es ab den 1930er-Jahren zu einem Gründungsboom von Skischulen in der Alpenregion. ${ }^{74}$

Der ÖSV erkannte schon sehr bald das wirtschaftliche Potenzial des Skisports und wusste dieses auch zu vermarkten. In seinem Selbstverständnis sah sich der ÖSV als der zuständige nationale Wintersportverband, der auf die touristische Bedeutung des Skilaufs aufmerksam zu machen und die wirtschaftliche Vermarktung voranzutreiben hätte. Das kommt auch in einem Artikel der im November 1931 erstmals erschienen amtlichen Verbandszeitschrift Der Skiläufer zum Ausdruck. Die offizielle ÖSV-Verbandszeitschrift wurde zweimal monatlich mit einer Auflage von 15000 Stück kostenlos an alle Mitglieder verschickt und hatte eine dementsprechende Auflage. ${ }^{75}$

\subsubsection{Regionale Zentren mit nationaler und internationaler Bedeutung}

Zum skisportlichen Zentrum des alpinen Skilaufs entwickelte sich in den 1920er- und 1930er-Jahren der Arlberg. Die in Tirol und Vorarlberg liegende Region konnte zu diesem Zeitpunkt schon auf eine 20-jährige Geschichte des organisierten Skilaufs zurückblicken. In St. Anton wurde kurz nach der Jahrhundertwende, am 3. Jänner 1901 der erste Tiroler Skiverein, der Skiclub Arlberg (SCA) gegründet. Zu den Gründungsmitgliedern zählten der Klubobmann Carl Schuler und sein Stellvertreter Adolf Rybitzka. ${ }^{76}$ Der deutsche Geologe und Mitbegründer des DSV und ÖSV Wilhelm Paulcke leitete die ersten Bergführerskikurse. Fünf Jahre nach der Gründung sollte der Club bereits 155 Mitglieder zählen. 1907 holte Carl Schuler den aus Stuben stammenden Hannes Schneider als Skilehrer nach St. Anton, dieser begründete später die Alpinschule. ${ }^{77}$ Nach dem Ersten Weltkrieg lehrte Schneider ab 1921/22 als Skilehrer am Arlberg den Stemmbogen als Vorläufer des Parallelschwungs. Diese Technik revolutionierte nicht nur den alpinen Skilauf, sondern machte den Arlberg zu einer weltweit bekannten und nachgefragten Destination in punkto Skiausbildung. ${ }^{78}$ In der von Hannes Schneider nach dem Ersten Weltkrieg wiedergegründeten Skischule unterrichteten Skilehrer und Skirennläufer wie Rudi Matt oder Josef Jenne-

74 Vgl. Schriftverkehr betreffend Errichtung von Skischulen, Abhaltung von Skikursen und Arbeitszulassungen für Skilehrer, SLA, PRÄ 1936/47-1185-6313 sowie Verzeichnis der Skischulen im Land Salzburg 1937, SLA, PRÄ 1938/47-0475-4599.

75 Vgl. Der Skiläufer. Amtliche Zeitschrift des Österreichischen Ski-Verbandes, 1 (1931) 1, S. 2.

76 Adolf Rybitzka war der Vater des späteren Skisportlers Benno Rybitzka.

77 Vgl. Adolf Lässer, 100 Jahre Fremdenverkehr in Tirol. Die Geschichte einer Organisation, Innsbruck 1989, S. 87.

78 Zur Entwicklung und Verbreitung der Arlbergtechnik vgl. u. a. Thöny, Arlberg, S. 121-122. 
wein. ${ }^{79}$ Beide sollten bis in die 1940er-Jahre hinein internationale Skisporterfolge feiern. Hannes Schneider unterrichtete die SchülerInnen erstmals in Gruppen bis zu 15 Personen gleicher Leistungsstärke und führte bestimmte Regeln ein, nach denen der Unterricht abzulaufen hatte. Seine Skilehrmethode veröffentlichte Schneider gemeinsam mit dem Filmemacher und Bergfilm-Regisseur Arnold Fanck in dem Skilehrbuch Wunder des Schneeschuhs 1925. ${ }^{80}$ Fünf Jahre zuvor sorgte ihr erster gemeinsamer, gleichnamiger Berg- und Skifilm für öffentliches und mediales Interesse. Das war der Beginn einer engen Zusammenarbeit. ${ }^{81}$

Auf Initiative von Ernst Janner errichtete das österreichische Unterrichtsministerium 1923 in St. Christoph am Arlberg ein staatliches Winterheim für den Skiunterricht, ${ }^{82}$ welches heute als Bundessportheim St. Christoph unter dem Namen „Ski Austria Academy“ den österreichischen SkilehrerInnen-Nachwuchs ausbildet. ${ }^{83}$ Der aus Dornbirn stammende Skipädagoge Janner war ein früher Förderer des Skisports in Theorie und Praxis. 1880 geboren, absolvierte er die k. k. Lehrerbildungsanstalt in Innsbruck und erlernte dort um 1900 das Skilaufen. Während des Ersten Weltkriegs war er ebenso wie Schneider als Ski-Ausbildner für die Armee tätig und danach als Ausbildner für zukünftige Turnlehrer. $^{84}$ Sein bekanntestes theoretisches Werk, Arlbergschule, erschien in 22 Auflagen. Mit der Veröffentlichung und Verbreitung des Skilehrbuches in mehreren Sprachen im Jahr 1926 wurde die Arlbergtechnik zur weltweiten Lehrmethode. Janner übernahm im selben Jahr die Leitung des neu gegründeten staatlichen Winterheimes am Arlberg, zuvor leitete er ab 1924 gemeinsam mit

79 Hannes Schneider betrieb schon vor dem Ersten Weltkrieg ab 1907 eine Skischule am Arlberg. Der Durchbruch des alpinen Skilaufs erfolgte aber erst in der Ersten Republik. Ab der Wintersaison 1924/25 erlernte Rudi Matt dort den Skilehrberuf. Vgl. dazu Thomas Ebster, Arlberg, Graz 2013, S. 21; Seefranz, Der Weiße Rausch, S. 65.

80 Vgl. Anneliese Gidl, Im Sog Hannes Schneiders - Zur Entwicklung des Skilaufs am Arlberg, in: Josef Riedmann/Richard Schober (Hg.), Tiroler Heimat. Jahrbuch für Geschichte und Volkskunde (Band 70), Innsbruck 2006, S. 173-181, hier S. 177-178.

81 Arnold Fanck gründete im März 1920 in Freiburg die Berg- und Sportfilm GmbH und fand auf der Suche nach einem Darsteller, der skiläuferische Kenntnisse hatte, in Hannes Schneider den idealen Kandidaten. Vgl. dazu Gunther Haarstark, Hannes Schneider in den Filmen von Arnold Fanck, in: Josef Riedmann/Richard Schober (Hg.), Tiroler Heimat. Jahrbuch für Geschichte und Volkskunde (Band 70), Innsbruck 2006, S. 182-189, hier S. 182-183; Christian Rapp, Sonne über dem Arlberg. Wie das Kino die Skier zum Laufen brachte, in: Tobias G. Natter (Hg.), Schnee. Rohstoff der Kunst, Bregenz 2009, S. 78-89, hier S. 82.

82 Vgl. Erwin Mehl, Grundriss des deutschen Turnens, Wien 1929, S. 482.

83 Vgl. http://skiakademie.at/skiakademie/lehrwesen/skipioniere.php (9.8.2018)

84 Vgl. Lebensdaten von Ernst Janner im Dornbirner Familienbuch: https://lexikon.dornbirn. at/startseite/geschichte/dornbirner-familienbuch (2.8.2019); Mehl, Grundriss, S. 482. 
Hannes Schneider die ersten Skikurse für Studenten der Leibeserziehung in St. Chistoph. ${ }^{85}$ Die achttägigen Skikurse für Lehrer aller Schulen in dem neu eröffneten staatlichen Winterheim in St. Christoph fanden von November bis Mai statt. Im Oktober 1926 schrieb Janner im Tagblatt über die Notwendigkeit der Skilehrerausbildung folgende Zeilen:

Da in Österreich über 92 Prozent der Schulen keinen Turnsaal und dadurch kein Schulturnen in den langen Wintermonaten hatten, nahm die Schulreform in den Lehrplan mit Absicht die winterlichen Uebungen, wie Schnee und Eisspiele, Eisschießen, Rodeln und den Skilauf auf. ${ }^{86}$

Janner arbeitete über die 1920er-Jahre hinweg eng mit Hannes Schneider zusammen. 1930 eröffnete er seine eigene, private Skischule in Gargellen. ${ }^{87} 1934$, unter der austrofaschistischen Sport- und Turnfront, folgte ihm der bis dahin in Salzburg tätige Lehrer und Fotograf Stefan Kruckenhauser als Leiter des Winterheimes nach. ${ }^{88} \mathrm{Ab} 1928$ war für die Berufsausübung die staatliche Skilehrerausbildung in St. Christoph am Arlberg vorgeschrieben. ${ }^{89}$ Damit wurde die Skilehrerausbildung österreichweit vereinheitlicht und der Arlberg zum zentralen Ausbildungsort bestimmt. In seinem 1933 herausgegeben skihistorischen Band über den Arlberg schreibt Walther Flaig über die Arlbergschule fünf Jahre nach deren Gründung folgende Zeilen:

In St. Christoph richtete das österreichische Bundesministerium eine Arlbergschule ein für Lehrer und Lehrerinnen, doch nehmen auch reichsdeutsche Lehrer und Private teil und bald gehen Hunderte durch diese von Professor Janner geleitete Arlbergschule, die sehr stramm aufgezogen ist und durch das berühmte ,erste und zweite Frühstück - gymnastische Lockerungsübungen auf Skiern bekannt wird. ${ }^{90}$

Im März 1928 fand am Arlberg das von der FIS offiziell als alpines Skirennen genehmigte erste Arlberg-Kandahar-Rennen statt. Dieses war wegweisend für

85 Vgl. Graf, Tiroler Sportgeschichte, S. 28.

86 Tagblatt, 22.10.1926, S. 5.

87 Vgl. u. a. Christof Thöny, Vorarlberger Skigeschichte, Erfurt 2012, S. 9 und 17

88 Stefan Krucknhauser, geboren 1905 in München, absolvierte ab 1925 die Turnlehrerausbildung in Wien und fand 1929 eine Anstellung als Lehrer in Salzburg. 1934 übernahm er die Stelle des Heim- und Kursleiters im Wintersportheim St. Christoph am Arlberg. Er wurde zudem in die staatliche Prüfungskommission für Skilehrer unter Vorsitz von Hannes Schneider berufen. Mit der nationalsozialistischen Machtübernahme 1938 wurde er von seinem Leitungsposten in St. Christoph enthoben und war von 1942 bis 1945 als Kriegsberichterstatter an der Ostfront eingesetzt. Vgl. Maria Emberger, Ski- und Fotopionier Stefan Kruckenhauser, Salzburg 2004, S. 5-6; http://skiakademie.at/skiakademie/lehrwesen/skipioniere.php (9.8.2018).

89 Frank, Die Entwicklung von Alpinistik, S. 128-129.

90 Walther Flaig, Arlberg. Ski und Schnee, München 1933, S. 13. 
die Anerkennung und Austragung späterer alpiner Skirennen durch die FIS. ${ }^{91}$ Auf diese Weise trafen am Arlberg Breiten- und Spitzensport zusammen. Während Angehörige europäischer Königshäuser und der gehobenen Schicht ihren Winterurlaub in St. Anton am Arlberg verbrachten und dort das Skifahren erlernten, wurde in St. Christoph am Arlberg das Skilehrwesen weiterentwickelt und weitergegeben sowie in den umliegenden Hängen der Skirennsport ausgeübt. In den 1930er-Jahren sollen sich in der Wintersaison täglich an die 300 bis 400 Skischul-SchülerInnen aufgeteilt auf mehrere Gruppen auf den Ski-Abfahrten getummelt haben.

Parallel zum Arlberg entwickelte sich der Hochkönig in der Zwischenkriegszeit zu einem weiteren Zentrum der skisportlichen Ausbildung, allerdings nicht für den alpinen Bereich, sondern im nordischen Skilanglauf und Skisprung. Die von Peter Radacher sen. 1923 gegründete Skischule in Mühlbach am Hochkönig zählte zur ersten im Bundesland Salzburg. Der aus St. Johann/Pongau stammende Gastwirt pachtete Anfang 1920 das Arthurhaus am Hochkönig und baute die Mitterbergalpe zu einem Wintersportplatz aus. Damals nannte sich das Arthurhaus noch Alpenwirtschaft Mitterberg. Diese beherbergte neben Bergsteigern die Büros für den Kupferbergbau. Über den Bergbau fand der nordische Skilauf seinen Weg nach Mühlbach. Norwegische Facharbeiter brachten die ersten Skier mit und veranstalteten in der Gegend noch vor dem Ersten Weltkrieg ihre Skisprungbewerbe. 1912 war Mühlbach bereits Austragungsort der Salzburger Landesskimeisterschaften. Peter Radacher sen. griff diese Tradition auf und gründete am Arthurhaus zunächst die Skischule. 1924 veranstaltete er das erste Mai-Skirennen, eine Kombination aus Sprung- und Langlauf. Ab Mitte der 1920er-Jahre hatte Radacher sen. das landesweite Skilehrwesen über und nahm die vereinheitlichten Skilehrerprüfungen im Bundesland Salzburg ab. Darüber hinaus organisierte er am Hochkönig Trainingskurse in der nordischen Kombination, zu denen Skiläufer aus ganz Österreich und dem Ausland anreisten. ${ }^{92}$ Überlieferte Bildaufnahmen von Trainingskursen zeigen österreichische Skispringer gemeinsam mit deutschen und norwegischen. ${ }^{93}$ Am Standort der Skischule des Peter Radacher sen. fanden in den 1930er-Jahren aber auch Vorberei-

91 Vgl. Frank, Die Entwicklung von Alpinistik, S. 127 und Hermann Nußbaumer, Sieg auf weißen Pisten. Bilanz des alpinen Skisports, Linz 1974, S. 51-52.

92 Vgl. Andreas Praher, SportlerInnen für den Krieg - KriegerInnen für den Sport, in: Minas Dimitriou/Oskar Dohle/Walter Pfaller/Andreas Praher (Hg.), Salzburgs Sport in der NS-Zeit. Zwischen Staat und Diktatur, Salzburg 2018, S. 255-290, hier S. 266; Interview mit Peter Radacher jun., geführt von Andreas Praher am 6.11.2014 in Mühlbach am Hochkönig; Peter Radacher, 5000 Jahre Mitterberg. 130 Jahre Arthurhaus. 100 Jahre Radacher, Mühlbach 1998, S. 21 und $27-32$.

93 Vgl. Fotos, Privatnachlass Peter Radacher sen., Kopien im Besitz des Verfassers. 
tungskurse für die Prüfungskanditen der staatlichen Skilehrerkurse statt. Diese wurden erstmals im Dezember 1931 gemeinsam vom ÖSV und dem Österreichischen Berufsskilehrerverband (ÖBSV) durchgeführt. Als Lehrwarte dieser Kurse entsendete der ÖSV die beiden staatlich geprüften Skilehrer Hannes Schneider und Anton Tschon, wobei Schneider die Gesamtleitung überhatte. Der promovierte Jurist und Regierungsrat Tschon war nicht nur Mitbegründer des Skiklubs Innsbruck und Mitglied im Alpenverein und ÖSV, sondern gleichzeitig Vorsitzender des Tiroler Skiverbandes. Schneider war durch die Arlbergtechnik und seine Arlberg-Skischule weltberühmt geworden. Die beiden ÖSV-Lehrwarte hatten Anfang der 1930er den amtlichen Lehrplan für Skiläufer des ÖSV überarbeitet und leiteten vom 5. bis 12. Dezember 1931 den einwöchigen Vorbereitungskurs am Arthurhaus. ${ }^{94}$

Im Jänner 1935 erhielt Radacher von der Landeshauptmannschaft Salzburg ein Schreiben, mit der Bitte, er möge die Gründungsversammlung des „Pflichtverbandes der Skilehrer im Lande Salzburg“ einberufen. Laut Skischulverordnung vom 29. Oktober 1934 war ein solcher Pflichtverband vorgesehen. Zum damaligen Zeitpunkt verfügten 48 Skischulen über eine Bewilligung der Salzburger Landesregierung. Radacher fungierte bereits als geschäftsführender Obmann des bisher freien Verbandes der Salzburger Berufsskilehrer. Nun sollte er mit Jahresbeginn 1935 die Agenden des Pflichtverbandes übernehmen. ${ }^{95}$ Neben Peter Radacher sen., der die Skilehrerprüfung im Land Salzburg am Arthurhaus offiziell abnehmen durfte, wurde noch das Seekarhaus des Alpenvereins unter der Leitung des Pächters und staatlich geprüften Skilehrers Peter Berner zugelassen. ${ }^{96}$

Touristisch gesehen blieb Mühlbach am Hochkönig in den 1920er- und 1930er-Jahren jedoch unbedeutend. Glanz und Glamour versprühte dagegen ein anderer Wintersportort, der sich in der Nachkriegszeit zum „Nabel“ des alpinen Skirennsports entwickeln sollte und schon vor dem Zweiten Weltkrieg internationale Wintersportgäste anzog. Von der Wintersaison 1925/26 bis 1931/32 verdreifachte sich die Zahl der Übernachtungen in Kitzbühel. ${ }^{97}$ Ab Jahresbeginn 1929 beförderte die Hahnenkammseilbahn die ersten SkiläuferInnen in das Skigebiet. 30000 Fahrgäste waren es in der ersten Wintersaison von 1929 auf 1930, 1934/35 beförderte die Bahn bereits 48000 Wintersportgäste auf den Hahnen-

94 Vgl. Privatnachlass Peter Radacher sen., Undatiertes Schreiben vom Vorbereitungskurs für die Prüfungskandidaten für die staatliche Skilehrerprüfung; Der Skiläufer, 1 (25.11.1931) 1, S. 8 und 10.

95 Vgl. Privatnachlass Peter Radacher sen., Brief der Landeshauptmannschaft Salzburg an Peter Radacher, Inhaber der Skischule am Arthurhaus, Salzburg 7. Jänner 1935.

96 Vgl. SLA, PRÄ 1938/47-0475-4599.

97 Vgl. Johann Skocek/Wolfgang Weisgram, Wunderteam Österreich. Scheiberln, wedeln, glücklich sein, Wien 1996, S. 152. 
kamm. ${ }^{98}$ Das Privatprojekt des Kitzbüheler Kaufmanns Josef Herold, an dem sich auch die Stadtgemeinde Kitzbühel finanziell beteiligte, war nicht unumstritten. Die Gesamtinvestitionen lagen bei 1,6 Millionen Schilling und lösten Fragen der Rentabilität aus. Der Erfolg ließ die kritischen Stimmen jedoch bald verstummen und die Innsbrucker Nachrichten lobten in einem Artikel im Oktober 1929 die Bahn ,als eine ganz hervorragende Tat für die Förderung des Fremdenverkehres“. 99

\subsubsection{Skisport im Dienste des Staates}

Die Zentralisierung der Skilehrerausbildung zeigte erstmals das nationale Interesse von Seiten des österreichischen Staates am Skilauf. Während andere Sportarten in der Ersten Republik und im austrofaschistischen Ständestaat großteils weiterhin im Amateurbereich tätig waren, gab es im Skisport schon früh Bestrebungen einer staatlichen Förderung und Lenkung sowie eine gewisse Professionalisierung durch Anstellungsverhältnisse im öffentlichen wie im privaten Sektor. Das nationale Skilehrwesen erlebte neben dem Bergführerwesen einen regelrechten Boom. Der im Aufschwung befindliche Alpinismus führte dazu, dass in den 1930er-Jahren selbst die als schwierig geltenden Gipfel der Alpen bewältigt werden konnten. Im Juli 1938 durchstiegen die beiden Österreicher Fritz Kasparek und Heinrich Harrer gemeinsam mit den Münchner Bergkameraden Andreas Heckmair und Ludwig Vörg die Eiger Nordwand. ${ }^{100}$ Die bergsteigerische Pionierleistung erfolgte bereits im Dienste des NS-Staates und wurde dementsprechend propagandistisch vom NS-Regime genutzt. ${ }^{101}$ Das NS-Regime war aber nicht das erste und einzige politische Regime, das sportliche Erfolge $\mathrm{zu}$ einem Mission-Statement erklärte. Neben dem austrofaschistischen Ständestaat waren noch andere diktatorisch regierte Staaten Europas, wie das faschistische Italien, darum bemüht, den Sport zu vereinnahmen und unter staatliche Kontrolle zu bringen. ${ }^{102}$ Aber schon vor 1934 förderte die Erste Republik den

98 Vgl. E. A. Pfeifer, Kitzbühel. Sonne und Pulverschnee, Kitzbühel 1992, S. 53.

99 Innsbrucker Nachrichten, 8.10.1929, S. 5-6.

100 Vgl. Frank, Die Entwicklung von Alpinistik, S. 115.

101 Vgl. Gunnar Mertz, Fritz Kasparek und die Erstbesteigung der Eiger-Nordwand in den österreichischen Erinnerungskulturen, in: Matthias Marschik/Agnes Meisinger/Rudolf Müllner/Johann Skocek/Georg Spitaler (Hg.), Images des Sports in Österreich. Innensichten und Außenwahrnehmungen, Göttingen 2018, S. 247-262, hier S. 249-250.

102 Vgl. u.a. Alfred W. Höck, In der Sportwelt radikal Ordnung schaffen. Sport im „Ständestaat“, in: Minas Dimitriou/Oskar Dohle/Walter Pfaller/Andreas Praher (Hg.), Salzburgs Sport in der NS-Zeit. Zwischen Staat und Diktatur, Salzburg 2018, S. 41-64, hier S. 44-45. 


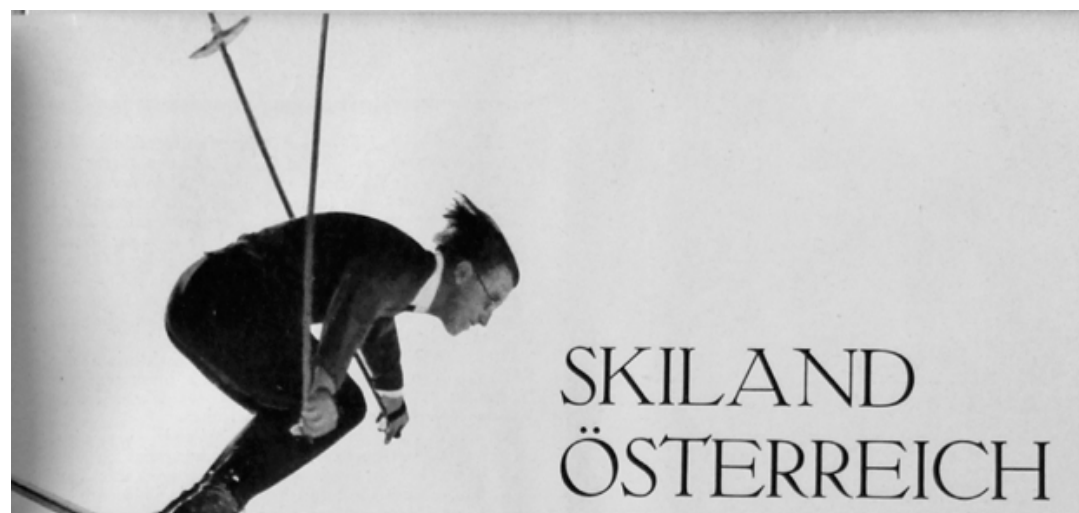

Von Dr. Robert Hentschel. Führer des Osterreichischen Skibundes.

fheinung trat: die Begeifterung und die aufopferungsvolle felbftlofe Hingabe, mit der faft gleichzitig und faft in allen Orten Ófterreichs, auch in den Städten, eine große Anzahl Männer in den Dienft des Skifportes Oben, Ein rassiger Geländeschwung. Pelándesciwung
photo Rubelt

D Sthneefall und Wer Winter eine fympathifche Jahreszeit, nnungen find, Kalte erfreuliche erfehnte Naturerfcheinehmen wollen, daß das Gebirge, felbft das Hochgebirge, im Winter ebenfo zugänglich ift wie im Sommer, nur noch mehr Genuß vermittelt, das alles erfacheint heute noch mehr Genuß vermittelt, das alles erfcheint heute
felbftverftändlich. Es find aber recht wenige Jahre verfloflen, feitdem diefe Selbftverftändlichkeit Allgemeinbegrift geworden ift. Das Gedädntnis unferer Zeit ift kurz. Es ift fdhon vergeffen, daß es nodh vor einer kurzen Spanne Zeit ganz anders war. Der Winter war die Zeit der Ruhe; die Täler und Berge Ofterreichs und ihre Wirtifhaften ruhten im Winterfachlaf im wahriten Sinne des Wortes. Das winterliche Gebirge war ein Begriff, der Angft und Unüberwindliches vermittelte. Wer gezwungen war, weitere Stredken abfeits der gewohnten Hauptverkehrswege zu überwinden, ftand vor Problemen fdiwerfter körperlicher Anftrengung und unbekannter Gefahren.

Was hat diefe Anderung unferer Einftellung zum Problem "Winter" in fo kurzer Zeit und fo grüdlich bewirkt? "Einem Paar fdhmaler, ungefähr mannshoher Hölzer gelang diefes Wunderwerk; der Ski war der Schlüffel, der die bis vor wenigen Jahren unbekannte Wunderwelt des Winters in Öterreich aufgefchloffen hat. Aber noch mehr: der Ski war es, der neue, unbekannte wirtichaftliche Kräfte auslöfte, pulfierendes Leben in Verkehr und Erwerb fchuf, große Gebiete Ofterreichs aus dem Winterfdalaf erweckte, vielen Tausenden Erwerb und Verdienft gab, kurzum, der cin neues bedeutungsvolles Gut fouf, den winterlichen Fremdenverkehr, der in kurzer Zeit fo bedeutungsvoll wurde, daß Ofterreich jetzt im Begriffe ift, das bedeutendite Fremdenverkehrsland von Europa zu werden. Es foll einmal ausgefprochen werden, was Ofterreich dem Ski dankt!

Diefer Erfolg ift niche in den Schoß gefallen, er muBte erarbeitet werden. Fs war eine fowwere Arbeit, die nur deshalb geleiftet werden konnte und nur deshalb fo rafich zur Ernte führte, weil ein anderes Wunder in Er- gründeten und mit der iportlichen Tätigkeit begannen. Unter Skifport ift die fportliche Tätigkeit im engeren Sinne, alfo der fportliche Wettkampf in den verfdhiedenen Wett-

kampf-Disziplinen, wie Langlauf, Sprunglauf, Abfahrtslauf ufw., als auch der touriftifche Skilauf zu verftehen. Sie find in ihrer Auswirkung untrennbar mitcinander verbunden. Die Skifportvereine, deren es nun in Ofterreich an die 400 gibt, haben auf beiden fkifportlichen Gebieten intenfivft gearbeitet.

Die fkitouriftifche Tätigkeit kommt vor allem der All-
lichen Gebieten intenfivft gearbeitet. gemeinheit zugute, denn fie erfachloß unbewußt und fyftematifch ganz Ofterreich von weftlich des Arlbergs bis zum Wechfel für den winterlichen Fremdenverkehr. Sie fouf die Skiwege, die Skimarkierungen, veranlabte die Winterbewirtfchaftung der Alpenvereinshütten, fchuf eigene Skihütten, fie forgte für die entfprechende Neuorganifation der Anreifeftrecken auf der Eifenbahn und im Autobusverkehr und lenkte auf diefe Weife die Skifahrer in die vorher vom Verkehr ganz oder teilweife abgefdhloflenen Gebiete Ofterreichs. Es gibt keine Modegegend in der Skitouriftik: wo einmal ein Skifahrer, neue Wege und neue Gegenden fuchend, feine Spur durch den. bis dahin jungfräulichen Sdhnee gezogen hat, dort beginnt von diefem Augenblick an neues Winterleben. Die Wunder, die die winterliche Touriftik erleben läßt, vermittelt die Photographie und die Winterfportliteratur, Vortrag und Werbung im In- und Ausland. Ständig läuft auf diefe Weife eine endlofe Kette, die immer mehr Menfchen zur Skitouriftik veranlaßt, neue Gebiete erfaließt. Heute ift die Skitouriftik fanon fo weit entwickelt, daß diefes $W$ interleben f́chon überall dort pulfiert, wo es Skimögliçkeiten gibt, alfo faft in ganz Ofterreich. Ebenfo intereffant ift die Entwidklung und die Aus. wirkung des Skifportes im engeren, rein fportlichen Sinne. Den Skifportveranft leungen verdanken letzten Endes alle bekannten öfterreichifchen Winteríport. plätze ihr Entitehen, ihre Entwidklung und ihre heutige Bedeutung. Das Intereffe an Skifportveranftaltungen war immer groß; die Befucher genoffen das fportliche Erlebnis und fahen die engere Umgebung, fie kamen immer gerne wieder, wenn fie fich felbft überzeugen konnten, daß die Umgebung foldher Orte gute Schneeund Tourenverhältnifle bietet; je bedeutender die fport-

Abb. 3: Bericht über das „Skiland Österreich“ in der von der austrofaschistischen Sport- und Turnfront herausgegebenen Zeitschrift Sport in Österreich vom 15. Dezember 1935. 
noch jungen Skisport, der stets eine enge Partnerschaft mit dem Wintersporttourismus pflegte. Sportliche Erfolge beflügelten die Fremdenverkehrswerbung und gaben Österreich ein Gesicht nach innen und außen. ${ }^{103}$ Aus touristischer Sicht können die 1920er-Jahre als Boom-Jahre bezeichnet werden. Die österreichische Bundesregierung erließ 1928 ein Investitionsbegünstigungsgesetz für Beherbergungsbetriebe. ${ }^{104}$ Das hatte positive Auswirkungen auf den Wintersporttourismus in den Alpenregionen. Das Landesverkehrsamt Salzburg veröffentlichte 1931 eine Liste jener 71 Berg- und 42 Skihütten, die für TouristInnen und SkiläuferInnen im Winter 1931/32 bereitgestellt werden konnten. ${ }^{105}$

Gleichzeitig entwickelte sich der moderne Sport zu einer nationalen Angelegenheit. Egal, ob auf Fußballplätzen oder in Skistadien, die Rivalität zwischen Nationen konnte im Sport ausgelebt werden. Mit den internationalen Bewerben, den Skiweltmeisterschaften und Olympischen Winterspielen, stieg nicht nur das Prestige, sondern auch das politische wie öffentliche Interesse an der Sportart. Der Skilauf in Österreich expandierte bis 1934 auf sportlicher, kommerzieller und medialer Ebene und weckte damit Begehrlichkeiten. ${ }^{106}$ Die FIS-Wettkämpfe, die im Februar 1933 in Innsbruck ausgetragen wurden, sollten zu einer Demonstration des österreichischen Skilaufs werden und beförderten den Wettstreit der Nationen im Skisport. Das war auch dem Plakatsujet der internationalen Skisportveranstaltung zu entnehmen. „Die Ski-Wettbewerbe der Nationen“ stand auf diesem zu lesen. ${ }^{107}$

\subsubsection{Skisport als nationale Agenda im Austrofaschismus}

Das austrofaschistische Regime erkannte die Bedeutung des Skisports und wusste das Potenzial zu nutzen. Die staatliche Förderung sollte gezielt für die Professionalisierung der Sportart eingesetzt werden. Gleichzeitig griff das austrofaschistische System in den Sportbetrieb ein und versuchte diesen zu kontrollieren und zu steuern. Kanzler Engelbert Dollfuß wählte für die Präsentation des Regierungsprogramms am 11. September 1933 bewusst den Wiener Trabrennplatz und inszenierte sich selbst gern als „Sportkanzler“. ${ }^{108}$ Neben der Massenwirkung war dem austrofaschistischen Regime die Wehrhaftigkeit und

103 Vgl. Graf, Tiroler Sportgeschichte, S. 30.

104 Vgl. Groß, Die Beschleunigung, S. 62.

105 Der Skiläufer, 1 (25.11.1931) 1, S. 10.

106 Vgl. Marschik, Sportdiktatur, S. 32; Reicher, Nationensport, S. 74.

107 Vgl. Plakat des Tiroler Künstlers Johannes Trojer für die FIS-Wettkämpfe 1933 in Innsbruck. Graf, Tiroler Sportgeschichte, S. 31.

108 Vgl. Marschik, Sportdiktatur, S. 32. 


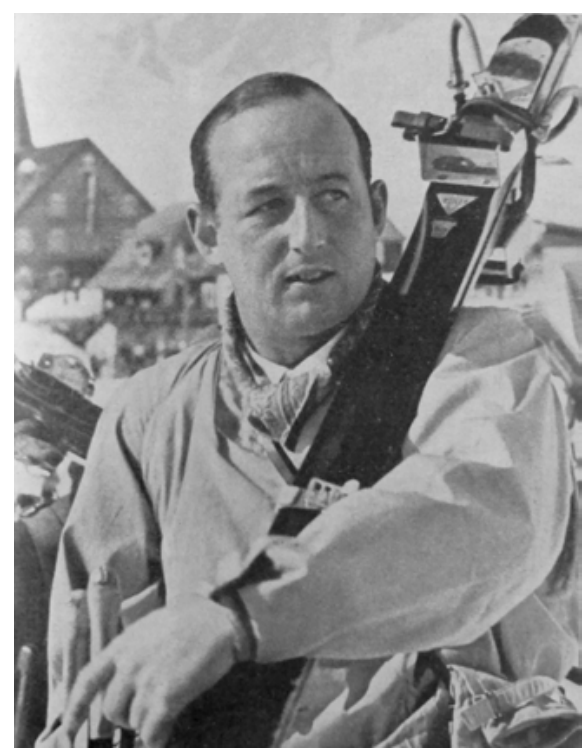

Abb. 4: Vizekanzler und Sportführer des austrofaschistischen Ständestaates Ernst Rüdiger Starhemberg in Sportkleidung und mit geschulterten Skiern in Zürs am Arlberg, Sport in Österreich, 10.4.1936.

Volksgesundheit über den Sport ein nationales Anliegen. Das am 30. Oktober 1934 eingeführte Gesetz über die „Österreichische Sport- und Turnfront“ (ÖSTF), das Dollfuß in seinen Grundzügen entworfen haben soll, regelte alle Belange des sportlichen Lebens in den Verbänden und Vereinen, koordinierte die Terminisierung der Wettbewerbe, die Teilnahme von SportlerInnen und war für die Finanzierung des Sportbetriebs zuständig.

Die exekutive Gewalt hatte der Heimwehrführer und Vizekanzler Ernst Rüdiger Starhemberg über, der zum Sportführer ernannt wurde. ${ }^{109}$ „Die Sport- und Turnfront forderte staatstreues Verhalten im Sport. Das Wir-Gefühl und die positive nationale Identität sollten über den Sport vermittelt werden." ${ }^{110}$ Die Steigerung eines „Wir-Gefühls“ kam besonders im Skisport zum Ausdruck. Dieses vermochte die ÖSTF auch immer wieder zu betonen und zu bedienen. So stand in Zusammenhang mit der Skischule Kitzbühel in Sport in Österreich zu lesen:

Daß Österreich von allen skisporttreibenden Ländern das erste war, das die Voraussetzungen für die gedeihliche Entwicklung von Skischulen schaffte und damit auch heute noch in der Organisation des Skisportes führend ist, mag uns allzu bescheidene Österreicher mit Genugtuung, aber auch mit dem Stolze erfüllen, für alle Zukunft die ersten zu bleiben. ${ }^{111}$

109 Vgl. Marschik, Sportdiktatur, S. 33-34; Emmerich Tálos, Das austrofaschistische Herrschaftssystem. Österreich 1933-1938, Wien/Berlin 2013, S. 416-417.

110 Tálos, Das austrofaschistische Herrschaftssystem, S. 417.

111 Sport in Österreich, Zeitschrift für Sport und Turnen, I. Jänner Heft 1937, o. D., S. 13. 
„Österreichs Alpenwelt“ wurde „als Wintersportparadies Europas“ verkauft. ${ }^{12}$ In diesem Sinne verstand auch der ÖSV seine Arbeit nicht nur als rein sportliche, sondern sah die Förderung des Tourismus „als Pflicht““.113 Die staatliche Förderung des Wintersportbetriebes war vor allem in den westlichen Bundesländern ein vorrangiges politisches Ziel der austrofaschistischen Regierung. Das lässt sich an den Fördersummen für das Bundesland Salzburg für das Geschäftsjahr 1937 ablesen. So wurden die Akademischen Weltwinterspiele in Zell am See mit 20000 Schilling dotiert und waren damit die teuerste Sportveranstaltung gefolgt von dem Automobilrennen auf dem Gaisberg. ${ }^{114}$

Tab. 2: Leistungen der Sport- und Turnfront für das Bundesland Salzburg im Geschäftsjahr 1937 in Schilling.

\begin{tabular}{lr}
\hline Sportveranstaltung/Sporteinrichtung & Summe \\
\hline Akademische Weltwinterspiele Zell am See & 20000 \\
\hline Skiwettläuferschule Zell am See & 13000 \\
\hline Segelfliegerschule Gaisberg und Koppl & 50000 \\
\hline Gaisbergrennen & 15000 \\
\hline Salzburger Reitervereinigung & 10000 \\
\hline Diverse Zuwendungen im Skilauf und Fußball & 6000 \\
\hline Insgesamt & $\mathbf{1 1 4 0 0 0}$ \\
\hline
\end{tabular}

Quelle: SLA, Rehrl-Brief 1937/719.

Die Subventionen sollten aber auch direkt den Spitzensport fördern. Ein Beispiel war die Eröffnung der staatlichen „Skischule für Rennläufer und Springer“, die mit 2. Jänner 1937 in Zell am See in Betrieb genommen wurde. Für die Standortwahl war neben der sportlichen Infrastruktur (Sprungschanzen und Skiabfahrten) auch die Schmittenhöhebahn entscheidend gewesen, die seit 1927 das Skigebiet erschloss. Die Ausbildung der RennläuferInnen erfolgte im Abfahrts-, Slalom-, Lang- und Sprunglauf, wobei die männlichen Ausbilder ein fixes Gehalt durch die ÖSTF bezogen. ${ }^{115}$ Die so genannte Skiwettläuferschule in Zell am See wurde im ersten Jahr ihres Bestehens mit 13000 Schilling subven-

112 Sport in Österreich, 49 (1.12.1937) 3, S. 2.

113 Österreichisches Sport-Jahrbuch. Handbuch für Sport und Turnen 1936. Amtliches Jahrbuch der Österreichischen Sport- und Turnfront. Wien 1936, S. 321.

114 Vgl. SLA, Rehrl-Brief 1937/719.

115 Vgl. Tätigkeitsbericht der Skischule für Rennläufer und Springer der Österreichischen Sport- und Turnfront in Zell am See 1936-1937. SLA, Rehrl-Brief 1937/3571; Salzburger Chronik, 21.12.1936, S. 7. 
tioniert. ${ }^{116}$ Insgesamt absolvierten 29 Skiläuferinnen und 106 Skiläufer die sieben Kurse, die von 2. Jänner bis 22. März 1937 an der Schmittenhöhe unter der sportlichen Leitung bekannter österreichischer Skisportler abgehalten wurden. ${ }^{117}$

Gleichzeitig war die austrofaschistische Sportführung bemüht, „die politische Opposition im Sportbereich auszuschalten", ${ }^{118}$ wie Emmerich Tálos schreibt. In Folge des Betätigungsverbotes der NSDAP waren nicht nur die deutschnationalen TurnerInnen, sondern auch deutschnationale Skisportfunktionäre und SkisportlerInnen von der Verfolgung durch die Behörden betroffen. Im Vergleich zum radikalen Verbot des Arbeitersports, ${ }^{119}$ offenbarte sich die Kontrolle der nationalsozialistischen Aktivitäten in den Skivereinen des ÖSV aber als weniger durchsetzungsstark. Das hatte mit der gesellschafts- und nicht zuletzt wirtschaftspolitischen Bedeutung des ÖSV zu tun. Die austrofaschistische Sportführung war sich durchaus bewusst, welchen nationalen und internationalen Stellenwert der vom ÖSV organisierte Skisport hatte. In einem Bericht der offiziellen Zeitschrift der ÖSTF Sport in Österreich wurde dieser Bedeutung Rechnung getragen. Laut diesem nahmen bei den jährlich 730 stattfindenden ÖSV-Skisportbewerben über 24000 SportlerInnen und an die 200000 ZuschauerInnen aus dem In- und Ausland teil. Die Umwegrentabilität dieser ÖSV-Sportveranstaltungen für die Tourismuswirtschaft wurde in dem Bericht auf über eine Million Schilling geschätzt. Hervorgehoben wurden weiters die Investitionen der ÖSV-Vereine in Sportanlagen wie Sprungschanzen, die ebenfalls eine wichtige Grundlage für die angeschlagene Wirtschaft gebildet hätten. Die ÖSTF schätzte diese auf rund 200000 Schilling pro Jahr zusätzlich größerer Vorhaben. ${ }^{120}$

Während Arbeitersportverbände wie der ASKÖ oder die Naturfreunde im Februar 1934 aufgelöst wurden, stand der ÖSV lediglich unter Beobachtung. Dennoch kam es vereinzelt zu behördlichen Auflösungen von Vereinen bzw. zu Absagen von Skisportveranstaltungen in Folge von Vereinsauflösungen. In der Wintersaison 1933/34 betraf dies die beiden Mitgliedsvereine des Salzburger Landesskiverbandes Neukirchen und Tauernpasshöhe. Nachdem die Skisportvereine behördlich aufgelöst wurden, hatte die ÖSTF einerseits den Abfahrtslauf in Neukirchen und andererseits den Radstädter-Tauernlauf abgesagt. Über

116 Vgl. SLA, Rehrl-Brief 1937/719.

117 Vgl. Tätigkeitsbericht der Skischule für Rennläufer und Springer der Österreichischen Sport- und Turnfront in Zell am See 1936-1937. SLA, Rehrl-Brief 1937/3571.

118 Tálos, Das austrofaschistische Herrschaftssystem, S. 417.

119 Vgl. Tálos, Das austrofaschistische Herrschaftssystem, S. 419.

120 Vgl. Der Skilauf als Wirtschaftsfaktor, in: Sport in Österreich, I. Jänner Heft 1937, o. D., S. 2-4. 
die Salzburger Landesmeisterschaft in der Abfahrt und im Slalom wurde das Standrecht verhängt und der Bewerb nicht durchgeführt. ${ }^{121}$ Warum dies geschah, geht aus den Quellen nicht hervor, aber ab dem Winter 1933/34 mehrten sich nationalsozialistische Kundgebungen im Rahmen von Skisportveranstaltungen und die austrofaschistische Sportführung sah sich mit illegalen NS-Aktivitäten konfrontiert, die sie zu unterbinden versuchte.

\subsubsection{Olympia 1936: zwischen nationalen Bestrebungen und internationalen Zugeständnissen}

Die nationale Vereinnahmung des Sports kam besonders im Rahmen der Vorbereitungen auf die Olympischen Spiele 1936 in Garmisch-Partenkirchen und Berlin zum Ausdruck. Ab 1935 war die austrofaschistische Sportführung darum bemüht, den Spitzensport olympiareif $\mathrm{zu}$ machen. ${ }^{122}$ Der zunächst ausgesprochene generelle Sportboykott der austrofaschistischen Regierung war nicht mehr als eine harmlose Drohgebärde gegenüber dem nationalsozialistischen Deutschland. ${ }^{123}$ Mit Herbst 1935 waren die sportlichen Vorbereitungen in Österreich zur Staatssache erklärt worden und die Losung lautete: „Österreich darf und kann bei den Olympischen Spielen von 1936 nicht fehlen“. ${ }^{124}$ In diesem Zusammenhang war gerade dem Skisport eine wesentliche Aufgabe zugedacht, er sollte die österreichische Nation in Garmisch-Partenkirchen gebührend vertreten. ${ }^{125}$ Nach den Erfolgen österreichischer SkiläuferInnen bei den FIS-Spielen 1933 und 1935 sahen ÖSV und ÖSTF die Chance gekommen, den österreichischen Skisport mit Edelmetall bei Olympia zu krönen. ${ }^{126}$ Alpine Skirennen in Abfahrt und Slalom waren erstmals olympisch zugelassen. ${ }^{127}$ Vor diesem Hinter-

121 Vgl. Jahresbericht Salzburger Landes-Skiverband 1933/34, S. 3.

122 Das Kapitel über die Olympischen Spiele 1936 in Garmisch-Partenkirchen geht großteils auf Recherchen für einen Beitrag im Sammelband „Salzburgs Sport in der NS-Zeit“ zurück und bezieht sich immer wieder auszugsweise auf diesen. Vgl. Andreas Praher, Salzburg und Olympia 1936 - Sichtweisen und Reflexionen, in: Minas Dimitriou/Oskar Dohle/Walter Pfaller/Andreas Praher (Hg.), Salzburgs Sport in der NS-Zeit. Zwischen Staat und Diktatur, Salzburg 2018, S. 87-107.

123 Vgl. Praher, Salzburg und Olympia, S. 88.

124 Salzburger Volksblatt, 9.12.1935, S. 8.

125 Vgl. Praher, Salzburg und Olympia, S. 92. Auch Matthias Marschik verweist darauf, dass an den Olympischen Spielen 1936 kaum jemand in Österreich achtlos vorbeisehen konnte. Vgl. Marschik, Sportdiktatur, S. 75.

126 Vgl. Sport in Österreich, 31.12.1935, S. 6-7 und Gidl/Graf, Skisport, S. 72.

127 In Garmisch-Partenkirchen wurden erstmals alpine Skiwettbewerbe ausgetragen. Abfahrtslauf und Slalom wurden dabei als alpine Kombination gewertet. Vgl. Willi Knecht, 100 
grund war der von Sportführer Ernst Rüdiger von Starhemberg 1935 ausgesprochene generelle Sportboykott gegenüber NS-Deutschland schnell vom Tisch und die nationale Losung in der von der ÖSTF gesteuerten Berichterstattung zu den Olympia-Vorbereitungen nicht zu überlesen. ${ }^{128}$ In seinen 1971 veröffentlichten Memoiren gibt Starhemberg an, dass er sich als Führer der Sport- und Turnfront „sehr energisch den Vorbereitungen dieses sportlichen Wettbewerbes“ gewidmet hätte, nachdem er anfänglich nicht für eine Teilnahme Österreichs gewesen wäre, sich aber von den Sportkreisen umstimmen habe lassen. ${ }^{129}$ Starhemberg meinte damit zwar die Vorbereitungen auf die Olympischen Sommerspiele in Berlin, doch schon jene für die Winterspiele in GarmischPartenkirchen bezeugen, dass die austrofaschistische Sportführung seine Boykottpolitik gegenüber NS-Deutschland zugunsten einer positiven Selbstdarstellung aufgab. Die ÖSTF berichtete bereits mit Beginn der Wintersaison in abgedruckten Pressemeldungen über den Stand der Olympia-Vorbereitungen und bewarb den österreichischen Spitzensport über sein eigenes Zentralmedium Sport in Österreich sowie die regionalen Medien. ${ }^{130}$ Das Landeskommissariat Salzburg der ÖSTF wies im Zuge der Olympia-Vorbereitungen im November 1935 auf einen Sport-Werbefilm hin, der im Salzburger Mirabellkino zur Aufführung kam und die Entwicklungen des Wettbewerbssports seit dem Ende des Ersten Weltkriegs thematisierte. ${ }^{131}$ Ungeachtet der internationalen Boykott-Aufrufe und trotz des national beschlossenen Sportboykotts fanden ab Spätherbst 1935 Trainingskurse der österreichischen Olympia-Skiauswahl statt. Zunächst ging es auf den Großglockner, danach in die Salzburger Tauern. Bei den österreichischen Skimeisterschaften in Bad Ischl sollte die endgültige Auswahl der Olympia-TeilnehmerInnen im Skilauf getroffen werden. ${ }^{132}$ Die Bewerbe mussten jedoch aufgrund des Schneemangels abgesagt werden. Ende November starteten Österreichs Springer erstmals auf der Olympia-Schanze in Garmisch-Partenkirchen. Die Sport- und Turnfront selbst hatte der Teilnahme an dem Neujahrsspringen zugestimmt. ${ }^{133}$ Ab Anfang November 1935 wurde das vom ÖSV ausgearbeitete Trainingsprogramm für die Skinationalmannschaft von Seiten der

Jahre Olympische Spiele der Neuzeit 1896-1996. München 1990, S. 85; Hermann Harster, Zum erstenmal im Zeichen der fünf Ringe: Abfahrtslauf und Slalom, in: Hermann Harster/Peter Le Fort (Hg.), Kampf und Sieg in Schnee und Eis. Winterolympia 1936, München 1936, S. 19-28, hier S. 19.

128 Vgl. Praher, Salzburg und Olympia, S. 90.

129 Vgl. Ernst Rüdiger Starhemberg, Memoiren, Wien/München 1971, S. 271.

130 Vgl. Sport in Österreich, 15.12.1935, S. 5-7; Salzburger Volksblatt, 9.12.1935, S. 8.

131 Vgl. Salzburger Volksblatt, 27.11.1935, S. 8.

132 Vgl. Wiener Montagsblatt, 18.11.1935, S. 15.

133 Vgl. Salzburger Volksblatt, 27.11.1935, S. 8. 
ÖSTF offiziell unterstützt. Den eigentlichen Trainingskursen im Schnee gingen gymnastische und konditionssteigernde Kurse voran. ${ }^{134}$ Mit Hilfe ausländischer Trainer sollten die „Olympiakämpfer auf den Höhepunkt ihrer Leistungsfähigkeit gebracht werden“", ${ }^{135}$ war Anfang Dezember 1935 im Salzburger Volksblatt zu lesen. Im November 1935 engagierte der ÖSV den norwegischen Trainer Bjarne Karlsen. Dieser leitete das Training für Springen und Laufen, während der Tiroler Anton Seelos das Abfahrts- und Torlauf-Training übernahm. Die Gesamtleitung hatte der Innsbrucker ÖSV-Sportwart Robert Lezuo über. ${ }^{136}$ Mitte November bezogen die Skiläufer das erste Olympia-Trainingslager am Hochtor an der Großglocknerstraße. ${ }^{137}$ Wie ausdifferenziert die Trainingskurse für Garmisch-Partenkirchen waren, lässt sich am Programm ablesen. Beim Hochtorhaus wurden zwei Olympia-Kurse abgehalten. In dem einen wurden die Kombinationsläufer und Speziallangläufer trainiert, in dem anderen die Abfahrts- und Torläufer. Die Trainingskurse dauerten bis 9. Dezember, daran anschließend belegten die Kombinations- und Spezialspringer bis 20. Dezember ein eigenes Trainingslager auf dem Wagrainerhaus. Elf Kombinationsläufer und zwölf Spezialspringer, darunter Josef Bradl und Gregor Höll, bereiteten sich auf dem Wagrainerhaus unter der Leitung des Norwegers Karlsen auf die Olympischen Spiele vor. Die Olympia-SkiläuferInnen, Männer und Frauen, trainierten zum Abschluss von 15. Jänner bis 6. Februar 1936 in Seefeld unter der Leitung von Anton Seelos, nachdem sie zuvor einen Trainingskurs in St. Anton am Arlberg bei Hannes Schneider absolviert hatten. Die Springer und Langläufer stellten sich nochmals dem Training unter Bjarne Karlsen. ${ }^{138}$

Die sportliche Ausbeute aufgrund der Nicht-Zulassung der SkilehrerInnen als Teilnehmer bei den Olympischen Spielen kam einer Misere gleich. Die Rennleitung des ÖSV hatte zuvor gemeinsam mit der ÖSTF beschlossen, keine Abfahrts- und Slalomläufer zu entsenden. Damit starteten in den alpinen Bewerben nur die Frauen. Grete Nissl landete als beste Österreicherin auf Platz 14, Wilhelm Köstinger belegte als bester Österreicher in der Nordischen Kombination den 15. Platz und Josef Bradl erreichte im Spezial-Springen nur Rang 19. ${ }^{139}$ Nichtsdestotrotz inszenierte die austrofaschistische Sportführung die Winterspiele als Erfolg. In dem Bildbericht zum Empfang der Olympia-SportlerInnen nach den absolvierten Spielen im Hotel Imperial bekräftigte die ÖSTF noch einmal die Ziele eines staatlich gelenkten Sports durch die austrofaschistische

134 Vgl. Sport in Österreich, 31.12.1935, S. 6.

135 Salzburger Volksblatt, 9.12.1935, S. 8.

136 Vgl. Praher, Salzburg und Olympia, S. 93.

137 Salzburger Volksblatt, 14.11.1935, S. 9; Sport-Tagblatt, 8.11.1935, S. 7.

138 Vgl. Sport in Österreich, 31.12.1936, S. 6-7.

139 Vgl. Sport in Österreich, 16.2.1936, S. 8; Sport-Tagblatt, 14.2.1936, S. 2. 
Sportführung: „Sport soll unpolitisch sein, in seinen Reihen darf Tagespolitik nicht hineingetragen werden [...] Sport ist aber eine Pflicht an Vaterland und Volk“ ${ }^{140}$ Gleichzeitig war die offizielle österreichische Sportpolitik angesichts der Wirkungsmacht der nationalsozialistischen Spiele schwach geworden und verkannte die Vorzeichen der nationalsozialistischen Gewaltpolitik, die sich am Horizont abzeichneten. ${ }^{141}$ Die Ausgrenzung und Diskriminierung der jüdischen Bevölkerung im nationalsozialistischen Deutschland, auch im Sport, waren bereits vor den Olympischen Spielen 1936 offensichtlich geworden und hatten mit den „Nürnberger Gesetzen“ 1935 einen ersten tragischen Höhepunkt erreicht. ${ }^{142}$ Für die Winterspiele in Garmisch-Partenkirchen erließ der Reichsminister des Inneren Wilhelm Frick auf Weisung von Adolf Hitler die Anordnung binnen zwei Wochen bis 17. Dezember 1935 sämtliche Schilder und Transparente mit judenfeindlichen Aufschriften an den Straßen und auf der Bahnstrecke zwischen München und Garmisch-Partenkirchen abmontieren zu lassen. ${ }^{143}$ Das war nur eine der Aktionen, um die Öffentlichkeit im Olympiajahr zu täuschen. Tatsächlich zeigte der IOC nur wenig Interesse, sich in die innenpolitische Situation des NS-Staates einzumischen. ${ }^{144}$ Die austrofaschistische Sportführung handelte somit, trotz bleibender internationaler Proteste, im Sinne des offiziellen Mission-Statement des IOC.

Schon vor und während der Winter- wie Sommerspiele waren kritische Stimmen von österreichischer Seite die Ausnahme. Ein Telegramm von Reichssportführer Hans von Tschammer und Osten an das Österreichische Olympische Comité (ÖOC), das die Zusammengehörigkeit der „zwei durch äußere Umstände getrennte Völker" betonte, schien mehr zu schmeicheln als zu verstören. ${ }^{145}$ Und die olympische Boykottbewegung war spätestens mit dem Juli-Abkommen 1936

140 Sport in Österreich, I. Jänner Heft 1937, o. D., S. 27.

141 Dem NS-Regime gelang es mit den Olympischen Spielen, seine wahren politischen und verbrecherischen Absichten zu verschleiern. Vgl. Ralf Schäfer, „....bis uns selbst das Dunkel empfängt.“ Reichserziehungsminister Bernhard Rust zur Eröffnung der XI. Olympischen Spiele von Berlin, 29. Juli 1936, in: Frank Becker/Ralf Schäfer (Hg.), Sport und Nationalsozialismus, Beiträge zur Geschichte des Nationalsozialismus (Band 32), Göttingen 2016, S. 217-233, hier S. 217.

142 Zum Ausschluss jüdischer SportlerInnen aus Sportvereinen in NS-Deutschland vor den Olympischen Spielen vgl. u. a. Michael Krüger, Olympische Spiele in Deutschland. Ausgefallen, mißbraucht, überschattet, gescheitert, in: Ommo Grupe (Hg.), Olympischer Sport. Rückblick und Perspektiven, Schorndorf 1997, S. 71-84, hier S. 74.

143 Schnellbrief, Berlin 3. Dez. 1935 Reichsminister des Inneren, vertraulich an Staatsminister des Inneren, Staatsarchiv München (StAM), LRA 133848.

144 Vgl. Marschik, Sportdiktatur, S. 76.

145 Vgl. Glückwunschtelegramm Hans von Tschammer und Osten, abgedruckt und veröffentlicht in Salzburger Chronik, 30.7.1936, S. 6; Praher, Salzburg und Olympia, S. 97. 
und der damit einhergehenden deutschlandfreundlichen Außenpolitik Österreichs kein politisches Thema mehr. ${ }^{146}$ Das zeigte sich nicht zuletzt an den Feierlichkeiten im Rahmen des olympischen Fackellaufs auf dem Wiener Heldenplatz, die Ende Juli 1936 von der austrofaschistischen Regierung als nationales Ereignis inszeniert und zelebriert wurden. ${ }^{147}$

\subsubsection{Nationalsozialistische Anbahnungen am Rande der Spiele}

Den ÖSV als national zuständigen Verband beschäftigten im Rahmen der Olympia-Vorbereitungen zwei Fragen sportpolitischer Natur. Einerseits war das österreichische Skiteam durch Abwanderung bzw. Flucht illegaler NationalsozialistInnen ins Deutsche Reich geschrumpft, andererseits schwebte mit den Amateurbestimmungen der FIS ein „Damoklesschwert“ über den OlympiakandidatInnen. Laut den Vorgaben des internationalen Skiverbandes waren keine SkiläuferInnen mit Profistatus und damit keine SkilehrerInnen zu den Winterspielen zugelassen. Aufgrund dessen beschloss die Rennleitung des ÖSV im Einvernehmen mit der ÖSTF, keine TeilnehmerInnen für den Abfahrts- und Torlauf zu entsenden, weil sich der ÖSV nicht in der Lage sah, ein konkurrenzfähiges alpines Skiteam nach Garmisch-Partenkirchen zu schicken. ${ }^{148}$ Wobei bei der Entscheidungsfindung nicht nur die Amateurfrage zum Tragen kam, sondern auch das Fehlen sportlicher LeistungsträgerInnen, die ab Mitte der 1930er-Jahre ins Deutsche Reich geflüchtet waren. So musste die ÖSTF zusehen, wie der ausgebürgerte NSDAP-Parteigänger Gustav Lantschner in Garmisch-Partenkirchen Olympia-Silber für NS-Deutschland holte und von der NS-Sportführung als reichsdeutscher Olympia-Gewinner gefeiert wurde. Neben den reichsdeutschen GoldmedaillengewinnerInnen Christl Cranz und Franz Pfnür bekam Lantschner einen Platz auf der Olympischen Ehrentafel eingeräumt. ${ }^{149}$ Lantschner holte aber nicht nur Silber in der Kombination (Abfahrt und Torlauf), er belegte zudem den dritten Platz in der Abfahrt. Diese Platzierung überraschte die NSSportpresse, war Lantschner doch aufgrund seiner Körpergröße und Statur nicht unbedingt der typische Abfahrer. „Gustav Lantschner wirkt zart und leicht wie ein Knabe und wurde doch Dritter in dieser schweren Konkurrenz", 150

146 Vgl. Praher, Salzburg und Olympia, S. 90.

147 Vgl. Starhemberg, Memoiren, S. 271.

148 Vgl. Salzburger Volksblatt, 16.1.1936, S. 8.

149 Vgl. Olympische Ehrentafel abgedruckt in: Die Olympischen Spiele 1936 in Berlin und Garmisch-Partenkirchen, Band 1, Hamburg 1936, S. 48.

150 Die Olympischen Spiele 1936 in Berlin und Garmisch-Partenkirchen, Band 1, Hamburg 1936, S. 8. 
schrieb dazu der Sportschriftleiter Walter Richter in dem 1936 erschienen ersten Olympia-Band in der Nachbetrachtung.

Bei den Frauen sorgte Gustavs Schwester Hadwig Lantschner im reichsdeutschen Trikot mit einem fünften Platz in der Kombination für eine solide Leistung. Die 1906 in Innsbruck geborene Skiläuferin nahm ab den frühen 1930erJahren regelmäßig an internationalen Skikonkurrenzen teil und konnte immer wieder Spitzenplatzierungen erreichen. Bei den Schweizer Damenmeisterschaften 1934 in Grindelwald belegte sie, damals schon für Deutschland startend, den zweiten Platz im Abfahrtslauf. ${ }^{151}$ Ein Jahr zuvor wurde sie bei den FIS-Skiwettkämpfen in Innsbruck, noch im Dress des Skiklubs Innsbruck, Sechste in der Abfahrt. Den Abfahrtssieg holte sich 1933 in Innsbruck ihre um ein Jahr jüngere Schwester Ingeborg Lantschner. ${ }^{152}$ Die Schwestern stammten aus der nationalsozialistisch gesinnten Skisport-Dynastie Lantschner. Ein Bruder, Fritz Lantschner, war der spätere Gauamtsleiter für Agrarpolitik in Tirol und Vorarlberg, ${ }^{153}$ der andere, Gustav Lantschner, wirkte im darauffolgenden Sommer als Kameramann für Leni Riefenstahl beim Film über die Olympischen Sommerspiele 1936 in Berlin. Hadwig Lantschner war mit dem Innsbrucker Skifahrer und Sportlehrer Gottfried Pfeifer verheiratet, der im Dezember 1931 in Innsbruck der NSDAP beitrat und nach seiner Flucht in das Deutsche Reich 1935/36 das Amt des reichsdeutschen Olympia-Cheftrainers übernahm sowie 1937 zum Deutschen Reichstrainer für den alpinen Skilauf berufen wurde. ${ }^{154}$ Sie selbst startete ab 1934 unter dem Namen Pfeifer-Lantschner für das Deutsche Reich und zählte neben den deutschen Skirennläuferinnen Christl Cranz und Käthe Grasegger zu den Medaillenhoffnungen des NS-Staates. Als Hadi Pfeifer landete sie bei den Olympischen Winterspielen in Garmisch-Patenkirchen 1936 auf Rang fünf in der Abfahrt und Rang vier im Slalom und belegte den fünften Platz in der Kombination für das reichsdeutsche Ski-Team. ${ }^{155}$

Abseits jener aus Österreich stammenden SkisportlerInnen, die bereits für NS-Deutschland sportlich und zum Teil auch politisch aktiv waren, befanden sich in der österreichischen Winterolympia-Mannschaft von 1936 nicht wenige, die mit dem Nationalsozialismus sympathisierten oder gar in der NS-Bewegung

151 Vgl. Neueste Sport-Zeitung, 15.1.1934, S. 8.

152 Vgl. Tiroler Anzeiger 9.2.1933, S. 9.

153 Vgl. TLA 10 Vr 2863/47.

154 Vgl. BArch (ehem. BDC), PK, Pfeifer, Gottfried, 31.3.1903; Gidl/Graf, Skisport, S. 62.

155 Die Schreibweise in der zeitgenössischen Berichterstattung variiert zwischen Hadi oder Hedi Pfeifer mit einem „““ und Hadi Pfeiffer mit zwei „ff“. Vgl. Neueste Sport-Zeitung, 15.1.1934, S. 8; Salzburger Volksblatt, 10.2.1936, S. 9; Sport in Österreich, 16.2.1936, S. 10; Die Olympischen Spiele 1936 in Berlin und Garmisch-Partenkirchen, Band 1, Hamburg 1936, S. 9. 
ihre Sporen verdient hatten. Der Geograf, Alpinist und Skiläufer Heinrich Harrer wurde für Garmisch-Patenkirchen in die österreichische Olympiamannschaft für Abfahrt und Slalom berufen und befand sich für zwei Jahre in der Auswahl. Harrer wurde am 6. Juli 1912 in Hüttenberg geboren und studierte an der Universität Graz Geografie und Turnen. Er war zunächst als Turnlehrer tätig, unternahm aber schon bald seine ersten Alpin-Expeditionen als Bergführer. 1934 absolvierte er die Prüfung zum staatlichen Skilehrer. $\mathrm{Zu}$ diesem Zeitpunkt war er bereits der illegalen SA beigetreten. Harrer war seit Oktober 1933 SA-Mitglied. Seine spätere Ehefrau Charlotte (Lotte) Wegener, mit der Harrer ab 1937 verlobt war, betätigte sich von 1936 an illegal im BDM. ${ }^{156}$ Nach den Amateurbestimmungen durfte der zweifache steirische Ski-Meister Harrer nicht in Garmisch-Partenkirchen starten und musste zuhause bleiben. Bei den darauffolgenden Akademischen Skimeisterschaften in Mallnitz im März 1936 fiel Harrer mit seinem zweiten Platz im Slalomlauf positiv auf, ${ }^{157}$ ein Jahr später holte er in Zell am See den Akademischen Weltmeistertitel in der Abfahrt.

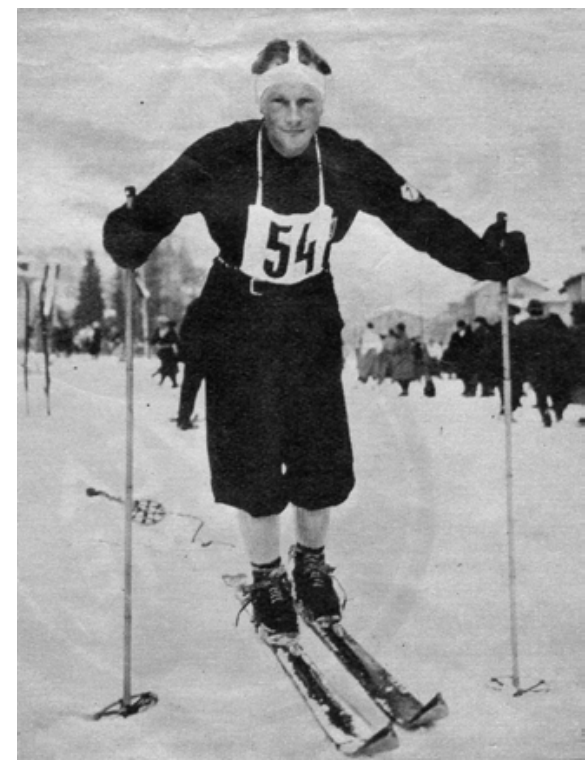

Abb. 5: Eine der seltenen Aufnahmen des späteren NS-Tibetforschers Heinrich Harrer auf Ski. Hier kurz nach seinem Abfahrtssieg bei den Akademischen Weltwinterspielen in Zell am See 1937, Bezirksarchiv Zell am See.

„Die Wahrheit ist, daß [sic] ich ein junger armer Schlucker aus Kärnten war, der sich als Abenteurer und Forscher verwirklichen wollte. Ich wollte, daß [sic]

156 Vgl. BArch (ehem. BDC), RS, Harrer, Heinrich, 6.7.1912; Pfeifer, Kitzbühel, S. 199. 157 Vgl. Sport-Tagblatt, 6.3.1936, S. 2; Sport-Tagblatt, 2.3.1936, S. 7. 
man auf mich aufmerksam wird“, ${ }^{158}$ sagte Harrer gegenüber dem deutschen Nachrichtenmagazin Spiegel in seinen späteren Jahren. Die Aufmerksamkeit von Seiten der NS-Führung wurde Harrer zwei Jahre nach den Olympischen Spielen im Juli 1938 zuteil, als ihm gemeinsam mit Andreas (Anderl) Heckmair, Fritz Kasparek und Ludwig Vörg die Erstbesteigung der Eiger Nordwand gelang. ${ }^{159}$ Für den Sportler Harrer wirkten die Versprechen des Nationalsozialismus anziehend, sie eröffneten ihm neue Möglichkeiten. Als Mitglied im Akademischen Turnverein Graz war ihm die NS-Ideologie nicht fremd. Als SA-Mann und späterer SS-Sportler hatte er diese verinnerlicht. Harrer war ab dem Frühjahr 1938 SS-Unterabteilungsleiter der SS-Sportgemeinschaft Graz. ${ }^{160}$ In seiner Funktion als Skilehrer trat er im Jänner 1939 als Lehrgangsleiter eines BDM-Skilagers in Bad Hofgastein in Erscheinung. ${ }^{161}$

Neben Harrer waren für Garmisch-Partenkirchen aber noch andere Gesinnungsgenossen nominiert, die ebenso bei der illegalen NSDAP und SA waren. Wilhelm Köstinger war in die Olympia-Auswahl für den zusammengesetzten Lauf (Springen und 18-Kilometer-Langlauf) beordert worden. ${ }^{162}$ Sein Eintritt in die NSDAP erfolgte 1933, in die SA $1934 .{ }^{163}$ Bei den Olympischen Spielen belegte Köstinger den 15. Platz in der Kombination. ${ }^{164}$ Der Grazer Spitzenlangläufer Alfred Rössner war bereits 1931 der SA beigetreten. Er war für den Langlauf-Bewerb über 18 Kilometer und für den Staffellauf über vier mal zehn Kilometer nominiert. ${ }^{165}$ Während Rössner in Garmisch-Partenkirchen im Langlauf von den 75 gewerteten Läufern abgeschlagen auf dem 40. Platz landete, ${ }^{166}$ gewann er im Anschluss an die Olympischen Spiele im März 1936 die Akademischen Skimeisterschaften in Mallnitz. ${ }^{167}$

158 „Ich wollte nie weg aus Tibet“ in: Der Spiegel 45/1997, S. 146, https://magazin.spiegel.de/ EpubDelivery/spiegel/pdf/8812688 (18.7.2019).

159 Vgl. Gunnar Mertz, Fritz Kasparek und die Erstbesteigung der Eiger-Nordwand in den österreichischen Erinnerungskulturen, in: Matthias Marschik/Agnes Meisinger/Rudolf Müllner/Johann Skocek/Georg Spitaler (Hg.), Images des Sports in Österreich. Innensichten und Außenwahrnehmungen, Göttingen 2018, S. 247-262, hier S. 249

160 Vgl. BArch (ehem. BDC), RS, Harrer, Heinrich, 6.7.1912.

161 Vgl. Johannes Hofinger, Nationalsozialismus in Salzburg. Opfer - Täter - Gegner, Innsbruck/Wien/Bozen 2016, S. 157.

162 Vgl. Praher, Salzburg und Olympia, S. 93.

163 Vgl. BArch (ehem. BDC), RS, Köstinger, Wilhelm 30.4.1914.

164 Vgl. Praher, SportlerInnen für den Krieg, S. 272.

165 Vgl. Tiroler Anzeiger, 18.1.1936, S. 7; Sport-Tagblatt, 11.1.1936, S. 5.

166 Vgl. Tiroler Anzeiger, 13.2.1936, S. 7.

167 Vgl. Neueste Sport-Zeitung, 2.3.1936; Tiroler Anzeiger, 29.2.1936, S. 13. 


\subsubsection{Exkurs I: Nationale und internationale Erfolge im Frauenskirennsport}

Wie andere Sportarten auch, war der Skisport bis in die Nachkriegszeit hinein männlich dominiert. Dennoch konnten Frauen im Skisport der 1920er- und 1930er-Jahre internationale Erfolge auf Spitzenniveau feiern. Anders als im österreichischen Fußball, in dem Frauenteams trotz internationaler Erfolge eine lokale Randerscheinung blieben, die sich auf die Metropole Wien konzentrierten und oftmals, wenn auch unterstützt von männlicher Seite belächelt wurden, ${ }^{168}$ war es Frauen im wettbewerbsbetriebenen Skisport möglich, sich durch sportliche Erfolge in einem männlich vorgegebenen Setting zu emanzipieren und öffentlich anerkannt zu werden. ${ }^{169}$ Sportliche Leistungen von Frauen wurden in diesem Kontext auch immer wieder auf Grundlage des biologischen Geschlechts diskutiert und geschmälert. ${ }^{170}$ „Hauptstreitpunkt war jetzt die Eignung der Frauen für den Leistungssport“", ${ }^{171}$ schreibt Getrud Pfister über den Sport in der Weimarer Republik. Diese Diskussionen können auch für die Erste Republik und den Austrofaschismus festgestellt werden. Dennoch bot gerade der leistungsbezogene Skisport Möglichkeiten, die den Geschlechtern zugeschriebenen Grenzen zu überschreiten. Gesamtgesellschaftliche Modernisierungsprozesse nach dem Ersten Weltkrieg hatten Einfluss auf die Körper- und Bewegungskultur, definierten Körperideale im Sport für Frauen und Männer neu, auch wenn die Geschlechterordnung bestehen blieb, und führten trotz aller Widersprüchlichkeiten und Widerstände zu einem Aufschwung des Frauensports. ${ }^{172}$ Frauen drangen in männliche Betätigungsfelder ein, entdeckten und eroberten diese für sich und manche von ihnen verdienten nachweislich ihren Lebensunterhalt mit dem Skisport, indem sie als Skilehrerinnen oder als Schau-

168 Vgl. hier vor allem Matthias Marschik, Frauenfußball und Maskulinität. Geschichte - Gegenwart - Perspektiven, Wien 2003 sowie Matthias Marschik, Leerstellen. Die ungeschriebene Geschichte des Frauenfußballs in Österreich, in: Siegfried Göllner/Andreas Praher/Robert Schwarzbauer/Minas Dimitriou (Hg.), Zwischenräume. Macht, Ausgrenzung und Inklusion im Fußball. Beiträge zur 2. Salzburger Fußballtagung, Göttingen 2019, S. 66-79.

169 Johanna Dorer und Matthias Marschik verweisen generell darauf, dass die Zahl sportlich aktiver Frauen in den 1920er-Jahren anstieg und über international erfolgreiche österreichische Sportlerinnen berichtet wurde, aber der Raum in dem sich diese Athletinnen bewegten von Männern vordefiniert war. Vgl. Dorer/Marschik, Sportliche Avancen, S. 96-97.

170 Vgl. hier u. a. die öffentlich geführten Debatten, ob Frauen an Ski-Rennen teilnehmen sollen, die über Fachzeitschriften geführt wurden. Vgl. Der Skiläufer, 1 (25.11.1931) 1, S. 2.

171 Gertrud Pfister, Weiblichkeitsideologie, Frauenrolle und Frauensport im Dritten Reich, in: Beiträge zur Historischen Sozialkunde, 13 (1983) 1, S. 19-28, hier S. 20.

172 Vgl. Gertrud Pfister, Die Balance der Differenz - Inszenierungen von Körper und Geschlecht im Sport (1900 bis 2000), in: Michael Krüger (Hg.), Menschenbilder im Sport, Schorndorf 2003, S. 197-234, hier S. 216-219. 
spielerinnen in Ski- und Bergfilmen tätig waren. ${ }^{173}$ Die neuen Berufsfelder, die aus der sportlichen Betätigung erwuchsen, waren Basis einer gewissen finanziellen wie sozialen Unabhängigkeit. Das zeigt sich auch im Fall von Käthe Lettner. Die 1906 in Bad Ischl geborene Skirennläuferin und Tochter des Stahlkanten-Erfinders Rudolf Lettner war Inhaberin eines Sportgeschäftes in Hallein. ${ }^{174}$

Ein Blick in die Sportpresse zeigt, dass trotz des christlich-konservativen Frauenbilds im Austrofaschismus die Berichterstattung über den Frauensport durchaus modern ausfallen konnte. Im Nationalsozialismus bedeute der Sport für Frauen bei all den geschlechtsspezifischen Zuschreibungen und sexistischen Sichtweisen auch Freiheiten. ${ }^{175}$ Frauen betraten demnach schon vor 1938 die Bühne des internationalen Skisports. Das vermochten auch die konservativen Konzepte der ÖSTF nicht zu verhindern. „In der Praxis erwies sich diese Konzeption auf der Basis weiblicher Sporterfahrungen der 1920er Jahre und der Entwicklungen im internationalen Frauensport als kaum umsetzbar", ${ }^{176}$ schreibt Matthias Marschik. Somit waren Frauen aus dem vorwiegend männlich dominierten Skirennzirkus spätestens ab Mitte der 1930er nicht mehr wegzudenken. Voraussetzung dafür boten neben der individuellen und familiär vorgeprägten Schulung, wie im Fall von Käthe Lettner, spezielle Förderangebote für SpitzensportlerInnen im Skirennsport. So veranstaltete der ÖSV eigene Trainingskurse für Athletinnen, die in Mitgliedsvereinen organisiert waren. Geleitet wurden diese Kurse allerdings von Männern. ${ }^{177}$ Zudem erfolgte eine sukzessive Zulassung von Athletinnen bei internationalen Skisportveranstaltungen. Schon beim ersten Arlberg-Kandahar-Rennen 1928 waren neben Männern auch Frauen

173 Eines der prominentesten Beispiele ist Leni Riefenstahl, die über ihre sportliche Leidenschaft zum Filmbusiness fand. Vgl. Hajo Bernett, Untersuchungen zur Zeitgeschichte des Sports, Schorndorf 1973, S. 118. Es gab aber auch weniger bekannte Frauen, die wettbewerbsmäßig skifuhren und für die sich über den Skilehrerinnenstatus eine berufliche Perspektive bot. $\mathrm{Zu}$ nennen wären hier Paula Kann Valar oder Elfriede Pembauer. Beide österreichischen Skirennläuferinnen migrierten bzw. flüchteten in den 1930er-Jahren in die USA. Während die Jüdin Valar dauerhaft in Nordamerika blieb, kehrte Pembauer wieder zurück. Auf beide Biografien wird noch in einem späteren Kapitel näher eingegangen.

174 Vgl. Skileben in Österreich, 1936, S. 101; Stadtarchiv Salzburg, Meldekartei Katharina Lettner.

175 Vgl. Johanna Dorer/Matthias Marschik, Sportlerinnen in Österreichs Medien 1900-1950. Das „Sportgirl“ als Symbol für die moderne Frau, in: Matthias Marschik/Rudolf Müllner (Hg.), „Sind's froh, dass Sie zu Hause geblieben sind.“ Mediatisierung des Sports in Österreich, Göttingen 2010, S. 238-247, hier S. 242-244.

176 Matthias Marschik, Turnen und Sport im Austrofaschismus (1934-1938), in: Emmerich Tálos/Wolfgang Neugebauer (Hg.), Austrofaschismus. Politik - Ökonomie - Kultur. 1933 1938, Wien/Berlin 2014, S. 372-389, hier S. 383.

177 Vgl. Der Skiläufer, 1 (1931) 1, S. 8-9. 
startberechtigt und 1936 durften Frauen erstmals an den Olympischen Winterspielen teilnehmen. ${ }^{178}$

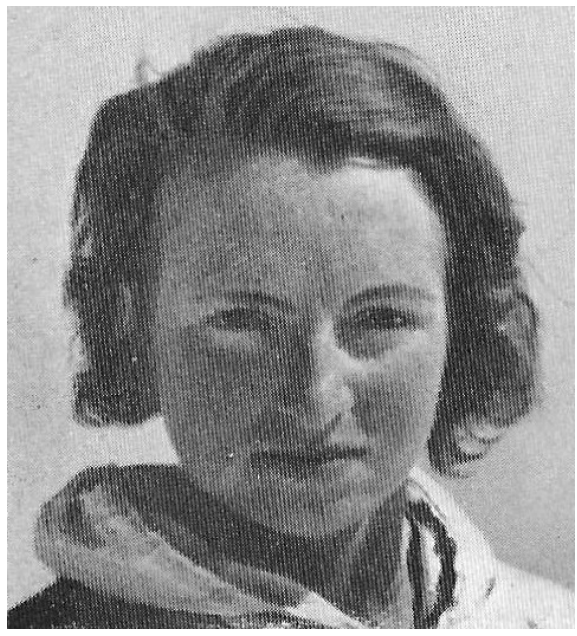

Abb. 6: Käthe Lettner, die Tochter des Stahlkanten-Erfinders Rudolf Lettner, nahm bis 1939 erfolgreich an Skirennen teil, Skileben in Österreich 1936.

Neben der Tirolerin Grete Nissl trat besonders eine österreichische Skirennläuferin aus dem Schatten ihrer männlichen Kollegen hervor. Es war dies die Tochter des Hoteliers und Gründungsobmannes des Skiklubs Bad Gastein Hans Windischbauer, Elisabeth Windischbauer, geboren 1912. Ihren skiläuferischen Durchbruch feierte sie zur Jahreswende 1935/36. Beim Trainingskurs der ÖSVWettläuferInnen am Arlberg schaffte Windischbauer im Dezember 1935 den Sprung in die Spitzengruppe, die von Anton Seelos geleitet wurde und in der sich auch die Salzburger Landesmeisterin Käthe Lettner befand. ${ }^{179}$ Im Jänner 1936 bestritt sie gemeinsam mit der zweifachen österreichischen Skimeisterin Emmy Ripper aus Wien das Olympia- und FIS-Lager des ÖSV in Seefeld. ${ }^{180}$ Ein Monat später belegte sie bei der Damenmeisterschaft des ÖSV in Bad Gastein den vierten Platz. Als beste Salzburgerin erhielt sie den Ehrenpreis des Landeshauptmannes überreicht und wurde daraufhin in den ÖSV-Kader für die internationalen FIS-Rennen berufen. ${ }^{181}$ Ein paar Tage nach der Einberufung in das österreichische Skinationalteam konnte Windischbauer beim internationalen Torlauf um die „Seefelder Silberkugel“ den Slalom für sich entscheiden. Sie erreichte im zweiten Lauf die Bestzeit von einer Minute, 30 Sekunden und vier

178 Vgl. Pfister, Weiblichkeitsideologie, S. 23.

179 Vgl. Salzburger Volksblatt, 21.12.1935, S. 11.

180 Vgl. Tiroler Anzeiger, 17.1.1936, S. 8.

181 Vgl. u. a. Salzburger Volksblatt, 3.2.1936, S. 8 und 6.2.1936, S. 10. 
Zehntel. ${ }^{182}$ Ihre Zeit sei besser gewesen als die der „meisten konkurrierenden Herren“, hieß es in einem Bericht im Salzburger Volksblatt im Februar 1936. ${ }^{183}$ Im Jänner 1937 wurde Elisabeth Windischbauer neben der Salzburgerin Käthe Lettner erneut in die erste Leistungsklasse des ÖSV berufen. ${ }^{184}$ Über ihre weitere sportliche Karriere ist, weil nicht dokumentiert, wenig bekannt.

Bei der Olympia-Teilnehmerin Käthe Lettner verhält es sich ähnlich. Nachdem sie in den 1930er-Jahren mehrere nationale und internationale Skirennen gewinnen konnte, startete sie zumindest bis in das Jahr 1939 für den Skiverein Salzburg, den Nachfolgeverein des Skiklubs Salzburg. ${ }^{185}$ Im Dezember 1937 zog sie nach Hallein, wo sie ein Sportgeschäft führte, in dem sie die Lettner-Stahlkanten vertrieb, und noch ein paar Jahre als Skiläuferin aktiv war. ${ }^{186}$ Über ihr weiteres Leben und Wirken ist wenig bis nichts bekannt. Lettner verstarb am 21. Jänner 1982 als Geschäftsfrau im Ruhestand im 76. Lebensjahr in der Stadt Salzburg. ${ }^{187}$

\subsubsection{Skilehrwesen als berufliche Perspektive}

Mit der staatlichen Berufsskilehrer-Ausbildung wurde es in den späten 1920erJahren und frühen 1930er-Jahren in Österreich erstmals möglich, mit dem Skilehrwesen als gesetzlich anerkanntes Gewerbe Geld zu verdienen und sozial abgesichert zu sein. Darin sahen viele junge Skisportler, aber zum Teil auch junge Skisportlerinnen, in Zeiten der wirtschaftlichen Krise eine Perspektive. Neben ihren Brotberufen absolvierten meist Männer deshalb die jährlich angebotenen staatlichen Skilehrerkurse und heuerten in der Folge als Skilehrer in einer Skischule an oder bemühten sich selbst um die Konzession einer Skischule. Die steigenden Zahlen der AbsolventInnen verdeutlicht den Zulauf zum neuen Beruf Skilehrer. Im Juli 1929, ein halbes Jahr nach der Einführung der staatlichen Skilehrerprüfung in Österreich, hatten insgesamt 123 staatlich geprüfte und anerkannte Skilehrer (nur Männer) das Ausbildungssystem durchlaufen. 94 waren im Berufsskilehrerverband organisiert, viele von ihnen konnten zudem auf eine Berg- und Skiführerausbildung des Alpenvereins verweisen. ${ }^{188}$ Laut Mitglieder-

182 Vgl. Tiroler Anzeiger, 18.2.1936, S. 9.

183 Salzburger Volksblatt, 18.2.1936, S. 8.

184 Vgl. Salzburger Volksblatt, 22.1.1937, S. 9.

185 Vgl. 100 Jahre Skiclub Salzburg, S. 60; Salzburger Volksblatt, 16.1.1939, S. 9.

186 Vgl. Stadtarchiv Salzburg, Meldekartei Katharina Lettner; Skileben in Österreich, 1936, S. 101 .

187 Vgl. Todesanzeige Katharina Lettner, in: Salzburger Nachrichten, 26.1.1982, S. 18.

188 Vgl. Privatnachlass Peter Radacher sen., Geprüfte bzw. anerkannte Skilehrer im Juli 1929, Kopie im Besitz des Verfassers. 
verzeichnis des österreichischen Berufsskilehrerverbandes aus dem Jahr 1935 waren allein für das Bundesland Tirol 204 BerufsskilehrerInnen im Verband gemeldet. Österreichweit waren 483 Männer und Frauen als Mitglieder im Berufsskilehrerverband organisiert. ${ }^{189}$ Diese staatlich geprüften SkilehrerInnen hatten die Möglichkeit, über die jeweilige Landesregierung eine Konzession für eine Skischule zu beantragen oder als Hilfs- bzw. Skilehrerin für eine Skischule tätig zu werden. Die Leitung einer Skischule war ab Dezember 1928 laut Bundesgesetz geregelt. Voraussetzung war unter anderem die Ablegung einer Prüfung vor einer staatlichen Prüfungskommission, die vom Bundesministerium für Unterricht bestellt und diesem unterstellt war. Die Kommission setzte sich aus einem Vorsitzenden und Fachprüfern zusammen. Für die Zulassung musste an diese ein Gesuch gerichtet werden, in dem nicht nur die schulische und berufliche, sondern auch die skiläuferische sowie bergsteigerische Ausbildung in Form eines Lebenslaufes darzustellen war. Daneben sollten auch sämtliche berg- und skisportlichen Aktivitäten angegeben werden. Über sämtliche Ausbildungen mussten Nachweise erbracht werden, ebenso wurde zur Überprüfung des Gesundheitszustandes ein amtsärztliches Attest verlangt. Der Antragsteller ${ }^{190}$ musste zudem mindestens 20 Jahre alt und durfte nicht älter als 45 Jahre sein. Neben einem Leumundszeugnis und einem Staatsbürgerschaftsnachweis, ${ }^{191}$ war noch ein Nachweis über eine achtjährige Schulbildung zu erbringen. ${ }^{192}$ Das zeigt die durchaus hohen Anforderungen an künftige Skischulbesitzer, die bereits Ende der 1920er-Jahre in Österreich gegolten haben. Schon die Prüfung zum staatlich geprüften Skilehrer ${ }^{193}$ an sich setzte einige Fähigkeiten und Kenntnisse voraus. Den KandidatInnen wurden Fertigkeiten im Skilauf und ein gewisses Lehrgeschick abverlangt, zudem wurden sie in Berg- und Schneekunde geprüft. Die Prüfung dauerte in der Regel fünf Tage und bestand aus theoretischen und praktischen Teilen. $\mathrm{Zu}$ Letzterem zählten die Durchführung einer Skitour und die Abhaltung einer Lehreinheit. ${ }^{194}$

189 Vgl. Privatnachlass Peter Radacher sen., Mitgliederverzeichnis Österreichischer Berufsskilehrerverband 1935, Kopie im Besitz des Verfassers.

190 Aufgrund der bisher getätigten Recherchen im Rahmen dieser Forschungsarbeit konnten keine Skischulbesitzerinnen für die Jahre vor 1938 ausgemacht werden.

191 Grundsätzlich war es auch nichtösterreichischen Staatsangehörigen erlaubt, um eine Skischulkonzession anzusuchen. Sie hatten aber eine höhere Prüfungsgebühr zu entrichten.

192 Vgl. Privatnachlass Peter Radacher sen., Errichtung von Skischulen, Befähigung des Leiters, Erlass vom 18.12.1928, Zl. 4417, Kopie im Besitz des Verfassers.

193 Ich verwende hier und in der Folge in Analogie zum zeitgenössischen Begriff die männliche Form.

194 Vgl. Privatnachlass Peter Radacher sen., Errichtung von Skischulen, Befähigung des Leiters, Erlass vom 18.12.1928, Zl. 4417, Kopie im Besitz des Verfassers. 


\section{Defterteidjifide Stilefjrer in fïnf G̈roteilen.}

Radbem farmes $S_{\text {d }}$ neiber, Borbilb und 2fbgott ber Stitäufer atler 28 elt, eine Reife gemad)t batte ins japanijde Reid, un im Ranbe Der aufgebenden Sonne feine berübmte Lebre vorgufübren, beganu ber 3 ug öfterreidiifher Stilebrer in bie $\$$ Belt binaus. Sie zogent binaus und wirten beute in aflen 3onen als Borbilo und Qebrer Der Beifen Sunit. Unb wie die 2̊nfänge ihres Sönnens vom "Rönig Des 2fribergs" ausgingen unb von ibm befrudtet wurben, fo fällt aud) ein ertledtiher Teil ibrer Eriolge ebrenvofl wieber auf ihn zurüd.

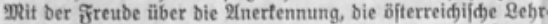
Ieiftung im 2uslande gefunben hat, Dürfen wir als Tiroler

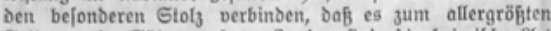

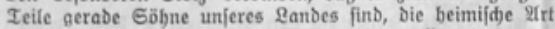
und heimildes gönnen in ber $\mathbb{R}$ elt fo ehrenooff vertreten.

\section{Mégèves und die Tiroler.}

BBer weiff, ob es beute einen burdggebenben Sdflafwagen Baris - Sallandies gäbe, bätten nidjt ein paar Tiroler ben

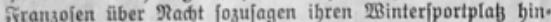
gefét: : Mégèves - Dmnibusverbindung mit Sallandes, zwei Bergbahnen und Riejenbotels, einjt winter[álafenb im Berg.

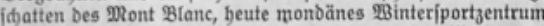

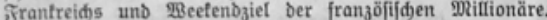
3uerit war es nur ein Iiroler, ber wie ungefäbr fíl) nach Qి es eine folonie von 3 wölf tirolifden Stifebrern und viertaufent Bejudter fint teine Seltenheit. Der Stiffub Paris, \$rotettor Des Banzen, hat beibe 5)änbe voll zu tun, um ben Betrieb um Die beliebten professeurs autrichiens $z^{4}$ regefin. Shre hervorragenditen Bertreter find Der befannte Innsbruder Renntăufer Dr. Sarald Reint und Ioni

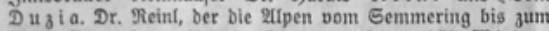
MRont Blanc imunerhin jiemlí, genau tennt, bält MRégèves - gerabezu für ben $2 B$ interiportplats. Er mirtt bort aud) als

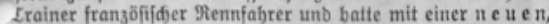
eigenwitligen $2 \mathrm{ehrmeth}$ obe jenfationelle Erjolge: Die heisen framzolen 2411 a is und $\$$ ignolfes (ber erite ein

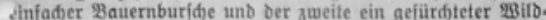

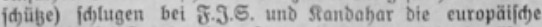
Spizentlalife! Im beurigen Gabre treibt ble blülfentoe öfterreidiliđe Stotonie von MRégèves einen frijđen 2tbleger fogar

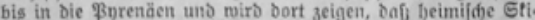
funft überall zu f)auje ift, wo immer es Sidjnee gibt! ?

\section{Géitrières.}

Seine Gigur ift fo volfstümtid) wie feine शienueriolge un๖ fein flinter Ballita. Wer tennt ibn nid)t - Sans $\Re$ o b II Er ift bas פtujterbeifpiel eines iportididen Selfmabemans, Der fin gans aus eigener frait, mit bewunbernswerter Energie

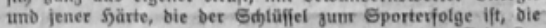

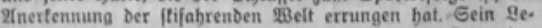

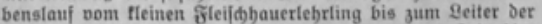
Gtiffule von Seftrières wurbe erit vor einiger 3eit hier erzäblt. Mun ift er vor wenigen Tagen mit feinem „Stabe"

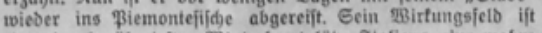
einer ber berilbmtefiten $\$$ Binteriportpläbe Staliens, eine wabre Samminung von Guperlatioen: Die modernften fotels, bei

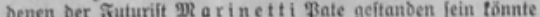
(Fuunbtîrme obne Dauernbe Sđjattenjeiten), bie tängften G(t) 3en, nämtich ben stronprinjen von 'Jtatien félber, als Oaft und - last, not least - einen ber beften Fennfabrer als Sebrer. Ein gebrer, Der wie alle anderen, aud im 2fustano Durd) und buris Tiroler bleibt, um fo jebe Eljrung und jeben

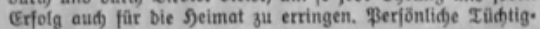

teit und Die llnteritüfung treuer frreunde balfen eintem Ber.

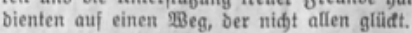

\section{Defterreider in atten Eroteilen.}

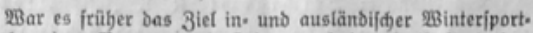
flubs, einen Yormeger als Rebrer zu haben, fo ift heute bas Borredbt, beften Geiitil zu fahren, auf Die Defterreidher über: gegangen. Iatjadge ift, baj Spibenteiftungen im Stifport nix.

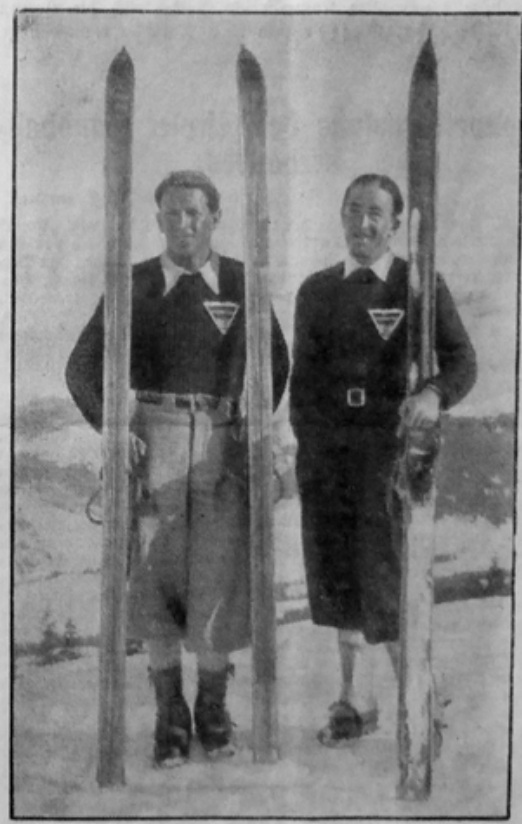

Dr. Sfaralb Meint (redtsts) un๖ Toni Dusia (lints)

gends auf fo breiter Brundage fitehen wie bei uns zu Sante.

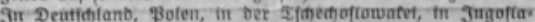
wien und in Itngarn find Defterreider als Seljrer tâtig. 216. fabrt uno Der funftwolle Sfafom find ibre Gebiete. Yur in Sprung. umb Ranglauf werben bie शorweger nodh vorgejogen. Ein Tiroler - EBalter 28 effi a t aus Innsbrud - Ieitete eine Stifdule in MRarolto uno lebrte Chriftiania auf ben

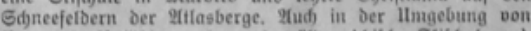

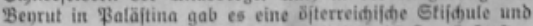
in Rmerifa arbeitete Der Safyburger $S_{\phi}$ roll. Den aufferiten Stipoftent aber bält woht ber Tiroter Sca beraffit mit leiner Etildule in - Etuftralien.

2fle biefe Defterreidfer vertreten im Rusfande ofterreidji-

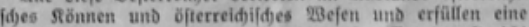
2 Tufgabe, bie bei Der beutigen Bedeutung Des Sportes oft nidt weniger midftig fein fann afs jene ber Diptomaten: fie wer-

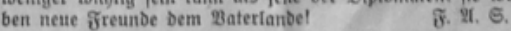

Abb. 7: Zeitungsbericht über die Tätigkeit österreichischer Skilehrer in anderen Ländern Europas und außerhalb davon, Neueste Sport-Zeitung, 2.12.1935. 
Die Ausbildung zum staatlich geprüften Skilehrer ermöglichte nicht nur in Österreich eine Aussicht auf eine Verdienstmöglichkeit, sondern erwies sich für viele als Sprungbrett ins Ausland. Bis dato gibt es keine quantitativ abgesicherten Daten wie viele ÖsterreicherInnen in der Zwischenkriegszeit tatsächlich einer Beschäftigung als SkilehrerInnen nachgingen. Die für diese Forschungsarbeit aus Mitgliederverzeichnissen erhobenen Zahlen zeigen, dass gegen Mitte der 1930er-Jahre knapp 500 Personen im Berufsskilehrerverband organisiert waren. ${ }^{195}$ Neben dem Deutschen Reich, das mit seinen weiteren Ausbildungs- und Aufstiegschancen ab 1933 einen verlockenden Boden darstellte, ${ }^{196}$ waren es zunächst andere Alpenregionen in Europa bzw. auch gebirgige Regionen in Nordafrika wie das Atlas-Gebirge in Marokko, die Berufsmöglichkeiten boten. Insbesondere waren es aber Gebiete in Übersee, die ab Mitte der 1930er-Jahre verstärkt zur Destination von österreichischen SkilehrerInnen wurden.

Das gesteigerte internationale Interesse an österreichischen SkilehrerInnen gegen Mitte der 1930er-Jahre hatte auch mit den Vorbereitungen der nationalen Verbände für die Olympischen Winterspiele in Garmisch-Partenkirchen zu tun. Im Jänner 1935 fragte der US-amerikanische Skiverband beim ÖSV an, ob dieser leihweise zwei bis drei Wettläufer als Amateurtrainer für die US-Auswahl bereitstellen könnte. Als vom amerikanischen Verband favorisierter Trainer stand Ludwig Lantschner aus Innsbruck zur Diskussion. ${ }^{197}$ Lantschner nahm allerdings kurze Zeit später ein Engagement als Skilehrer in der Schweiz an. ${ }^{198}$ Anton Seelos aus Seefeld stand zu diesem Zeitpunkt bereits als Trainer der reichsdeutschen Kampfmannschaft unter Vertrag und Leo Gasperl aus Kitzbühel trainierte ab 1935 die italienische Olympia-Mannschaft. ${ }^{199}$

195 Vgl. Privatnachlass Peter Radacher sen., Mitgliederverzeichnis Österreichischer Berufsskilehrerverband 1935, Kopie im Besitz des Verfassers.

196 Auf die Migrationsbewegungen und ab 1933 Fluchtbewegungen von österreichischen Skisportlern und -lehrern nach NS-Deutschland wird in einem späteren Kapitel eingegangen.

197 Vgl. Der Ski, 6.1.1935, S. 70.

198 Vgl. Der Ski, 1.3.1935, S. 119.

199 Vgl. Der Ski, 20.1.1935, S. 81. Leo (eigentlich Leopold) Gasperl wurde am 25.10.1911 in Mitterndorf in der Steiermark geboren und trat am 1. März 1933 der NSDAP bei. Er schloss sich 1937 der „Österreichischen Legion“ an. BArch (ehem. BDC), PK, Gasperl, Leopold, 25.10.1911. 


\subsubsection{Exkurs II: Saisonale Arbeits- und Karrieremigration österreichischer SkilehrerInnen}

Die Professionalisierung im internationalen Skisport beförderte auch eine globale Arbeits- und Karrieremigration, die sich meist saisonal vollzog aber ebenso in eine dauerhafte Auswanderung übergehen konnte. Österreichische SkilehrerInnen waren spätestens ab Mitte der 1930er-Jahren weltweit nachgefragte ExpertInnen. ${ }^{200}$ Ihr Wirkungsbereich reichte bis nach Argentinien, Chile, Marokko in die USA oder nach Japan. Nicht nur private Unternehmer waren an dem Spezialistentum interessiert, selbst Regierungen buhlten um staatlich geprüfte SkilehrerInnen aus Österreich. Die Aufgabengebiete waren unterschiedliche. Neben der Erschließung von neuen Skigebieten in entlegenen Gebirgsgegenden sowie dem Aufbau von Skischulen und der Schulung von RennläuferInnen war das Training und die Ausbildung von Skisoldaten ein weiteres Tätigkeitsfeld mehrheitlich männlicher „Skipioniere“. ${ }^{201}$ Die Arbeitsverhältnisse waren zumeist nicht von Dauer, sondern beschränkten sich auf eine oder mehrere Saisonen. Die Angebote waren durchwegs lukrativ und versprachen einen gewissen Gestaltungsfreiraum. Der Wissenstransfer hatte zur Folge, dass ab Mitte der 1930er-Jahre in Nord- und Südamerika bisher dünn besiedelte Gebirgsregionen für den Ski- und Wintertourismus erschlossen wurden. Der Popularitätswert österreichischer SkiathletInnen gründete sich nicht nur auf deren Leistungen. Die durchschlagenden internationalen Erfolge wären ohne das aufstrebende Filmbusiness der 1920er- und 1930er-Jahre nicht möglich gewesen. Spätestens seit den Skifilmen von Arnold Fanck waren der alpine Skilauf und damit seine AkteurInnen zu weltweiten Exportschlagern geworden. Die in den Filmen skilaufenden meist männlichen Helden wurden zu Stars mit Glamourfaktor. ${ }^{202}$ Die

200 Vgl. u. a. den Bericht über „Auslandstrainer“ in der Zeitschrift Der Ski über die Verpflichtung österreichischer Skilehrer und Skisportler in Deutschland, Italien, Frankreich und Ungarn, Der Ski, Nr. 2, 15.11.1933, S. 22-23; Zur transatlantischen Migrationsbewegung im Skisport vgl. u.a. Andreas Praher, Destination Amerika. Arbeitsmigration und Flucht im österreichischen Skilauf der 1930er Jahre und der Einfluss des österreichischen Skisports auf den transatlantischen Wissenstransfer, in: Wintersport Museumsbote, 27 (2019) 101, S. 6-7.

201 Das Engagement österreichischer Skilehrer in Skischulen anderer europäischer bzw. außereuropäischer Länder beschränkte sich zunächst vorwiegend auf Männer. Erst mit der verstärkten transatlantischen Arbeitsmigration von SkilehrerInnen ab Mitte der 1930er-Jahre fanden auch Frauen Anstellungen in Übersee.

202 Eine der wenigen Frauen, die sich hier von ihren männlichen Kollegen absetzen und emanzipieren konnte, war die deutsche Schauspielerin und Filmregisseurein Leni Riefenstahl. Vgl. Christian Rapp, „Der weiße Rausch“. Der Skisport im deutschen Bergfilm um 1930, in: Markwart Herzog (Hg.), Skilauf - Volkssport - Medienzirkus. Skisport als Kulturphänomen, Stuttgart 2005, S. 111-122, hier S. 111 und 120-122; Andrew Denning, Alpine Modern: Central 
Streifen liefen unter anderem in den Kinos von New York. Skifilmklassiker wie Der weiße Rausch (1931) machten den Erfinder der Arlbergtechnik Hannes Schneider berühmt und hatten einen nicht unerheblichen Anteil am internationalen Interesse an der jungen Sportart, die in den österreichischen Alpen perfektioniert wurde. ${ }^{203}$ Der US-amerikanische Dokumentarfilmer Ian Scully spricht von einer ersten Welle von österreichischen Skilehrern und Skirennfahrern, ${ }^{204}$ die Anfang bis Mitte der 1930er-Jahre in die USA emigrierten. Die meisten von ihnen seien gekommen, weil ihre Erfahrung nachgefragt worden sei und sie ihre Lebenssituation verbessern wollten. ${ }^{205}$ Einer, der zu dieser ersten Welle gehörte, war der gebürtige Oberösterreicher Felix Schaffgotsch.

\subsubsection{Felix Schaffgotsch oder ein „glühender Nationalsozialist“ im Sonnen- Tal}

Der amerikanische Skihistoriker John B. Allen weist daraufhin, dass der Skisport in den USA der 1930er-Jahre zu einem ,gesellschaftlichen Ereignis“ wurde. Ausschlaggebend für die Entstehung von Skigebieten waren Straßen- und Zugverbindungen, aber gerade die Anbindung der neu geschaffenen Wintersportorte an das Eisenbahnnetz erleichterte den skifahrenden StädterInnen die Anreise in die Wintersportgebiete von Neu England und des Westens der USA. ${ }^{206}$ Eisenbahngesellschaften brachten SkitouristInnen aus New York und Boston in die Berge nach Vermont und New Hampshire oder von San Francisco, Los Angeles und Denver in die Rocky Mountains. 1935 beförderte Northwest Airlines die ersten Fluggäste zum Skiurlaub in nordamerikanische Wintersportorte. ${ }^{207}$ Die meisten SkiurlauberInnen gelangten aber mit den so genannten snow

European Skiing and the Vernacularization of Cultural Modernism 1900-1939, in: Central European History 46 (2013) 4, S. 850-890, hier S. 884-885.

203 Vgl. Erwin Lauterwasser/Rainer Mülbert/Fritz Wagnerberger (Hg.), Faszination Skilauf. Vor hundert Jahren fing es an, Heidelberg 1995, S. 14-15 und 52.

204 Ich verwende hier bewusst nur die männliche Form, da Ian Scully in seinem Beitrag nur Männer erwähnt.

205 Vgl. Ian Scully, Austria's Influence on American Skiing, in: Wintersportmuseum Mürzzuschlag (Hg.), $3^{\text {rd }}$ FIS Ski History Conference, Mürzzuschlag/Graz 2004, S. 179-184, hier S. 179. Unter dem Titel „Legacy: Austria’s Influence on American Skiing“ produzierte der Filmemacher Ian Scully 2005 eine dreiteilige Dokumentation darüber, wie österreichische Skilehrer den USamerikanischen Skisport beeinflussten.

206 Vgl. John B. Allen, From Skisport to Skiing. One Hundred Years of an American Sport, 1840-1940, Amherst 1993, S. 107-109. John Allen betont, dass der US-amerikanische Skisport trotz seiner massiven Verbreitung in den 1930er-Jahren ein Phänomen der weißen Mittelschicht war.

207 Vgl. Allen, From Skisport, S. 109. 
trains zu den Skiabfahrten. ${ }^{208}$ An die 70000 skifahrende Gäste sollen in den ersten Monaten des Jahre 1936 aus New York City in verschiedene Skigebiete an der Ostküste geströmt sein. ${ }^{209}$ Was folgte, waren Investitionen in Aufstiegshilfen wie Sessellifte. Der weltweit erste Sessellift ging im Dezember 1936 in Sun Valley, Idaho in Betrieb. Im selben Jahr erschloss eine Seilbahn den Cannon Mountain in New Hampshire. ${ }^{210}$ Mitglieder der neu gegründeten Skiklubs in den USA griffen auf ihren Europa-Reisen die Arlbergtechnik auf. ${ }^{211}$ Der US-Skirennläufer Richard Durrance erlernte den Parallelschwung von Anton (Toni) Seelos. Er hatte zunächst bei dem Österreicher gelernt. ${ }^{212}$ Um die junge Skitechnik aus Österreich lehren zu können, lockten Geschäftstreibende wie William Averell Harriman staatlich geprüfte SkilehrerInnen aus den Alpen in die Skigebiete der Vereinigten Staaten. Sun Valley im Bundesstaat Idaho war eines dieser Skigebiete. Die Gründung des Wintersportplatzes geht auf den Österreicher Felix Schaffgotsch zurück. Schaffgotsch wurde von dem Eisenbahn-Tycoon Harriman angeheuert, um potenzielle Skigebiete im Westen der USA auszukundschaften, die von der Union Pacific Railroad angefahren wurden. ${ }^{213}$ Harriman war Inhaber der Union Pacific Railroad, Bankier und hatte Anteile an verschiedenen Reedereien. Schaffgotsch, der adeliger Abstammung war und eine elitäre Schulbildung, unter anderem am Wiener Theresianum, genossen hatte, ${ }^{214}$ dürfte den amerikanischen Geschäftsmann im Haus eines englischen Lords kennenglernt haben. ${ }^{215}$ Anfang Dezember 1930 unternahm er als 26-jähriger Student seine erste Amerika-Reise. Von Southampton aus bestieg er am 3. Dezember 1930 die S. S. Majestic und kam sechs Tage später in New York an. Im November 1933

208 Vgl. Allen, The Culture, S. 227.

209 Vgl. Allen, From Skisport, S. 108.

210 Vgl. Allen, The Culture, S. 229.

211 Vgl. Allen, The Culture, S. 224-225.

212 Vgl. Allen, From Skisport, S. 125.

213 Vgl. Günter Bischof, American Bucks and Austrian Buccaneers. Sun Valley - The Making of America's First Winter Resort, in: Philipp Strobl/Aneta Podkalicka, (Hg.), Leisure Cultures and the Making of Modern Ski Resorts, Cham 2019, S. 143-160, hier S. 145-146. Der Historiker Günter Bischof weist in seinem 2018 erschienen Artikel über die Geschichte des US-Wintersportressorts Sun Valley auf die Bedeutung österreichischer Skilehrer für die Entwicklung des Skigebietes im Bundesstaat Idaho hin. Sein Aufsatz stützt sich vorwiegend auf US-amerikanische Quellen und Fachliteratur. Diese Perspektive vernachlässigt die Entwicklung des Skisports auf internationaler Ebene sowie die wirtschaftliche und politische Situation in Europa und Österreich und die damit verbundenen Motive, warum diese SkilehrerInnen nach Übersee emigrierten.

214 Vgl. Oberösterreichisches Landesarchiv (OÖLA), BG Gmunden, A-Akten, 272/49, Schaaffgotsche; Wiener Salonblatt, 23.7.1923, S. 3-4.

215 Vgl. Innsbrucker Nachrichten, 28.12.1936, S. 15. 
und 1935 reiste er erneut über New York in die Vereinigten Staaten. ${ }^{216}$ Eines seiner Ziele waren die Berge im Bundesstaat Idaho rund um die Kleinstadt Ketchum. „This is the place“ soll er seinem Auftraggeber Harriman telegrafiert haben. ${ }^{217}$ Harriman hielt zwar wenig von den skiläuferischen Fähigkeiten des Felix Schaffgotsch, schätzte aber die Kenntnisse des Österreichers, wenn es um die Errichtung von Skigebieten ging. ${ }^{218}$ Nur ein Jahr nachdem Schaffgotsch die Region um Ketchum für den Skisport entdeckte, fanden sich in Sun Valley die beiden Salzburger Skilehrer Hans und Max Hauser ein. Sie sollten die dortige Skischule leiten. Das neu geschaffene Skiressort, das im Dezember 1936 seine Eröffnung feierte, lockte schon bald Hollywood-Größen, Schriftsteller und andere Stars des Showbusiness an. Unter den ersten Gästen befanden sich der USFilmschauspieler Gary Cooper und der Industriellensohn und spätere Politiker Nelson Rockefeller. In der amerikanischen Presse wurde das Engagement des österreichischen Grafen Schaffgotsch aufmerksam verfolgt. ${ }^{219}$ Kolportierte 1,5 Millionen US-Dollar sollen von der Union Pacific Railroad Company in die touristische Infrastruktur investiert worden sein. Neben Skipisten und einem Sessellift verfügte das Skiressort über ein Hallenbad, einen Tanzsaal und Reitmöglichkeiten. ${ }^{220}$ Unter dem Titel „Oesterreichische Skilaufkunst in Amerika“ berichteten die Innsbrucker Nachrichten Ende Dezember 1936, kurz nach der Eröffnung des Skigebiets, von den Leistungen des Österreichers in Sun Valley. ${ }^{221}$

Schaffgotsch reiste im Oktober 1937 erneut in die USA, dieses Mal bereits als Mitbegründer des neu geschaffenen Nobel-Skiortes. Der britische Schauspieler David Niven, der ab 1934 in Hollywood Karriere machte, lernte Schaffgotsch auf seiner Rückreise in die USA kennen. Schaffgotsch dürfte zu diesem Zeitpunkt gerade auf dem Weg nach Sun Valley gewesen sein. Niven beschreibt den Österreicher in seiner Autobiografie The Moon's a Balloon folgendermaßen: „A handsome and affable ,Graf“, he was also a dyed-in-the-wool Nazi.“222 In den Augen des Briten soll Schaffgotsch ein glühender Nationalsozialist gewesen sein, der angeblich Stunden über Hitler und seine Pläne schwadronieren konnte. Unter anderem habe er dem Hollywood-Schauspieler Niven erzählt, er würde ein Dutzend guter Skilehrer aus Österreich in die USA bringen, ebenfalls alle

216 Vgl. New York, Passenger and Crew List, 1820-1957, Felix Schaffgotsch, www.ancestry. com (7.5.2019).

217 Allen, From Skisport, S. 143.

218 Vgl. Allen, The Culture, S. 231.

219 Vgl. Des Moines Register, 28.2.1937, S. 70.

220 Vgl. Lancaster Eagle-Gazette, 28.11.1936, S. 9; Edwardsville Intelligencer, 2.2.1937, S. 2.

221 Innsbrucker Nachrichten, 28.12.1936, S. 15.

222 David Niven, The Moon's a Balloon, London 1971, S. 189. 
Nazis. ${ }^{223}$ Inwieweit diesen Zeilen über die politische Gesinnung von Schaffgotsch Glauben geschenkt werden darf, ist fraglich. Jedenfalls versprach Niven zum Skifahren nach Sun Valley zu kommen und machte sein Versprechen im Februar 1938 wahr. In den sechs Wochen, die Niven in Sun Valley verbrachte, konnte er sich von dem Erfolg des österreichischen Skisportpioniers überzeugen. ${ }^{224}$ Die Freundschaft der beiden war nur von kurzer Dauer. Als der Zweite Weltkrieg ausbrach, trennten sich die Wege des Briten und des Österreichers. Das Salzburger Volksblatt meldete am 1. September 1942, dass ein gewisser Oberjäger Felix Graf Schaffgotsch aus Altmünster am Traunsee gefallen sei. Einen Tag später korrigierte die Zeitung den Nachnamen auf Schaaffgotsche. ${ }^{225}$ Das Neue Wiener Tagblatt veröffentlichte ebenfalls am 1. September 1942 eine Todesanzeige, nach der Schaffgotsch als Oberjäger in einem Gebirgsjäger-Bataillon bei Kämpfen im Osten „den Heldentod“ erlitten habe. ${ }^{226}$ In den Beständen des oberösterreichischen Landesarchivs finden sich keine Dokumente bezüglich der politischen Einstellung oder der militärischen Laufbahn von Felix Schaffgotsch, auch sonst konnte zu seinen Lebensdaten in Oberösterreich nichts erhoben werden. ${ }^{227}$ In den Akten des Bezirksgerichts Gmunden findet sich aber die Todesfallmeldung seiner Mutter Aglaia (Aglae) Maria Johanna Felicia Schaaffgotsche, wohnhaft in Altmünster, die am 1. März 1949 in Linz verstorben ist. ${ }^{228}$ Darin wird auch sein um ein Jahr jüngerer Bruder Friedrich erwähnt, der laut Hans Thöni ab Mitte der 1930er-Jahre Skilehrer unter Hannes Schneider war und den Arlberg bei internationalen Werbefahrten vertrat. ${ }^{229}$ Demnach waren sowohl Friedrich als auch Felix Schaffgotsch im internationalen Skigeschäft tätig. Der Tod von Felix Schaffgotsch ist bei der Deutschen Dienststelle WASt verzeichnet. Schaffgotsch verstarb am 11. August 1942 an den Folgen einer Schussverletzung nach Kampfhandlungen an der Ostfront im Feld-

223 Vgl. Niven, The Moon's, S. 189.

224 Vgl. Niven, The Moon's, S. 190.

225 Vgl. Salzburger Volksblatt, 1.9.1942, S. 3 und Salzburger Volksblatt, 2.9.1942, S. 4.

226 Vgl. Neues Wiener Tagblatt, 1.9.1942, S. 5.

227 Vgl. Schreiben des Oberösterreichischen Landesarchivs vom 15.1.2018, GZ LA-2018-8580/ 2-Sch.

228 Aglaia (Aglae) Schaaffgotsche (geb. Witt-Döring) war mit dem Grafen Franz Schaaffgotsche verheiratet und hatte mit diesem vier Kinder: Johanna (1901), Felix (1904), Friedrich Karl (1905) und Franz de Paula. Letzterer starb bereits im Alter von 16 Jahren. Vgl. OÖLA, BG Gmunden, A-Akten, 272/49, Schaaffgotsche sowie Wiener Salonblatt, 31.5.1919, S. 4; 7.7.1923, S. 3.

229 Friedrich Karl Schaaffgotsche (Schaffgotsch), geboren 1905, war von 1934 bis 1938 Skilehrer in der Skischule von Hannes Schneider. Er soll das Arlberg-Skigebiet unter anderem bei der Weltausstellung in Brüssel 1935 vertreten haben. Vgl. Hans Thöni, Hannes Schneider zum 100. Geburtstag des Schipioniers und Begründers der Arlbergtechnik, St. Anton/Bludenz/Ludesch, 1990, S. 119. 
lazarett Kurjamaja. Zu diesem Zeitpunkt diente er in der 5. Kompanie des Lehrregiments Brandenburg z.b.V. 800. ${ }^{230}$ Der als „Brandenburger“ bezeichnete Verband war eine Sonderformation der Wehrmacht, die vorwiegend aus freiwilligen Elitesoldaten bestand und für getarnte Einsätze und Aufklärungsoperationen hinter den feindlichen Linien ausgebildet war. Teile dieser aus hochspezialisierten Einzelkämpfern zusammengesetzten Formation verübten Kriegsverbrechen. ${ }^{231}$ Inwieweit Schaffgotsch in Kriegsverbrechen involviert war, lässt sich nach derzeitigem Quellenstand nicht feststellen. Laut letzter Meldung wurde Schaffgotsch am 10. August 1942 von einem Infanteriegeschoss an der linken Schulter getroffen und erlag einen Tag danach seinen Verletzungen. ${ }^{232}$ Erwähnung fand sein Tod an der Ostfront auch in einem Brief von Bridget von Bernstorff, die mit ihm befreundet gewesen sein soll: „Felix has been shot in the lung and is lying in a cowshed in South Russia being eaten up by bugs.“233 Ob Schaffgotsch, wie Günther Bischof schreibt, ein „,...] outspoken Nazi among the Sun Valley Austrians““234 war, bleibt ebenso ungeklärt wie seine NSDAP-Parteimitgliedschaft.

\section{2.7.2 Die Gebrüder Hans und Max Hauser in Sun Valley}

Sollte Schaffgotsch vor 1938 mit dem NS-Regime sympathisiert haben, war er zumindest nicht der einzige in den USA tätige österreichische Skilehrer. Gemeinsam mit Hans Hauser migrierte auch sein Bruder Max Hauser für eine Saison nach Sun Valley. Die beiden erfolgreichen Skiläufer und Skilehrer aus Aigen bei Salzburg übernahmen ab der Wintersaison 1936/37 die dortige Skischule als Direktoren. ${ }^{235}$

Das Engagement verdankte Hans Hauser Felix Schaffgotsch, der ihn vermittelte. ${ }^{236}$ Hans setzte zunächst Anfang Oktober 1936 im Auftrag des amerikani-

230 Felix Schaffgotsch, eigentlich Felix von Schaffgotsch (Schaaffgotsche), wurde am 16. Februar 1904 in Enns an der Donau/Oberösterreich geboren und verstarb am 11. August 1942 im Feldlazerett Kurjamaja/UdSSR an den Folgen einer Schussverletzung, ein Infanteriegeschoss zerfetzte am 10. August 1942 seine linke Schulter. Vgl. Auskunft der Deutschen Dienststelle (WASt) vom 16.5.2018, Kopie im Besitz des Verfassers.

231 Vgl. http://www.bundesarchiv.de/DE/Content/Virtuelle-Ausstellungen/Die-Brandenburger-Kommandotruppe-Und-Frontverband/die-brandenburger-kommandotruppe-und-frontverband.html (7.5.2019).

232 Vgl. Auskunft derDeutschen Dienststelle(WASt)vom16.5.2018, Kopieim Besitzdes Verfassers. 233 Bridget von Bernstorff zit. nach Julia Boyd, Travellers through the Third Reich. The Rise of Facism through the Eyes of Everyday People, London 2018, S. 385.

234 Bischof, American Bucks, S. 151. Bischof gibt das Sterbejahr von Felix Schaffgotsch fälschlicherweise mit 1943 an.

235 Vgl. Mount Carmel Item, 3.2.1937, S. 6; Skiing Heritage, 17 (2005) 3, S. 23.

236 Vgl. Salzburger Chronik, 7.10.1936, S. 4. 
schen Bankiers und Transportunternehmers Harriman von Bremen über nach New York, um in Sun Valley seine saisonale Stelle als Skilehrer anzutreten. ${ }^{237} \mathrm{Im}$ November 1937 folgten sein Bruder und weitere Salzburger Skilehrer nach. ${ }^{238}$ Beide Brüder verfügten über die staatliche Skilehrerprüfung und hatten zuvor das Skischulwesen auf dem Salzburger Gaisberg aufgebaut, wo sie als Wirtshaussöhne eigene Skischulen gründeten. ${ }^{239}$ Hans Hauser feierte 1934 seinen dritten Landesmeistertitel und den Sieg bei den Dreiländermeisterschaften. 1935 fuhr er bei den Salzburger Landesmeisterschaften in der Abfahrt vom Gaisberg in fünf Minuten und 15 Sekunden die Bestzeit. ${ }^{240}$ Auch international war Hans Hauser aufgrund seiner Skirennläuferkarriere bekannt. In der Saison 1931/32 wurde er in Cortina d'Ampezzo Vizeweltmeister in der Kombination und holte Bronze im Slalom, ein Jahr später landete er beim internationalen FIS-Rennen in Innsbruck auf dem dritten Platz. ${ }^{241}$ In den USA erwartete den Skilehrer als Skischulleiter in Sun Valley ein Pauschalgehalt von 1000 US-Dollar für die Saison inklusive Kost und Logis sowie der Hin- und Rückreise mit dem Passagierschiff. ${ }^{242}$

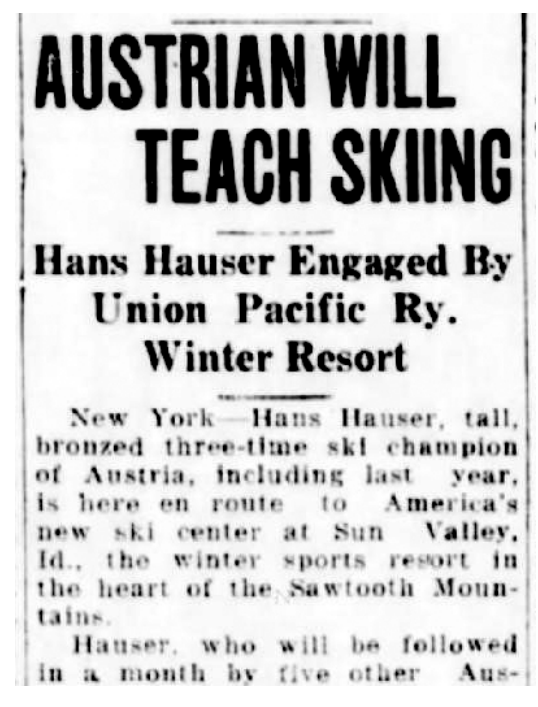

Abb. 8: Zeitungsbericht über das Engagement von Hans Hauser als Skilehrer in Sun Valley in der Escanaba Daily Press vom 29. November 1936.

237 Vgl. New York, Passenger and Crew Lists, 1820-1957, Hans Hauser, 1936, Microfilm Serial: T715, 1897-1957, Microfilm Roll 5882, Line 19, Page Number 56, www.ancestry.com (9.12.2016). 238 Vgl. New York, Passenger and Crew Lists, 1820-1957, Hans Hauser, Microfilm Serial: T715, 1897-1957, Microfilm Roll 6081, Line 21, Page Number 60, www.ancestry.com (9.12.2016).

239 Vgl. SLA, PRÄ 1936/47-2683.

240 Vgl. Praher, Sport und Körperkultur, S. 272.

241 Vgl. Joachim Glaser, Schatztruhe: 200 Geschichten aus der Salzburger Sporthistorie, Salzburg 2016, S. 27.

242 Vgl. Salzburger Chronik, 7.10.1936, S. 4. 


\subsubsection{SA- und SS-Männer auf Saison in Amerika}

Laut Erhebungen der Salzburger Gendarmerie im November 1934 sympathisierten Hans und Max Hauser mit der illegalen NSDAP. Den Brüdern konnte aber nichts nachgewiesen werden. Dennoch waren die Behörden alarmiert worden, Hans und Max Hauser „fortwährend im Auge zu behalten“. Nicht zuletzt deswegen, weil ihre verwitwete Mutter Maria Hauser Mitglied des deutschnational ausgerichteten Landbundes war und ebenfalls in Verdacht stand, mit dem Nationalsozialismus zu sympathisieren. ${ }^{243}$

Während Max nach Österreich zurückkehrte, blieb Hans Hauser in Amerika, unterrichtete zeitweise in Portillo in den chilenischen Anden und heiratete später Virginia Hill. ${ }^{244}$ Der Eintritt der USA in den Zweiten Weltkrieg im Dezember 1941 veränderte das glamouröse Leben des Skilehrers schlagartig. Das FBI nahm Hauser ebenso wie andere österreichische Skilehrer, darunter Friedl Pfeifer und Joseph (Sepp) Fröhlich, als so genannte enemy alien fest. Hauser blieb bis Kriegsende in Haft. ${ }^{245}$ Während Hans Hauser bei einer Überprüfung durch die österreichische Exekutive im Dezember 1934 keine Zugehörigkeit zur NSDAP oder einem Wehrverband nachgewiesen werden konnte, ${ }^{246}$ war sein Bruder Max seit 1930 SA-Mitglied und ab 1. Mai 1936 Bewerber der SS, wobei seine Dienstzeit in der SA laut SS-Stammkarte der SS-Personalakte im Bundesarchiv Berlin mit 1931 beginnt und jene in der SS mit 1934 bzw. laut eigenen Angaben mit 1936. ${ }^{247}$ Max Hauser gehörte also schon vor seiner Saison als Skilehrer im Winter 1937/38 in den USA mehrere Jahre der Sturmabteilung an und bewarb sich vor seiner Ausreise aktiv um die Aufnahme in den SS-Dienst. ${ }^{248}$ Nach seiner

243 Vgl. SLA, PRÄ 1936/47-2683.

244 Vgl. Annie Gilbert Coleman, Ski Style. Sport and Culture in the Rockies, Lawrence 2004, S. 52.

245 Vgl. Bischof, American Bucks, S. 151; The Green Bay Press-Gazette, 12.1.1942, S. 16; Republican and Herald, 19.1.1942, S. 4.

246 Laut einem Bericht des Gendarmeriepostenkommandos Aigen an die Bezirkshauptmannschaft Salzburg vom 14.12.1934 war Hans Hauser Mitglied der Vaterländischen Front. Er habe zwar mit der NSDAP sympathisiert, strafrechtlich lag aber laut dem Schreiben nichts gegen ihn vor und er galt als „moralisch einwandfrei“. Vgl. Gendarmeriepostenkommando an die Bezirkshauptmannschaft Salzburg, 14.12.1934, SLA, PRÄ 1936/47-2683.

247 Über die SA- und SS-Eintrittsdaten von Max Hauser gibt es in den erhalten gebliebenen Akten verschiedene Angaben. Fest steht, dass Hauser vor seiner Ausreise in die USA im Winter 1936/37 der SA beigetreten war und sich zumindest in der SS beworben hatte. Vgl. Erhebungsbericht Max Hauser durch die Bundespolizeidirektion Salzburg, 1.12.1948, OÖLA, LG Linz, Sondergerichte, Sch. 497, VgVr 4830/48; Max Hauser; BArch (ehem. BDC), SM, Hauser, Max, 6.12.1912.

248 Max Hauser soll ab 1935 SS-Anwärter gewesen sein und ab 1936 SS-Mann. Vgl. Max Hauser; BArch (ehem. BDC), SM, Hauser, Max, 6.12.1912. 
Rückkehr nach Österreich erfolgte am 15. September 1938 seine Vereidigung zum SS-Mann und zwei Monate später rückte er zum SS-Sturmmann auf. ${ }^{249}$ Das gleichgeschaltete Salzburger Volksblatt berichtete am 12. April 1939 unter dem Titel „Brief aus Sun Valley“ von den sportlichen Erfolgen der Hauser-Skischule in den USA. ${ }^{250}$ Der veröffentlichte Brief des Salzburger Skiläufers Andreas Hennig kann als Propagandabericht gewertet werden. So stand am Ende im Sinne der Instrumentalisierung des Sports zugunsten des NS-Regimes zu lesen: „Die neun Salzburger Skilehrer arbeiten einheitlich, halten kameradschaftlich zusammen und bekennen stramm ihre deutsche Gesinnung. “251 Interessant ist, dass Hennig, dessen Bericht noch im April 1939 als Teil der NS-Propaganda veröffentlicht wurde, sich nach dem Kriegseintritt der USA der $10^{\text {th }}$ Mountain Division anschloss. ${ }^{252}$ Während Hennig seine skiläuferischen Fähigkeiten ab dem Winter 1942/43 dem US-Militär im Kampf gegen den Nationalsozialismus anbot, hatten sich andere ausgewanderte österreichische Skisportler dem NS-Regime schon vor 1938 angedient. Unter den Saisonarbeitern, die ab Mitte der 1930erJahre in die USA auswanderten, befanden sich nachweislich Skiläufer, welche die frühe und ab 1933 illegale NS-Bewegung in Österreich unterstützten und ab 1938 im NS-Sportsystem Karriere machten. So war der alpine Abfahrer Peter Radacher ebenso wie Max Hauser laut Wehrstammblatt schon vor 1938 der SA beigetreten und seit 1932 in dieser aktiv. ${ }^{253}$

Radacher, der in den 1930er-Jahren für den SC Mühlbach an den Start ging, setzte am 17. November 1938 von Bremerhaven nach New York über und ging am 26. November im Hafen von New York von Bord. ${ }^{254}$ Auf der S. S. Deutschland, die in Hamburg ablegte, befanden sich außer Radacher noch die beiden Hauser-Brüder sowie die Skilehrer-Kollegen Roland Cossmann und Paul Deschmann. ${ }^{255}$ Nach einer Wintersaison in Sun Valley kehrte der aus dem Pinzgau stammende Skirennläufer und Skilehrer im Mai 1939 in das Deutsche Reich zu-

249 Vgl. Erhebungsbericht Max Hauser durch die Bundespolizeidirektion Salzburg, 1.12.1948, OÖLA, LG Linz, Sondergerichte, Sch. 497, VgVr 4830/48.

250 Vgl. Salzburger Volksblatt, 12.4.1939, S. 10.

251 Salzburger Volksblatt, 12.4.1939, S. 10.

252 Vgl. Traussnig, Militärischer Widerstand von aussen. Österreicher in der US-Armee und Kriegsgeheimdienst im Zweiten Weltkrieg, Wien/Köln/Weimar 2016, S. 172.

253 Vgl. Wehrstammblatt, Peter Radacher, OÖLA, LG Linz, Sondergerichte, Sch. 103, VgVr 4072/46. Peter Radacher, geboren am 25. September 1910 in Taxenbach war staatlich geprüfter Skilehrer und Bergführer. Er war der Neffe des Skischulbesitzers von Mühlbach am Hochkönig Peter Radacher sen. und ein erfolgreicher Abfahrtsläufer.

254 Vgl. Reisepass Peter Radacher, ausgestellt am 2.9.1938 von der Bezirkshauptmannschaft St. Johann im Pongau, Privatnachlass Peter Radacher, Kopie im Besitz des Verfassers.

255 Vgl. New York, Passenger and Crew Lists, 1820-1957, Peter Radacher, www.ancestry.com (12.8.2019). 
rück. ${ }^{256}$ Während seiner Auslandsaison war Radacher nicht nur als Skilehrer über die Union Pacific Railroad Company in der Skischule von Sun Valley angestellt, sondern feierte auch skisportliche Erfolge. Im März 1939 gewann Radacher mit dem ersten Platz im kombinierten Abfahrts- und Slalomlauf den internationalen Harriman Cup. Zudem wurde Radacher aufgrund seiner Platzierungen bei den offenen US-Meisterschaften mit dem Titel „best all-around skier in America" ausgezeichnet. ${ }^{257}$ Die US-Presse berichtete damals in anerkennender Weise von den Erfolgen des Österreichers und schrieb von einer Ehre, die Radacher zu Teil wurde. ${ }^{258}$
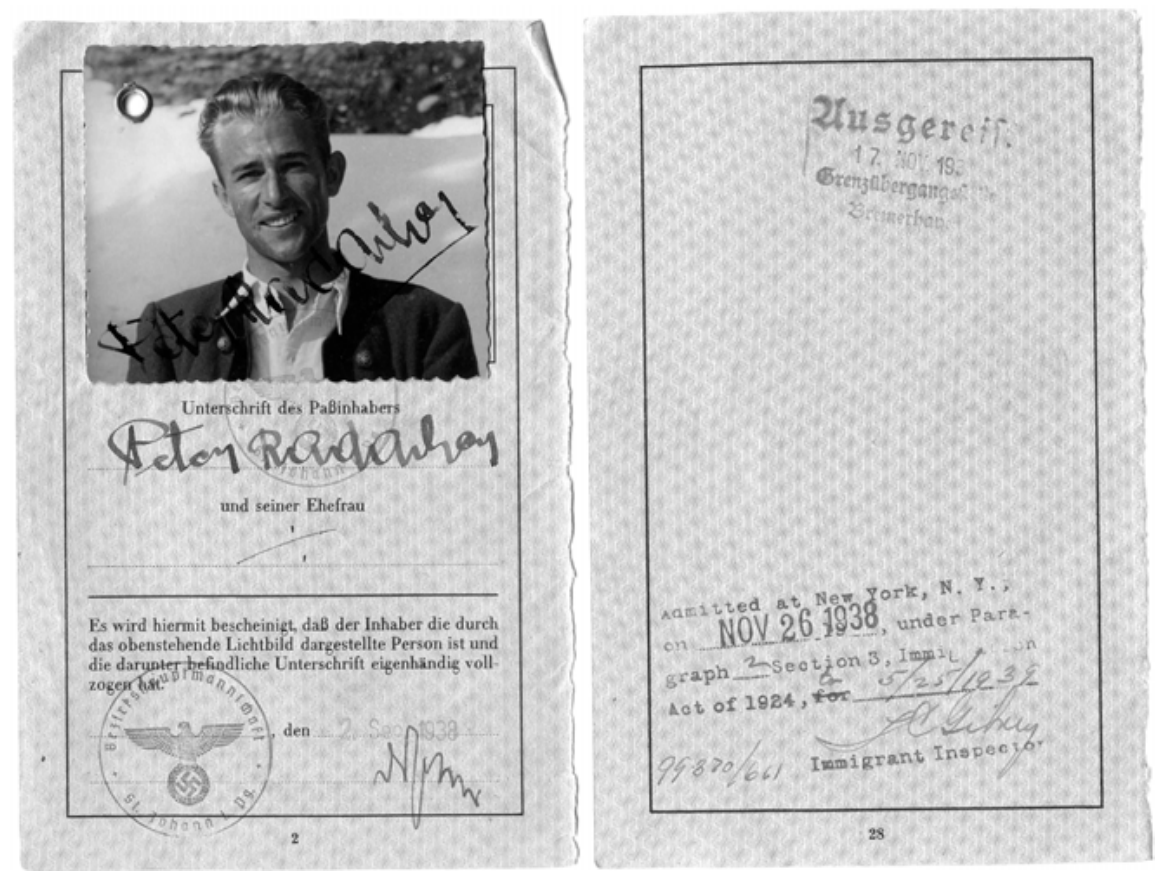

Abb. 9: Reisepass des staatlich geprüften Skilehrers und Abfahrers Peter Radacher mit Einreisestempel vom 26. November 1938 in New York, Privatbesitz.

256 Vgl. Reisepass Peter Radacher.

257 Die offenen US-Meisterschaften im Skilauf wurden in den vier Disziplinen Abfahrt, Slalom, Langlauf und Skispringen durchgeführt. Peter Radacher konnte in Abfahrt, Slalom und Langlauf jeweils den zweiten Platz belegen und landete im Skispringen auf dem siebten Platz. Im kombinierten Abfahrts- und Slalomlauf holte er den Sieg und damit auch den Harriman Cup, den die beiden Jahre zuvor der US-Amerikaner Dick Durrance in der Kombination gewinnen konnte. Vgl. u. a. The Post-Register, 28.3.1939, S. 9; Salt Lake Telegram, 27.3.1939, S. 12. 258 Vgl. The Post-Register, 28.3.1939, S. 9. 
Unter dem Titel „Wir fuhren nach Amerika“ veröffentlichte Radacher später seine Erinnerungen in der NSRL-Zeitschrift Durch Pulver und Firn. Darin beschreibt der Skisportler unter anderem die stürmische Überfahrt, von der er seekrank wurde, und schildert die Teilnahme an den Open-Air-Ski-Shows in Boston und New York, die als Werbeveranstaltungen für den Wintersportort Sun Valley abgehalten wurden: „Der Betrieb in Madison Square Garden würde bei uns in Europa als ein Theater auf Skiern gelten.“259

Nach einem zehntägigen Aufenthalt und den publikumswirksamen SkiShows in Boston und New York ging es für Radacher und seine Kollegen über Chicago nach Sun Valley. Die ausgeschmückten Darstellungen Radachers müssen im Kontext der NS-Ideologie und NS-Sportpolitik gelesen werden. Die Show sei eine gute Reklame für den deutschen Skisport gewesen, jedoch hätten sie bei Beginn der Vorführung die Hakenkreuzfahne vermisst, und als „größte Viecherei“ beschrieb Radacher in dem Erlebnisbericht für die NSRL-Zeitschrift seine erste Begegnung mit einem „Neger“. ${ }^{260}$ Diese Schilderungen Radachers verdeutlichen nicht nur seine Anpassungsleistungen gegenüber dem NS-Regime, sondern zeigen zugleich die Strategie der reichsdeutschen Sportführung, die ideologisch aufgeladenen Erfahrungsgeschichten von SpitzensportlerInnen verkaufen zu wollen.

\subsubsection{Kurt Thalhammer - ein illegaler Parteigenosse auf Amerika-Tournee}

Im Gefolge von Hans und Max Hauser gelangte vor 1938 aber noch ein anderer Salzburger Skiläufer nach Amerika, der ebenfalls mit der NS-Ideologie sympathisierte und sich für die illegale NS-Bewegung engagierte. Kurt Thalhammer suchte kurz vor dem Verbot der NSDAP um Aufnahme in die Partei an und trat im März 1933 in die NSDAP ein. Während des Verbots der NSDAP in Österreich organisierte er für das NSKK Waffentransporte, importierte nationalsozialistisches Propagandamaterial und half flüchtigen Nationalsozialisten über die Grenze ins Deutsche Reich. Außerdem warb er neue Mitglieder für die illegale NDSAP an. ${ }^{261}$ Der am 10. Februar 1913 in Salzburg geborene Thalhammer war nicht nur staatlich geprüfter Skilehrer, sondern hatte auch die Segelfliegerprüfung abgelegt. Nach der Handelsschule volontierte er zunächst in Graz und arbeitete dann ab 1931 in der Firma des Vaters Franz Thalhammer als Angestell-

259 Peter Radacher, Wir fuhren nach Amerika, in: Durch Pulver und Firn. Das Buch der Deutschen Skiläufer. Jahrbuch des Nationalsozialistischen Reichsbundes für Leibesübungen/Fachamt Skilauf, Innsbruck 1939/40, S. 130-133, hier S. 130.

260 Vgl. Radacher, Wir fuhren nach Amerika, S. 131.

261 Vgl. OÖLA, LG Linz Sondergericht, Sch. 485, VgVr 4132/48; SLA, NS-Sonderkommission (NS-SOKO), Kurt Thalhammer; BArch (ehem. BDC), PK, Thalhammer, Kurt, 20.2.1913. 
ter. In den Jahren von 1933 bis 1938 hielt sich Thalhammer drei Mal in England, in Belgien, in der Schweiz und drei Mal in den USA auf. ${ }^{262}$ Am 10. Dezember 1936 bestieg er die S. S. Hansa von Hamburg nach New York. ${ }^{263}$ Der aus Salzburg stammende Sohn einer Kaufmannsfamilie arbeitete zunächst für eine Saison gemeinsam mit dem ausgewanderten Sig Buchmayr ${ }^{264}$ als Skilehrer in Sugar Hill, New Hampshire und dann im Winter 1937/38 als Hilfsskilehrer in Woodstock im US-Bundesstaat Vermont. ${ }^{265}$ Der staatlich geprüfte Skilehrer Roland Cossmann aus Saalfelden erinnerte sich 1945 im Zuge des Entnazifizierungsverfahrens an die gemeinsam mit Thalhammer verbrachte Zeit in den USA von 1936 bis 1938 und dass dieser „mit all seinem sportlichen Können Österreichs Farben bestens und erfolgreich vertreten hat. “266 Nach seiner Rückkehr im Frühjahr 1938 übernahm der gelernte Kaufmann und Skilehrer Thalhammer das „arisierte“ Textilgeschäft der jüdischen Familie Ornstein und des Julius Neuwirth. Thalhammer war zu diesem Zeitpunkt Mitglied der NSDAP und des NSFK. ${ }^{267}$ Am 17. September 1938 schaltete Thalhammer ein Inserat in der Salzburger Landeszeitung in dem er bekannt gab, dass er mit heutigem Tage die Leitung das Kleiderhaus Ornstein übernommen habe, und machte in der Anzeige deutlich, dass er bestrebt sei, die Firma im Sinne der Familientradition des bestbekannten Hauses Thalhammer stets als „arischen Betrieb“ $z u$ führen. ${ }^{268}$

\subsubsection{Hans Nöbl - ein Tiroler in den argentinischen Anden}

Der Innsbrucker Skiläufer und Skilehrer Hans Nöbl war im Mai 1936 von der argentinischen Regierung nach Buenos Aires berufen worden. Nöbl war zu Beginn der 1930er-Jahre ein erfolgreicher Kombinierer (Abfahrts- und Sprunglauf) und Mitglied im Skiklub Innsbruck aus dem später die „Roten Teufel“ hervorgehen

262 Vgl. SLA, NS-SOKO, Kurt Thalhammer.

263 Vgl. New York Passenger and Crew Lists, 1820-1957, Kurt Thalhammer, www.ancestry. com (12.8.2019).

264 Sig Buchmayr stammte aus Bad Hofgastein und wanderte bereits 1929 in die USA aus. Er begründete die Skischule bei Pecketts in Sugar Hill im Bundesstaat New Hampshire. Nachdem er dort acht Jahre die alpine Skilauftechnik unterrichtete, übersiedelte er nach Woodstock, Vermont.

265 Vgl. Rutland Daily Herald, 6.12.1937, S. 6; Rutland Daily Herald, 21.1.1938, S. 11; John B. Allen, Images of Sports. New Hampshire on Skis, Portsmouth 2002, S. 66 und 68.

266 Erklärung Roland Cossmann, 30.11.1945, SLA, NS-SOKO, Kurt Thalhammer.

267 Das Herrenkonfektionsgeschäft und die Lodenmantelerzeugung der Firma L. Ornstein in der Getreidegasse 24 in Salzburg war zu 30 Prozent im Eigentum von Julius Neuwirth und zu je 23,5 Prozent im Eigentum der Brüder Richard, Rudolf und Robert Ornstein. Vgl. SLA, NS-SOKO, Kurt Thalhammer; OÖLA, LG Linz, Sondergerichte, Sch. VgVr 4132/48 (485).

268 Zit. nach Albert Lichtblau, ,Arisierungen“ in Salzburg, in: Helga Embacher, Juden in Salzburg, Salzburg 2002, S. 67-83, hier S. 71. 
sollten. ${ }^{269}$ Vor seiner Auswanderung nach Argentinien leitete er gemeinsam mit dem gebürtigen Steirer Leo Gasperl vom Skiklub Kitzbühel die staatliche Skischule des faschistischen Italiens in Sestriere. Dort war er mit der Organisation des Heeres-Skisportes betraut. Zeitungsberichten zu Folge soll er unter anderem

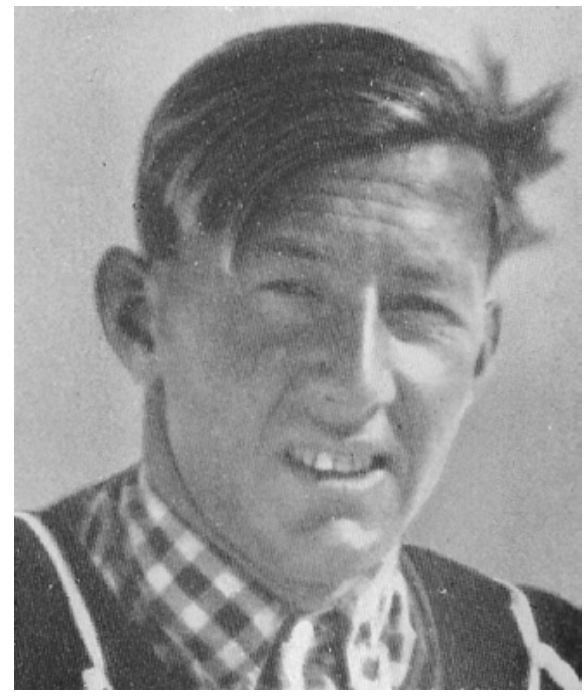

Abb. 10: Der 1909 in Innsbruck geborene Skilehrer Hans Nöbl wanderte 1936 nach Argentinien aus, Skileben in Österreich 1936.

den beiden Söhnen Benito Mussolinis Skiunterricht gegeben haben. ${ }^{270}$ Nöbl und Gasperl waren mit November 1933 vom italienischen Skiverband mit der Leitung betraut worden. ${ }^{271}$ Nöbl hatte für den Winter 1934/35 erneut die Auslandsbewilligung erhalten und befand sich ab Anfang Dezember wieder in Sestriere. ${ }^{272}$ Die Neueste Sport-Zeitung berichtete ein Jahr später in einem Porträt im Dezember 1935 unter dem Titel „Musterbeispiel eines sportlichen Selfmademans“ vom Aufstieg Nöbls vom Fleischhauerlehrling zum Leiter der Skischule in Sestriere. ${ }^{273}$ Im Rahmen seiner Leitungstätigkeit bildete Nöbl in Sommerskikursen italienische Offiziere am Cevedale im Ortlergebiet aus. ${ }^{274}$ In Argentinien war Nöbl mit dem Aufbau eines neuen Skigebietes rund um die Stadt San Carlos de Bariloche im Norden Patagoniens betraut. Er sollte darüber hinaus den argentinischen Wintersport organisieren. Grundlage bildete ein Fünfjahresvertrag, abge-

269 Vgl. Tiroler Anzeiger, 22.2.1932, S. 10.

270 Vgl. Tiroler Anzeiger, 26.5.1936, S. 9.

271 Vgl. Der Ski, Nr. 2, 15.11.1933, S. 22-23.

272 Vgl. Der Ski, Nr. 3, 01.12.1934, S. 40.

273 Vgl. Neueste Sport-Zeitung, 2.12.1935, o. S.

274 Vgl. Skileben in Österreich, 1936, S. 107. 
schlossen mit der argentinischen Regierung. ${ }^{275}$ Die argentinische Regierung hatte die Region rund um den See Nahuel Huapi im Jahr 1922 zum Nationalparkgebiet erklärt. ${ }^{276}$ In den darauffolgenden Jahren sollte die Andenregion um den Rio Negro eine touristische Aufwertung erfahren. Dazu trug nicht nur die Anbindung an die Bahn nach Buenos Aires bei, sondern ebenso Investitionen in den Ausbau der Hotelinfrastruktur. ${ }^{277}$

Dass Nöbl ausgerechnet nach Bariloche auswanderte, um dort den Skisport zu organisieren, war kein Zufall. Die Stadt war 1902 per Regierungsdekret gegründet worden und geht auf eine deutsche Kolonie zurück. ${ }^{278} 1931$ hatte hier der bayerische Bergsteiger Otto Meiling den Club Andino Bariloche gegründet und damit begonnen den Skilauf zu unterrichten. ${ }^{279}$ Das Vorbild für die Gründung des „Andenvereins“ soll der Deutsche und Österreichische Alpenverein gewesen sein. Karl Ilg nennt in seiner Publikation über das Deutschtum in Chile und Argentinien aus dem Jahr 1982 Süddeutsche, Schweizer und Österreicher als „Gründungsväter“ des Club Andino Bariloche. ${ }^{280}$ Eine andere Veröffentlichung spricht von „einigen Deutschen“, die den Club Andino Bariloche im August 1931 gegründet hätten. ${ }^{281}$

Tatsächlich stammte nur Otto Meiling aus Deutschland, nämlich aus Landshut. Die anderen Mitbegründer hatten zwar auch einen Migrationshintergrund, aber keinen deutschen. Der Sohn Schweizer Einwanderer und Arzt Juan Neumeyer wurde bereits in Argentinien, in der Provinz Santa Fe geboren und auch Emilio Frey stammte aus Santa Fe, während der Unternehmer Reinaldo Knapp aus England einwanderte. ${ }^{282}$ Jedenfalls erfolgte mit der Gründung des Club An-

275 Vgl. Tiroler Anzeiger, 8.11.1937, S. 8; 13.5.1937, S. 9.

276 Hans Schulz, Bariloche: Breve Historia de la Comunidad Alemana y su Escuela 19072004, San Carlos de Bariloche 2004, S. 43.

277 Vgl. Wilhelm Lütge/Werner Hofmann/Karl Wilhelm Körner, Geschichte des Deutschtums in Argentinien, Buenos Aires 1955, S. 258.

278 San Carlos des Bariloche ist eine Gründung von deutschen Siedlern, die im Zuge der Landnahme gegen Ende des 19. Jahrhunderts von Chile aus die östlichen Anden erschließen wollten und zunächst am Südufer des Nahuel Huapi Handelsniederlassungen etablierten. Vgl. Schulz, Bariloche, S. 41 und 49.

279 Der Historiker Hans Schulz gibt das Gründungsjahr erst mit 1932 an. Laut Vereinsschriften wurde der Club Andino Bariloche aber bereits am 13. August 1931 gegründet. Vgl. Schulz, Bariloche, S. 51; 25 Aniversario Club Andino Bariloche. 1931-1956, S. 3.

280 Vgl. Karl Ilg, Das Deutschtum in Chile und Argentinien, Wien 1982, S. 73.

281 Vgl. Wilhelm Lütge/Werner Hoffmann/Karl Wilhelm Körner/Karl Klingenfuss (Hg.), Deutsche in Argentinien 1520-1980, Buenos Aires 1980, S. 327.

282 Vgl. Schulz, Bariloche, S. 51; Tabare W. Parsons, Enciclopedia Historica Centenaria de Bariloche 03/05/1902 - 03/05/2002, Almanes y Austriacos Pioneros Olividados, Tomo 1, Bariloche 2002, S. 103; Rio de Janeiro, Brazil, Immigration Cards, 1900-1965, Juan Javier Neumeyer, www.ancestry.com (11.6.2021); El Doctor Juan Javier Neumeyer y la historia del Club Andino 
dino Bariloche (CAB) eine erste systematische skitechnische Erschließung der umliegenden Berge. Meiling errichtete auf dem Cerro Otto eine erste Hütte, die auch dem Skilauf diente. ${ }^{283}$ Gleichzeitig betrieb er in Bariloche eine Skifabrik. Die Skilehrerausbildung absolvierte Meiling in Österreich. ${ }^{284}$

Im Jahr 1934 wurde das 1922 festgelegte Gebiet am Nahuel Huapi in einen Nationalpark umgewandelt und im selben Jahr wurde die Bahnstrecke nach Buenos Aires eröffnet. ${ }^{285}$ Dies hatte zur Folge, dass in der Andenstadt nun auch das zahlungskräftige Großbürgertum aus der Hauptstadt Argentiniens als Gästeschicht begrüßt werden konnte. Damit einhergehend gründeten in Bariloche ansässige Auswanderer-Familien aus Österreich, Italien, Deutschland und der Schweiz Hotel- und Unterkunftsbetriebe und das Stadtzentrum wurde im alpenländischen Stil umgebaut. ${ }^{286}$ Als Nöbl zwei Jahre später im deutschsprachig geprägten Bariloche ankam, fand er also schon eine gewisse Infrastruktur vor, auf die er aufbauen konnte. Zudem war es die Nationalparkverwaltung, die Nöbl eine Anstellung anbot und ihn unter Vertrag nahm. Das veranlasste den Österreicher den europäischen Sommer in Argentinien zu verbringen und sich bis in die Nachkriegszeit hinein im Club Andino Bariloche zu engagieren. Als Skigebiet wählte Nöbl den rund 20 Kilometer von Bariloche entfernten 2400 Meter hohen Cerro Catedral anstatt des Cerro Otto. ${ }^{287}$ Heute befindet sich dort eines der größten Skigebiete Südamerikas.

Recherchen im Tiroler Landesarchiv ergaben in Bezug auf Nöbl keine politischen Auffälligkeiten. Er war den Akten zufolge weder in der NSDAP noch in einem Wehrverband Mitglied. Ein Foto in den Innsbrucker Nachrichten unmittelbar nach dem „Anschluss“ im März 1938 zeigt Nöbl allerdings mit anderen Skilehrerkollegen in Sestriere als Leiter der staatlichen Skischule mit der erhobenen rechten Hand zum „Deutschen Gruß“. „Innsbrucker Skilehrer feiern den Sieg“ war der Bildunterschrift zu entnehmen. Zudem behaupteten die Innsbrucker Nachrichten, dass Nöbl in einem „begeisterten Briefe [sic]“ im Zuge des „Anschlusses“ mitgeteilt habe, dass „die kleine Tiroler Kolonie in Sestriere in

Bariloche, in: El Cordillerano, 14.8.2013, https://www.elcordillerano.com.ar/noticias/2013/08/ 14/56101-el-doctor-juan-javier-neumeyer-y-la-historia-del-club-andino-bariloche (11.06.2021).

283 Otto Meiling war Turner, Alpinist und Skiläufer. Er wanderte 1924 nach Argentinien aus, wo er zunächst in Buenos Aires im Deutschen Turnverein aktiv war, bevor er sich immer mehr für die Gegend rund um San Carlos de Bariloche zu interessieren begann. Vgl. Arko Toncek, Otto Meiling. Patriarca del esqui y andinismo argentino, Bariloche 2016, S. 30-40.

284 Vgl. Lütge/Hoffmann/Körner/Klingenfuss (Hg.), Deutsche in Argentinien, S. 327.

285 Vgl. Schulz, Bariloche, S. 53.

286 Vgl. Ilg, Das Deutschtum, S. 74.

287 Vgl. Vojko Arko, Otto Meiling. Un pionero de Bariloche, Bariloche 2006, S. 25. 
einem völligen Taumel der Freude war“. ${ }^{288}$ Nöbl dürfte also zu diesem Zeitpunkt durchaus mit dem NS-Regime kokettiert haben, während die NS-Presse ihrerseits ebenso Versuche unternahm, den Tiroler Skilehrer für ihre Zwecke zu vereinnahmen. Ebenfalls im März 1938 erschien im Deutschen Telegraf ein ausführlicher Bericht über Nöbls skisportliche Leistungen im „Wintersportparadies über der Pampa“, gemeint war das argentinische Patagonien. ${ }^{289}$

Wie der Vertrag in der staatlichen Skischule in Sestriere zustande kam, konnte nicht geklärt werden. Auch nicht auf wessen Initiative sein Engagement in Bariloche zurückgeht. In den 1930er-Jahren existierten jedoch intensive Sportkontakte zwischen Italien und Argentinien, beispielsweise im Fußball, die $\mathrm{zu}$ einem regen Austausch führten und frühe Formen der Sportmigration erleichterten. ${ }^{290}$ Weiters war die argentinische Einwanderungsgesellschaft vor dem Zweiten Weltkrieg von einer starken Auswanderung aus süd- und mitteleuropäischen Regionen geprägt. ${ }^{291}$ Die saisonale Arbeitsmigration von Hans Nöbl muss demnach auch vor diesem Hintergrund gesehen werden.

Zumindest bis 1938 war Nöbl abwechselnd in Argentinien (Bariloche) und Italien (Sestriere) beschäftigt. ${ }^{292}$ In den Jahren ab 1938 bis über den Zweiten Weltkrieg hinaus hielt sich Nöbl in Argentinien auf. Nöbl dürfte aber weiterhin zwischen 1939 und 1945 in Europa gewesen sein und auch Engagements als Skilehrer in den USA angeboten bekommen haben. Das geht zumindest aus diversen Einreisedokumenten und Passagierlisten hervor. Im Juni 1939 fragte die Union Pacific Railroad Company um die Einreisegenehmigung von Nöbl bei der US-amerikanischen Einwanderungsbehörde an. ${ }^{293}$ Die Union Pacific Railroad Company beschäftigte auch andere österreichische Skilehrer in den USA. Ob Nöbl tatsächlich für die Wintersaison 1939/40 in die USA reiste, geht aus den Quellen nicht hervor. Als temporären Wohnsitz in Argentinien gibt Nöbl bei den Einreise im September 1941 die Avenida Alvear, Nummer 1891, in Buenos Aires

288 Innsbrucker Nachrichten, 30.3.1938, S. 15.

289 Vgl. dazu die Berichterstattung in Deutscher Telegraf, 31.3.1938, S. 6.

290 Vgl. Marco Impiglia, Fußball in Italien in der Zwischenkriegszeit, in: Christian Koller/Fabian Brändle (Hg.), Fussball zwischen den Kriegen. Europa 1918-1939, Berlin 2010, S. 145-182. 291 Neben den USA galten die südamerikanischen Länder Argentinien und Brasilien zu den bevorzugten Zielländern transatlantischer Migration in der Zwischenkriegszeit. Vgl. Sylvia Hahn, Historische Migrationsforschung, Frankfurt am Main 2012, S. 174 und 179.

292 Vgl. Tiroler Anzeiger, 13.5.1937, S. 9.

293 Vgl. US National Archives and Records Administration (NARA), Roll 25, Subject Index to Correspondence and Case Files of the Immigration and Naturalization Service, 1903-1952, Hans Nöbl, www.ancestry.com (11.6.2021). 
an. ${ }^{294}$ Unter dieser Adresse befand sich ab 1932 das bei europäischen Reisenden beliebte Luxushotel Alvear Palace. ${ }^{295}$ Der Reisepass war vom deutschen Konsulat in Turin am 15. November 1938 ausgestellt worden. ${ }^{296}$ Warum die Einreise über Brasilien erfolgte, ist nicht bekannt. Nach Ende des Zweiten Weltkriegs war Nöbl bis in die 1950er-Jahre hinein in der Funktion des technischen Direktors für den argentinischen Skiverband tätig. ${ }^{297}$ Laut Adressverzeichnis und Mitgliederlisten des Club Andino Bariloche war der ständige Wohnsitz des Tirolers in den 1950er-Jahren San Carlos de Bariloche. ${ }^{298}$ Die Kontakte zum mitteleuropäischen Skisport, insbesondere zum italienischen, rissen aber nie gänzlich ab. Mitte der 1950er-Jahre traf Nöbl im italienischen Cervinia (eigentlich Breuil-Cervinia) wieder auf seinen früheren Skischulkollegen Leo Gasperl, der dort nach 1945 eine Skischule leitete. Während seiner Aufenthalte in den italienischen Alpen kam Nöbl auch mit dem italienischen Skirennläufer und späteren Radiound Fernsehmoderator Michele (Mike) Bongiorno zusammen. ${ }^{299}$

Dass der Tiroler für die Stadt Bariloche und die Region durchaus eine Bedeutung besitzt, davon zeugen zahlreiche Erwähnungen in regionalhistorischen Publikationen. ${ }^{300}$ Der argentinische Chronist Tabare W. Parsons erwähnt Nöbl in seiner mehrbändigen Enzyklopädie über europäische Einwanderer in Bariloche als österreichischen Pionier. ${ }^{301}$ Darüber hinaus ist Nöbl als Begründer des größten argentinischen Skigebietes in Bariloche noch heute präsent. So widmete sich eine historische Ausstellung im hiesigen Tourismusbüro über den Ski-

294 Vgl. Rio de Janeiro, Brazil, Immigration Cards, 1900-1965, Hans Nöbl, www.ancestry.com (11.6.2021).

295 Vgl. dazu die Homepage des Hotels Alvear Palace in Buenos Aires: www.alvearpalace. com/en/luxury-hotel-in-buenos-aires (28.1.2019).

296 Vgl. Rio de Janeiro, Brazil, Immigration Cards, 1900-1965, Hans Nöbl, www.ancestry.com (11.6.2021).

297 Vgl. Club Argentino de Ski, Comision Directiva 1954-1955, in: Anuario Club Argentino de Ski, 13 (1954), Buenos Aires, o. S.

298 Vgl. u. a. Anuario Club Andino Bariloche, 18 (1950), San Carlos de Bariloche, 1950.

299 Vgl. Mike Bongiorno, Sempre Più in Alto. La Montagna secondo, Turin 2012, S. 98. Michele (Mike) Bongiorno (eigentlich Michael Nicholas Salvatore Bongoiorno), geboren und aufgewachsen als Sohn einer italienischen Einwandererfamilie 1924 in New York, zog in den 1930er-Jahren nach Turin und lernte in den italienischen Alpen das Klettern und Skifahren. Im Zweiten Weltkrieg schloss er sich den Partisanen an und diente in einem Skiverband. 1944 kam er in deutsche Kriegsgefangenschaft, zunächst in das Lager Gries am Brenner und dann in das Lager Reichenau bei Innsbruck. Nach dem Zweiten Weltrkieg machte er Karriere als Radio- und Fernsehmoderator.

300 Vgl. u. a. Arko, Otto Meiling, S. 25.

301 Parsons, Enciclopedia, S. 191. 
sport in den Anden im Jahr 2017 unter anderem den ski- und wintersportlichen Pioniertaten des in Bariloche tätigen Tirolers. ${ }^{302}$

\subsubsection{Resümee}

Die hier kurz skizzierten Biografien sollten die Aufstiegs- und Karrierechancen sowie die Berufsmöglichkeiten und Betätigungsfelder österreichischer SkilehrerInnen in den 1930er-Jahren aufzeigen. Aufgrund der Quellenlage wurde hier auf Erfolgsgeschichten zurückgegriffen und nicht auf jene des Scheiterns. Die saisonalen Migrationen können als eine spezielle Form der Arbeitsmigration im Sinne einer ExpertInnenmigration gesehen werden. Frauen nahmen daran, wenn auch in geringerem Ausmaß, ebenso teil wie Männer. Wobei die Geschlechterverhältnisse genauer analysiert werden müssten. Als eine der wenigen Migrationen von österreichischen Skilehrerinnen vor 1938 ist jene von Elfriede Pembauer dokumentiert. Sie emigrierte im November 1936 im Alter von 23 Jahren in die USA, um dort nicht nur ihr Studium als Psychiaterin abzuschließen, sondern in Lake Placid Skiunterricht zu geben. ${ }^{303} \mathrm{Im}$ Warenhaus von Frederick Loeser in Brooklyn, New York hielt die gebürtige Salzburgerin im Dezember 1936 zudem Ski-Gymnastikkurse ab. Das Handelsunternehmen hoffte mit der Salzburger Olympionikin das Weihnachtsgeschäft ankurbeln zu können. ${ }^{304}$ Pembauer war im Jänner 1936 für den olympischen Abfahrts- und Torlauf in Garmisch-Partenkirchen nominiert worden und zählte neben Käthe Lettner $\mathrm{zu}$ den Medaillenhoffnungen. ${ }^{305}$ Im Februar 1936 konnte sie bei den international ausgeschriebenen Damen-Skimeisterschaften des ÖSV in Badgastein den zweiten Platz belegen. ${ }^{306}$ Nach ihrem Engagement in New York arbeitete sie unter anderem als Skilehrerin in der Nähe von Québec in Kanada. Sie hielt am Lac Beauport Skikurse für die Gäste des Luxushotels Chateau Frontenac ab, ${ }^{307}$ das von der Canadian Pacific Railway Company betrieben wurde. ${ }^{308}$

302 Besuch der Ausstellung im Tourismusbüro von Bariloche im Rahmen einer Recherchereise des Verfassers im Februar 2017 nach San Carlos de Bariloche und dessen Umgebung.

303 Vgl. New York Passenger and Crew Lists, 1820-1957, Elfriede Pembauer, www.ancestry. com (11.6.2021); The Brooklyn Daily Eagle, 22.11.1936, S. 11.

304 Vgl. The Brooklyn Daily Eagle, 6.12.1936, S. 86.

305 Vgl. Sport in Österreich, 7 (16.1.1936), S. 17; Sport-Tagblatt, 18.1.1936, S. 5.

306 Vgl. Freie Stimmen, 4.2.1936, S. 7-8.

307 Vgl. Vgl. The News Chronicle, 1.2.1938, S. 5; Rochester Democrat and Chronicle, 23.1.1938, S. 10D.

308 Das Chateau Frontenac in der Altstadt von Québec wurde unter der Leitung des Generaldirektors der Canadian Pacific Railway Company William Van Horne erbaut und 1893 eröffnet. Es war eines der Luxushotels, die von der Canadian Pacific Railway Company betrieben wurden und zählt seit 1985 zum UNESCO-Weltkulturerbe. Vgl. Christoph Mertha, Die Geschichte 
Das Skigebiet am Lac Beauport, wenige Kilometer von Québec entfernt, erstreckte sich in der Wintersaison 1937/38 bereits auf über 70 Pistenkilometer. ${ }^{309}$ Warum Pembauer nach zwei Wintersaisonen im Jahr 1938 wieder zurückkehrte, ist nicht bekannt. Im darauffolgenden Winter 1938/39 startete sie jedenfalls, ebenso wie ihre langjährige Mitbewerberin Käthe Lettner, für die NSRL-Kreismeisterschaften. ${ }^{310}$

Wie die einzelnen Fallbeispiele gezeigt haben, handelte es sich bei den migrierten SkilehrerInnen nicht um eine homogene, sondern um eine sehr heterogene Personengruppe. Gemeinsamkeiten lassen sich lediglich im Alter und Familienstatus finden. Die meisten der hier porträtierten SkilehrerInnen waren bei ihrer Ausreise Anfang bis Mitte 20 und ledig. Bei der sozialen Herkunft, dem Berufsstand und der politischen Einstellung unterscheiden sich die Biografien jedoch voneinander. Eines lässt sich jedoch feststellen: Neben NS-SympathisantInnen tummelten sich auf amerikanischen Skipisten in den 1930er-Jahren genauso GegnerInnen des NS-Regimes wie Anhänger. Das Kapitel der Arbeitsmigration im Skisport wirkt also in die Skisportgeschichte des Nationalsozialismus hinein und umgekehrt. Denn die Migrationsgeschichten haben enge Bezüge zu späteren Fluchtgeschichten und direkte wie indirekte Auswirkungen auf diese. Sie stehen unmittelbar im Zusammenhang mit der nationalsozialistischen Vertreibungs- und Verfolgungspolitik. Kontakte, die vor der NS-Machtübernahme aufgebaut worden waren, konnten gegen Ende der 1930er-Jahre hilfreich und für jüdische SkisportlerInnen oder Regimegegner überlebenswichtig sein. Der Kriegseintritt der USA am 8. Dezember 1941 eröffnete zudem neue Arbeitsfelder für die ausgewanderten und geflüchteten SkilehrerInnen in der US-Armee. Auf der anderen Seite bedeuteten Kontakte nach Übersee für gesuchte NSSportler und NS-Skisportfunktionäre, bisher sind nur männliche Fälle bekannt, mitunter eine Möglichkeit nach 1945 ab- und unterzutauchen. Auf diese Geschichten wird in späteren Kapiteln noch ausführlich eingegangen und Bezug genommen.

der Canadian Pacific Hotels und das Chateau Frontenac, in: Frank Norbert Nagel (Hg.), Kanada. Von Akadien zum Yukon, Norderstedt 2013, S. 65-67.

309 Vgl. Rochester Democrat and Chronicle, 23.1.1938, S. 10D.

310 Vgl. Der Montag, 16.1.1939, S. 10. 